NIST Technical Note 1678

\title{
Safety Assessment of Parallel Wire Suspension Bridge Cables Under Thermal Effects
}

Joseph A. Main

William E. Luecke

National Institute of Standards and Technology • U.S. Department of Commerce 



\title{
NIST Technical Note 1678
}

\section{Safety Assessment of Parallel Wire Suspension Bridge Cables Under Thermal Effects}

\author{
Joseph A. Main \\ Materials and Construction Research Division \\ Building and Fire Research Laboratory \\ William E. Luecke \\ Metallurgy Division \\ Materials Science and Engineering Laboratory
}

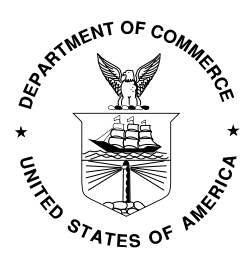

U.S. Department of Commerce

Gary Locke, Secretary 
Certain commercial entities, equipment, or materials may be identified in this document in order to describe an experimental procedure or concept adequately. Such identification is not intended to imply recommendation or endorsement by the National Institute of Standards and Technology, nor is it intended to imply that the entities, materials, or equipment are necessarily the best available for the purpose.

National Institute of Standards and Technology Technical Note 1678

Natl. Inst. Stand. Technol. Tech. Note 1678, 93 pages (October 2010) CODEN: NTNOEF 


\section{Abstract}

This report summarizes a NIST study aimed at assessing the safety of parallel wire suspension bridge cables under thermal effects. Both low temperatures, potentially embrittling the bridge wires, and high temperatures, potentially softening the wires, are considered. Recommended thermal and mechanical properties of suspension bridge wire are developed based on published data and on tensile testing carried out as part of this study. These recommended properties are incorporated in a computational model developed to analyze the thermal and mechanical response of a parallel wire suspension bridge cable subjected to prescribed surface temperatures. The analysis results indicate that embrittlement due to low temperatures does not significantly reduce the ultimate capacity of the cable. Exposure to high temperatures, on the other hand, could lead to failure of the cable, due to thermal softening of the steel wires and thermal expansion, which causes the heated outer wires to shed load. Reducing the surface area exposed to high temperatures is found to increase the exposure time required to produce failure.

Keywords: Failure analysis, suspension bridge cables, steel properties, thermal analysis, computational modeling. 


\section{Table of Contents}

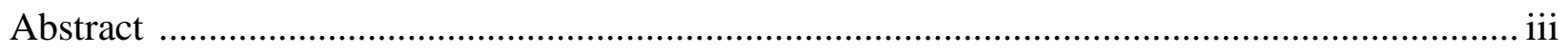

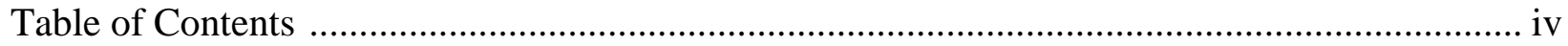

Acknowledgements ..................................................................................................... vi

Executive Summary .......................................................................................................... vii

Part 1. Analysis of a Parallel Wire Suspension Bridge Cable Subjected to Prescribed Surface Temperatures - Joseph A. Main ............................................ 1

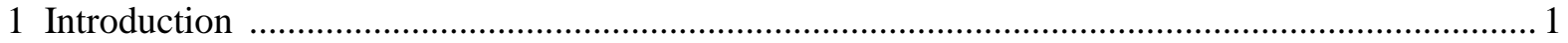

2 Temperature-Dependent Stress-Strain Behavior of Steel Wire …………………………………... 3

2.1 Wire Fracture …………………………………………………………………….

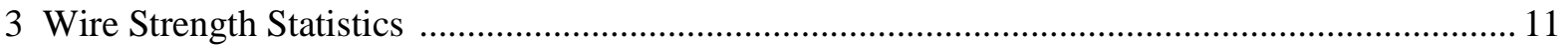

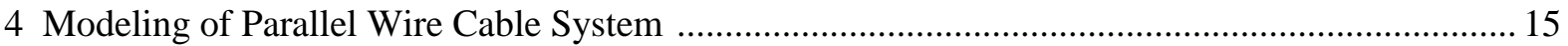

5 Heat Conduction Analysis .............................................................................................. 19

5.1 Effective Thermal Properties of Parallel Wire Bundle ………………………………….... 19

5.2 Analytical Solution for Uniform Axisymmetric Heat Conduction ……………………….... 22

5.3 Finite Element Modeling of Heat Conduction …………………………………………... 23

5.4 Interpolation of Wire Temperatures from Finite Element Model …………………………. 26

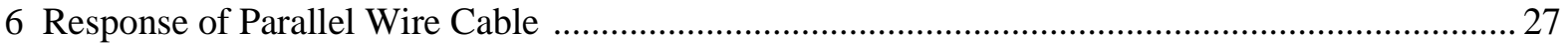

6.1 Uniform Axisymmetric Cooling …………………………………………………..... 28

6.2 Uniform Axisymmetric Heating …………………………………………………..... 34

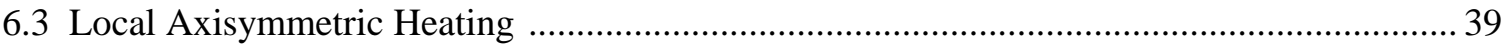

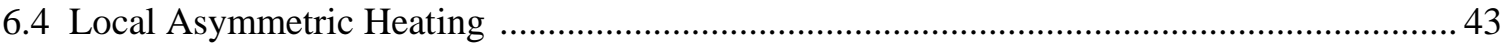

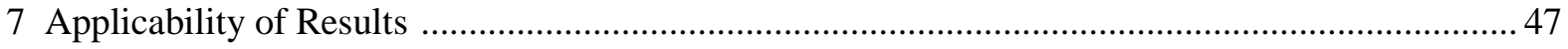

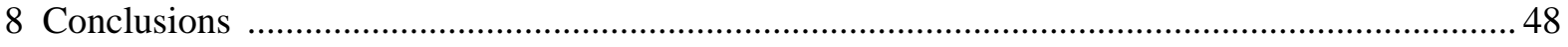

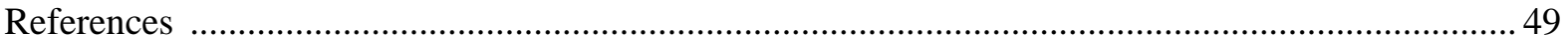

Part 2. Data Summary, Analysis, and Recommended Values: Mechanical Properties of Suspension Bridge Cable Wire - William E. Luecke ..............51

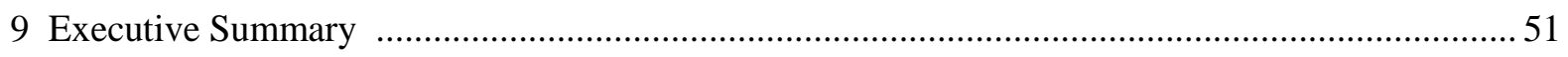

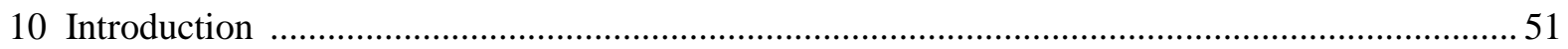

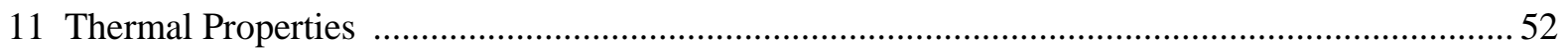

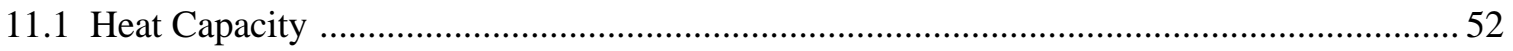




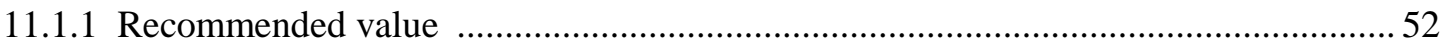

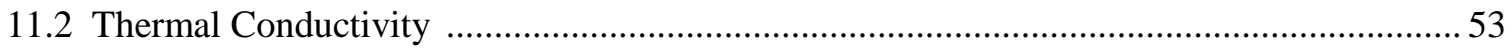

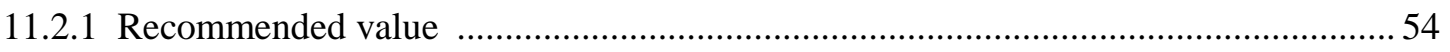

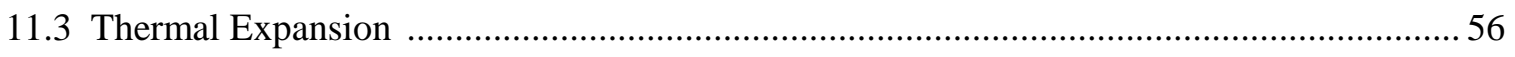

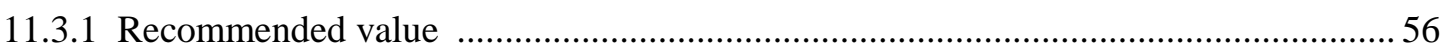

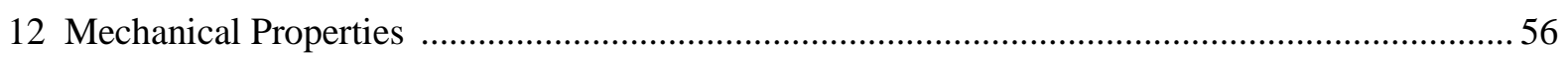

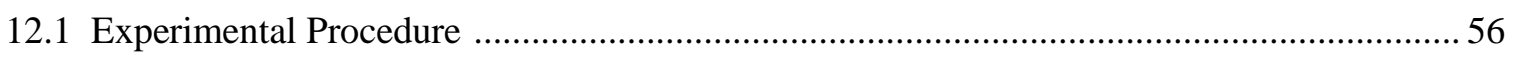

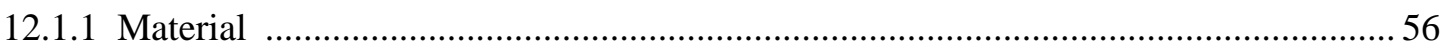

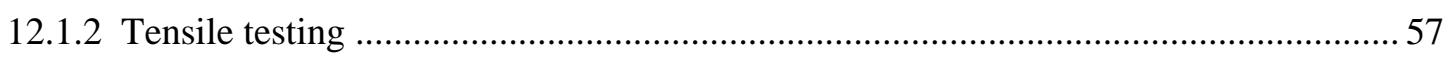

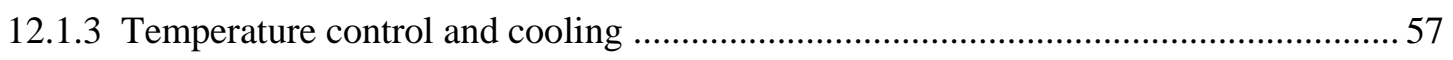

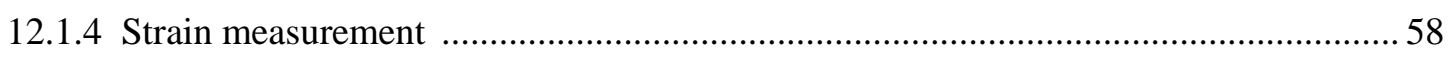

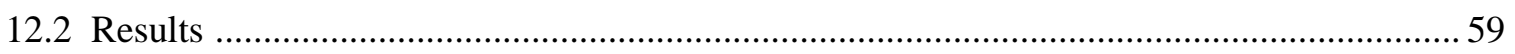

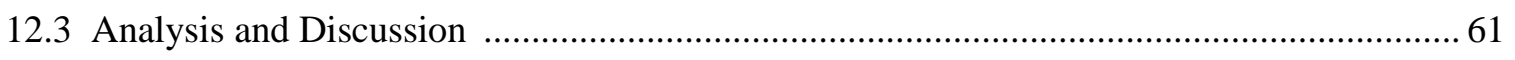

12.3.1 Representing stress-strain behavior at all temperatures .......................................... 61

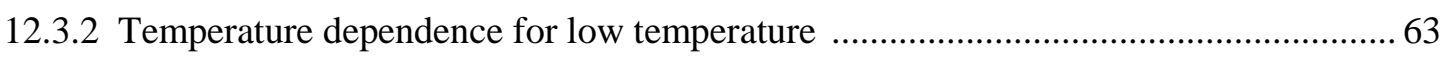

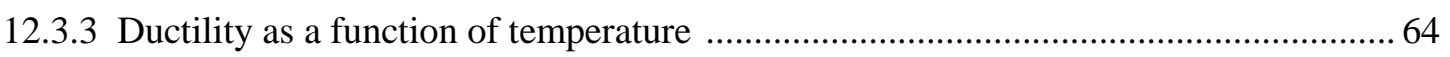

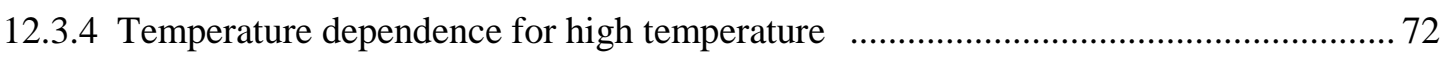

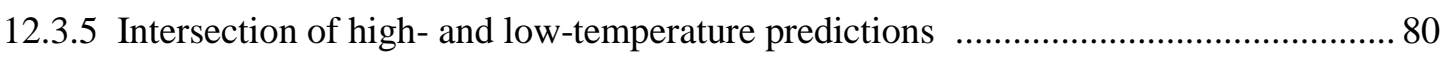

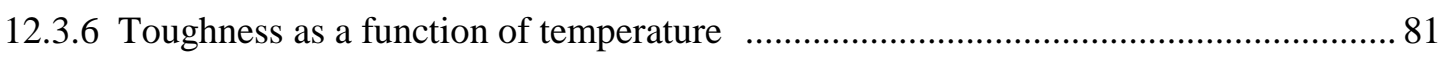

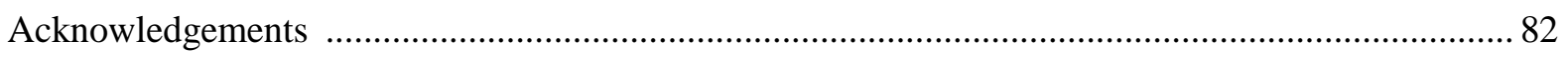

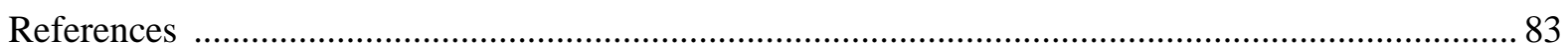




\section{Acknowledgements}

This work was performed under the sponsorship of the Intelligence Technology Innovation Center and the Department of Homeland Security. The authors are grateful to Professor Raimondo Betti of Columbia University and Dyab Khazem of Parsons Inc. for supplying the $30 \mathrm{~m}$ spool of wire used in this study, to Stephen Cauffman and Joannie Chin of NIST for valuable input during the course of this study, and to Dilip Banerjee, Dat Duthinh, and Fahim Sadek for helpful review comments on this document. 


\section{Executive Summary}

The main cables of suspension bridges are non-redundant structural elements upon which the safety of the entire bridge structure depends critically. Historical examples exist of complete suspension bridge collapse resulting from failure of a main suspension element. Safety factors for suspension bridge cables may be reduced over time due to corrosion and cracking of wires as well as increases in traffic loads on bridges. These reduced safety factors could render the bridge cables more vulnerable to abnormal loading scenarios not considered in the original design.

This report summarizes a NIST study aimed at assessing the safety of parallel wire suspension bridge cables under thermal effects. Both low temperatures, potentially embrittling the bridge wires, and high temperatures, potentially softening the wires, are considered. Part 1 describes a computational approach to analyze the thermal and mechanical response of a parallel wire suspension bridge cable subjected to prescribed surface temperatures and presents analysis results from selected cooling and heating scenarios. Part 2 recommends values for important thermal and mechanical properties of suspension bridge cable wire, based on available data from published sources and on data obtained from tensile testing of bridge wire carried out as part of this study. The recommended properties in Part 2 provide the basis for the computational approach.

The analysis results in Part 1 indicate that embrittlement due to low temperature exposure does not significantly reduce the ultimate capacity of a suspension bridge cable. Although embrittlement at low temperatures can cause the wires with initial cracks to fracture, these cracked wires are brittle even at room temperature, and it is primarily the ductile, uncracked wires that determine the ultimate capacity of the cable. Exposure to high temperatures, on the other hand, could lead to failure of the cable, due to thermal softening of the steel wires and thermal expansion, which causes heated wires to shed load. Reducing the surface area exposed to high temperatures is found to increase the exposure time required to produce failure. 



\title{
Part 1.
}

\section{Analysis of a Parallel Wire Suspension Bridge Cable Subjected to Prescribed Surface Temperatures}

\author{
Joseph A. Main \\ Materials and Construction Research Division, Building and Fire Research Laboratory \\ National Institute of Standards and Technology \\ 100 Bureau Drive, Stop 8611, Gaithersburg, MD 20899 USA
}

\section{Introduction}

The main cables of suspension bridges are non-redundant structural elements upon which the safety of the entire bridge structure depends critically. Historical examples exist of complete suspension bridge collapse resulting from failure of a main suspension element. A suspension bridge crossing the Rio Grande collapsed in November 1939 after tensile failure of one of the main suspension cables in its anchorage due to corrosion (Stahl and Gagnon 1995, p. 57). The Silver Bridge used steel chains, rather than parallel wire cables, as the main suspension elements, and the entire bridge collapsed in December 1967 following the fracture of an eyebar element of one of the main suspension chains due to stress corrosion cracking (National Transportation Safety Board 1971, Bennet and Mindlin 1973).

Safety factors for suspension bridge cables may be reduced over time due to corrosion and cracking of wires as well as increases in traffic loads on bridges. Table 1 shows original and current safety factors against failure for four suspension bridges based on the analysis of Haight et al. (1997). The table shows that in three out of four cases, the suspension bridge cables have lost approximately $30 \%$ of their original strength. While the original safety factors ranged between 2.7 and 4.5, current safety factors range between 2.0 and 3.0. These reduced safety factors under design loads could render the bridge cables more vulnerable to abnormal loading scenarios not considered in the original design. 
Table 1: Safety factors of suspension bridge main cables (based on Haight et al. 1997).

\begin{tabular}{|c|c|c|c|}
\hline $\begin{array}{l}\text { Suspension } \\
\text { Bridge }\end{array}$ & $\begin{array}{l}\text { Original Safety Factor } \\
\text { Against Failure } \\
\text { (Year of Construction) }\end{array}$ & $\begin{array}{c}\text { Current Safety Factor } \\
\text { Against Failure }{ }^{c} \\
\text { (Year of Inspection) }\end{array}$ & $\begin{array}{c}\text { Fraction of Original } \\
\text { Cable Strength }\end{array}$ \\
\hline Williamsburg & $4.5(1903)$ & $3.0(1988)$ & 0.68 \\
\hline Bear Mountain & $3.4(1924)$ & $2.4(1991,1993)$ & 0.70 \\
\hline Triborough & $2.8^{\mathrm{b}}(1936)$ & $2.0(1991)$ & $0.70^{b}$ \\
\hline Golden Gate & 2.7 (1937) & $2.4(1990)$ & 0.95 \\
\hline
\end{tabular}

${ }^{a}$ Based on actual wire strength tests at the time of construction, except where noted.

b Based on originally specified minimum wire strengths

c Based on the "ductile-brittle" wire model

This report summarizes a NIST study aimed at assessing the safety of parallel wire suspension bridge cables ${ }^{1}$ under thermal effects. Both low temperatures, potentially embrittling the bridge wires, and high temperatures, potentially softening the wires, are considered.

The outline of Part 1 of this report is as follows. Section 2 discusses the modeling approach used to represent the temperature-dependent stress-strain behavior of steel bridge wire, based on test data, analysis, and recommended values presented in Part 2 of this report. Section 3 discusses the modeling approach used to represent the statistical variability of wire strength resulting from corrosion and crack development. Section 4 outlines the approach used to analyze the behavior of a bridge cable consisting of thousands of parallel wires with temperature-dependent properties. Section 5 discusses the approaches used to analyze heat conduction through a bridge cable, and Section 6 discusses analysis results from several prescribed temperature exposure scenarios.

The analysis results indicate that embrittlement due to low temperature exposure does not significantly reduce the ultimate capacity of a suspension bridge cable. Although embrittlement can cause the wires with initial cracks to fracture, these cracked wires are brittle even at room temperature, and it is primarily the ductile, uncracked wires that determine the ultimate capacity of the cable. Exposure to high temperatures, on the other hand can lead to failure of the cable, due to thermal softening of the steel wires and thermal expansion, which causes heated wires to shed load. Reducing the surface area exposure to high temperatures is found to increase the time required to produce failure.

\footnotetext{
${ }^{1}$ Most suspension bridges in the United States have main cables composed of parallel wires. Some bridges, mostly with shorter spans, have main cables composed instead of helical wire strands. Helical wrapping introduces differences in axial stiffness and in inter-wire contact within the cable cross section, which affects heat conduction. This study considers only main suspension cables composed of parallel wires.
} 


\section{Temperature-Dependent Stress-Strain Behavior of Steel Wire}

This section summarizes the approach used to model the temperature-dependent mechanical properties of steel bridge wire, based on the recommendations given in Part 2 of the report. The wire properties presented herein correspond to zinc-coated steel bridge wire with a nominal diameter of $d=4.92 \mathrm{~mm}$ (0.196 in). The chemical composition of the bridge wire is summarized in Table 5 in Section 12.1.1.

The stress-strain behavior of the steel wire is modeled as linearly elastic until yielding, with power-law strain hardening thereafter:

$$
S=\left\{\begin{array}{cl}
E e, & e \leq e_{y} \\
K_{e} e^{n_{e}}, & e>e_{y}
\end{array}\right.
$$

where $S$ is the engineering stress, $e$ is the engineering strain, $K_{e}$ is the work-hardening exponent, $n_{e}$ is the work-hardening exponent, and $e_{y}$ is the engineering strain at the yield point, which is given by the intersection of the two expressions in Eq. (1):

$$
e_{y}=\left(\frac{K_{e}}{E}\right)^{\frac{1}{1-n_{e}}}
$$

A temperature-independent value of $n_{e}=0.108$ is recommended for the work-hardening exponent. This is the average value of the work-hardening exponent obtained from tensile tests below room temperature (see Section 12.3.3), and because of insufficient data, the same value is recommended for use at high temperatures (see Section 12.3.4). Following Luecke et al. (2005), the temperature-dependence of the elastic modulus $E$ (in $\mathrm{GPa}$ ) can be represented as a cubic function of the temperature $T$ (in ${ }^{\circ} \mathrm{C}$ ):

$$
E=e_{0}+e_{1} T+e_{2} T^{2}+e_{3} T^{3}
$$

where the coefficients are given by $e_{0}=206.0 \mathrm{GPa}, \quad e_{1}=-0.04326 \mathrm{GPa} /{ }^{\circ} \mathrm{C}$, $e_{2}=-3.502 \times 10^{-5} \mathrm{GPa} /{ }^{\circ} \mathrm{C}^{2}$, and $e_{3}=-6.592 \times 10^{-8} \mathrm{GPa} /{ }^{\circ} \mathrm{C}^{3}$ (see Section 12.3.4). The elastic modulus is plotted against temperature in Figure 1. 


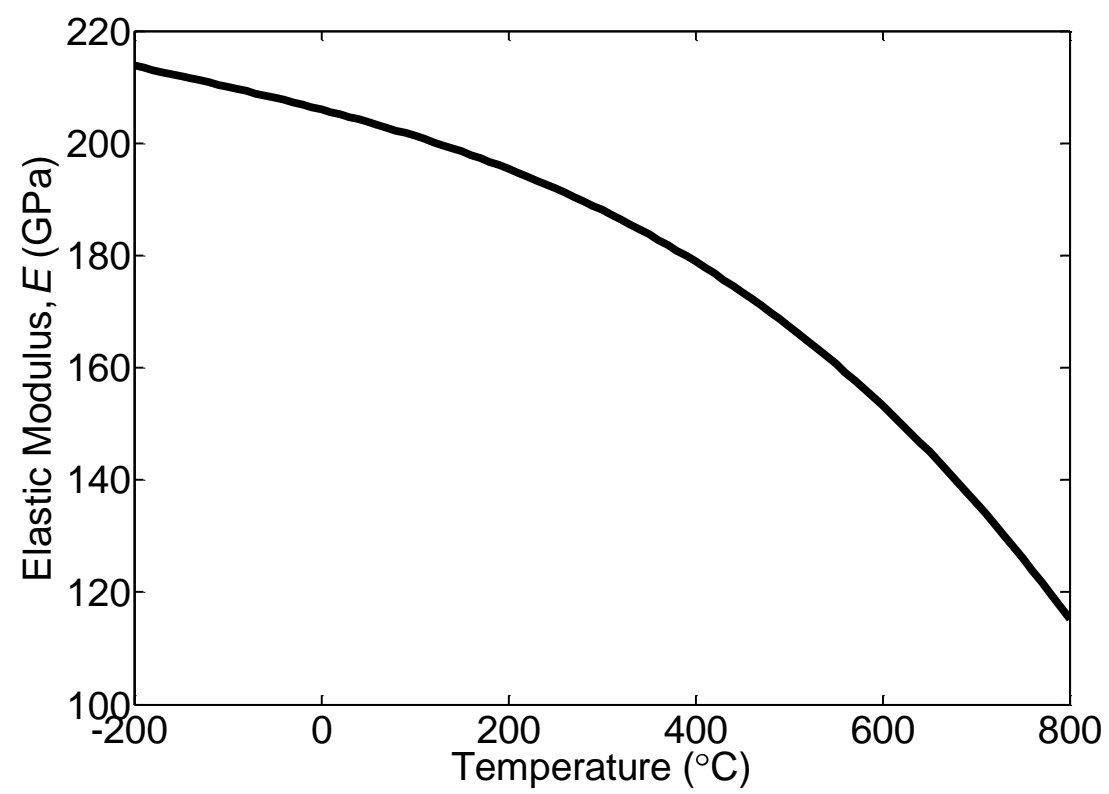

Figure 1: Variation of elastic modulus with temperature.

The temperature-dependence of the work-hardening coefficient $K_{e}$ can be represented using different expressions above and below room temperature (see Sections 12.3.3 and 12.3.4):

$$
K_{e}=\left\{\begin{array}{cc}
K_{0 e}\left(1-\left(\frac{T-T_{R}}{T_{m}-T_{R}}\right)^{m_{e}}\right), & T \leq 20^{\circ} \mathrm{C} \\
k_{0 e} \exp \left(-\left(\frac{T}{k_{2}}\right)^{k_{1}}\right), & T>20^{\circ} \mathrm{C}
\end{array}\right.
$$

where recommended values for the parameters in Eq. (4), including the reference temperature $T_{R}$ and the melting temperature $T_{m}$, are listed in Table 2. The work-hardening coefficient is plotted against temperature in Figure 2.

Table 2: Recommended values for parameters in Eq. (4).

\begin{tabular}{c|c|c|c}
\hline \multicolumn{2}{c|}{ Below Room Temperature $\left(T \leq 20^{\circ} \mathrm{C}\right)$} & \multicolumn{2}{c}{ Above Room Temperature $\left(T>20^{\circ} \mathrm{C}\right)$} \\
\hline Parameter & Recommended Value & Parameter & Recommended Value \\
\hline$K_{0 e}$ & $3867 \mathrm{MPa}$ & $k_{0 e}$ & $2433 \mathrm{MPa}$ \\
$m_{e}$ & 0.545 & $k_{1}$ & 3.722 \\
$T_{m}$ & $1534{ }^{\circ} \mathrm{C}$ & $k_{2}$ & $586.8{ }^{\circ} \mathrm{C}$ \\
$T_{R}$ & $-273.15^{\circ} \mathrm{C}$ & & \\
\hline
\end{tabular}




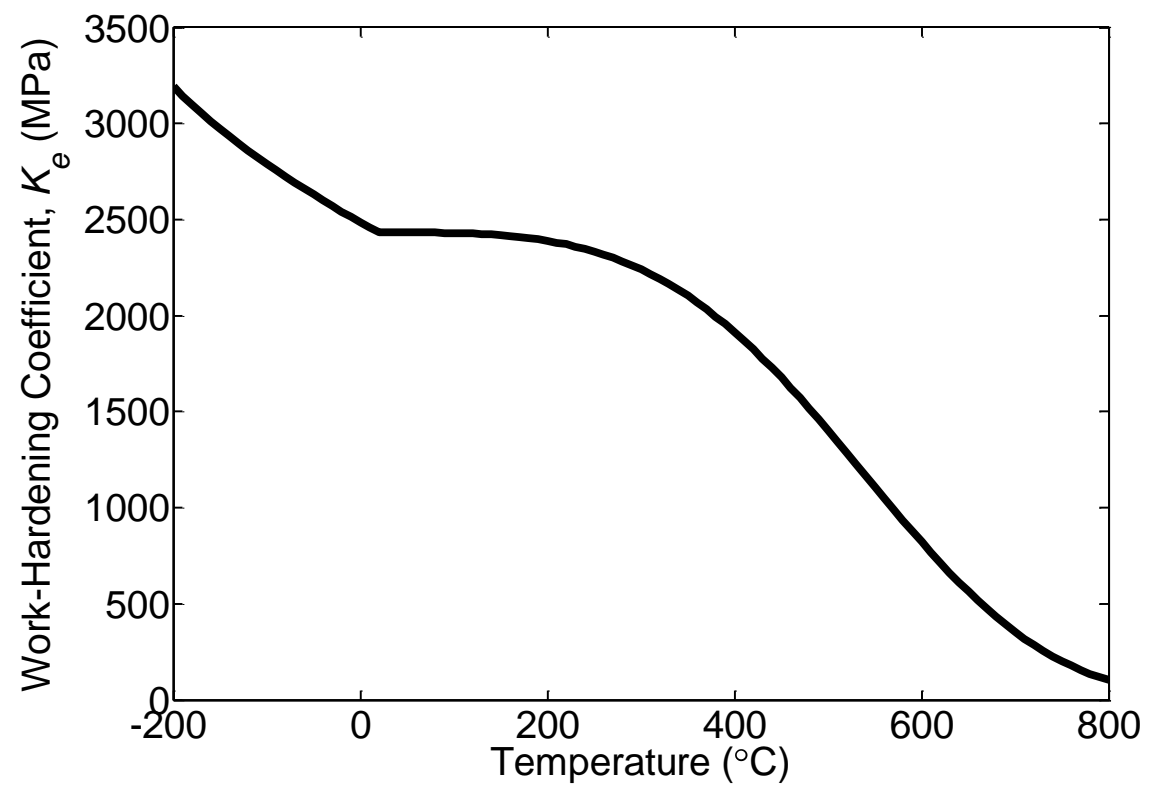

Figure 2: Variation of work-hardening coefficient with temperature.

Eq. (1) can be inverted to solve for the strain in the wire as a function of its stress:

$$
e=\left\{\begin{array}{cc}
\frac{S}{E}, & S \leq S_{y} \\
\left(\frac{S}{K_{e}}\right)^{1 / n_{e}}, & S>S_{y}
\end{array}\right.
$$

where the $S_{y}=E e_{y}$ is the engineering stress at yield.

\subsection{Wire Fracture}

A pristine steel wire fails in a ductile manner, exhibiting work hardening as given by Eq. (1) and reaching an ultimate engineering stress $S_{u}$ at an engineering strain of $e_{u}$, before fracture occurs with appreciable necking. Below room temperature, $e_{u}$ is approximately constant, with a mean value of $e_{0 u}=0.057$ obtained experimentally for new wire (see Section 12.3.3). Above room temperature, $e_{u}$ decays exponentially with increasing temperature (see Section 12.3.4):

$$
e_{u}=\left\{\begin{array}{cc}
e_{0 u}, & T \leq 20^{\circ} \mathrm{C} \\
e_{0 u} \exp \left(-\left(\frac{T}{c_{2}}\right)^{c_{1}}\right), & T>20^{\circ} \mathrm{C}
\end{array}\right.
$$


where $c_{1}=1.828$ and $c_{2}=684.8^{\circ} \mathrm{C}$. Figure 3 shows a plot of both the yield strain (from Eq. (2)) and the ultimate strain for new wire (from Eq. (6) with $e_{0 u}=0.057$ ) against temperature.

The ultimate engineering stress $S_{u}=K_{e} e_{u}^{n_{e}}$ can be expressed using Eqs. (1), (4), and (6) as

$$
S_{u}=\left\{\begin{array}{cc}
K_{0 e}\left(1-\left(\frac{T-T_{R}}{T_{m}-T_{R}}\right)^{m_{e}}\right) e_{0 u}^{n_{e}}, & T \leq 20^{\circ} \mathrm{C} \\
k_{0 e} \exp \left(-\left(\frac{T}{k_{2}}\right)^{k_{1}}-n_{e}\left(\frac{T}{c_{2}}\right)^{c_{1}}\right) e_{0 u}^{n_{e}}, & T>20^{\circ} \mathrm{C}
\end{array}\right.
$$

Note that the ultimate stress at $20^{\circ} \mathrm{C}$, denoted $S_{u, 20}$, can be expressed in the following alternate forms, in which the numerical coefficients follow from substitution of values given in Table 2:

$$
S_{u, 20}=\left\{\begin{array}{c}
K_{0 e}\left(1-\left(\frac{20^{\circ} \mathrm{C}-T_{R}}{T_{m}-T_{R}}\right)^{m_{e}}\right) e_{0 u}^{n_{e}}=0.6289 K_{0 e} e_{0 u}^{n_{e}} \\
k_{0 e} \exp \left(-\left(\frac{20^{\circ} \mathrm{C}}{k_{2}}\right)^{k_{1}}-n_{e}\left(\frac{20^{\circ} \mathrm{C}}{c_{2}}\right)^{c_{1}}\right) e_{0 u}^{n_{e}}=1.000 k_{0 e} e_{0 u}^{n_{e}}
\end{array}\right.
$$

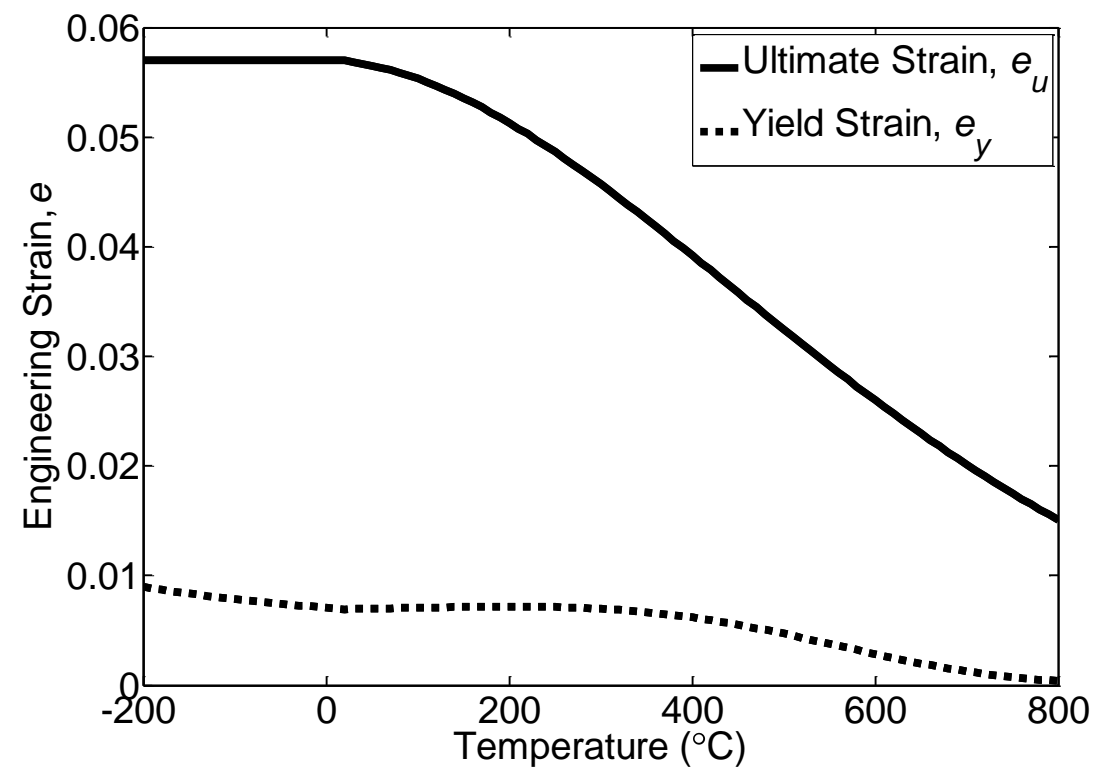

Figure 3: Variation of yield strain and ultimate strain (new wire) with temperature. 
Using Eqs. (7) and (8), the temperature-dependent ultimate stress can be expressed in terms of $S_{u, 20}$, its value at room temperature:

$$
S_{u}=\left\{\begin{array}{cc}
\frac{S_{u, 20}\left(1-\left(\frac{T-T_{R}}{T_{m}-T_{R}}\right)^{m_{e}}\right),}{0.6289} & T \leq 20^{\circ} \mathrm{C} \\
S_{u, 20} \exp \left(-\left(\frac{T}{k_{2}}\right)^{k_{1}}-n_{e}\left(\frac{T}{c_{2}}\right)^{c_{1}}\right), & T>20^{\circ} \mathrm{C}
\end{array}\right.
$$

A mean value of $S_{u, 20}=1784 \mathrm{MPa}$ was found experimentally for new wire (see Section 12.3.3). Figure 4 shows a plot of both the yield stress $S_{y}=E e_{y}$ and the ultimate stress for new wire (from Eq. (9) with $S_{u, 20}=1784 \mathrm{MPa}$ ) against temperature. Figure 5 shows engineering stress-strain curves for new wire at different temperatures using Eq. (1). When the ultimate strain given in Eq. (6) is reached, the curves drop to zero stress, indicating failure.

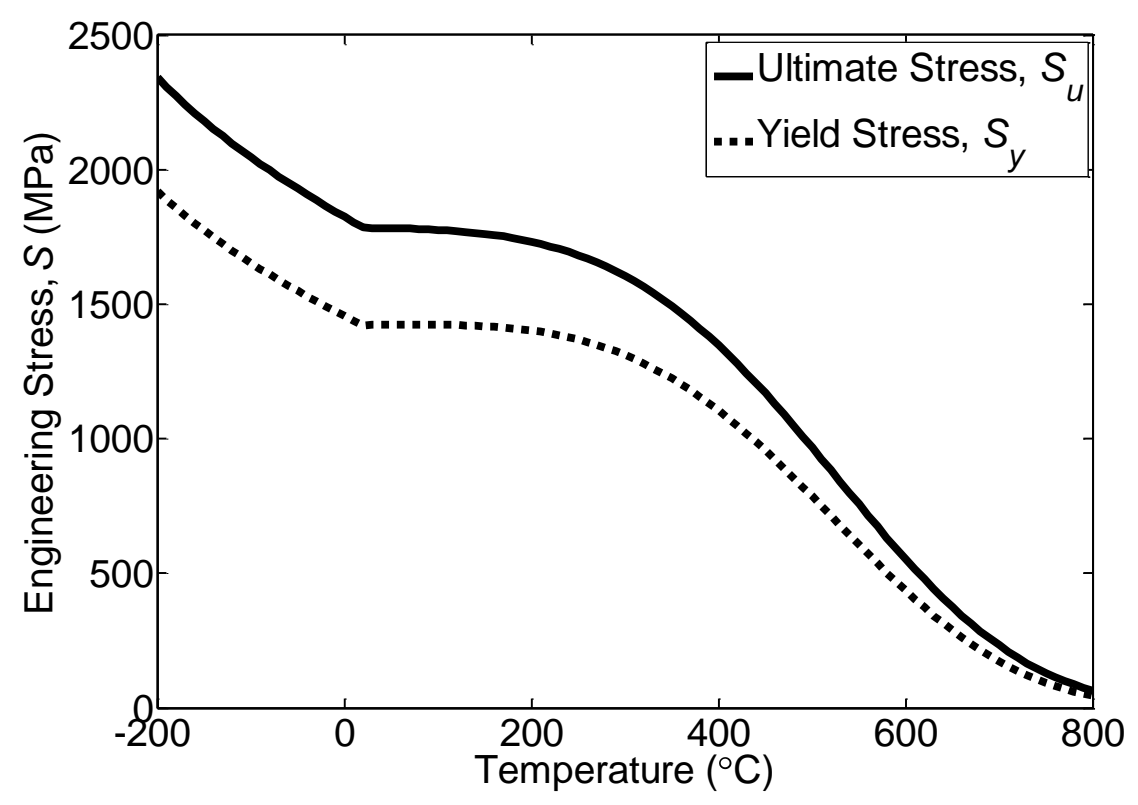

Figure 4: Variation of yield stress and ultimate stress (new wire) with temperature. 


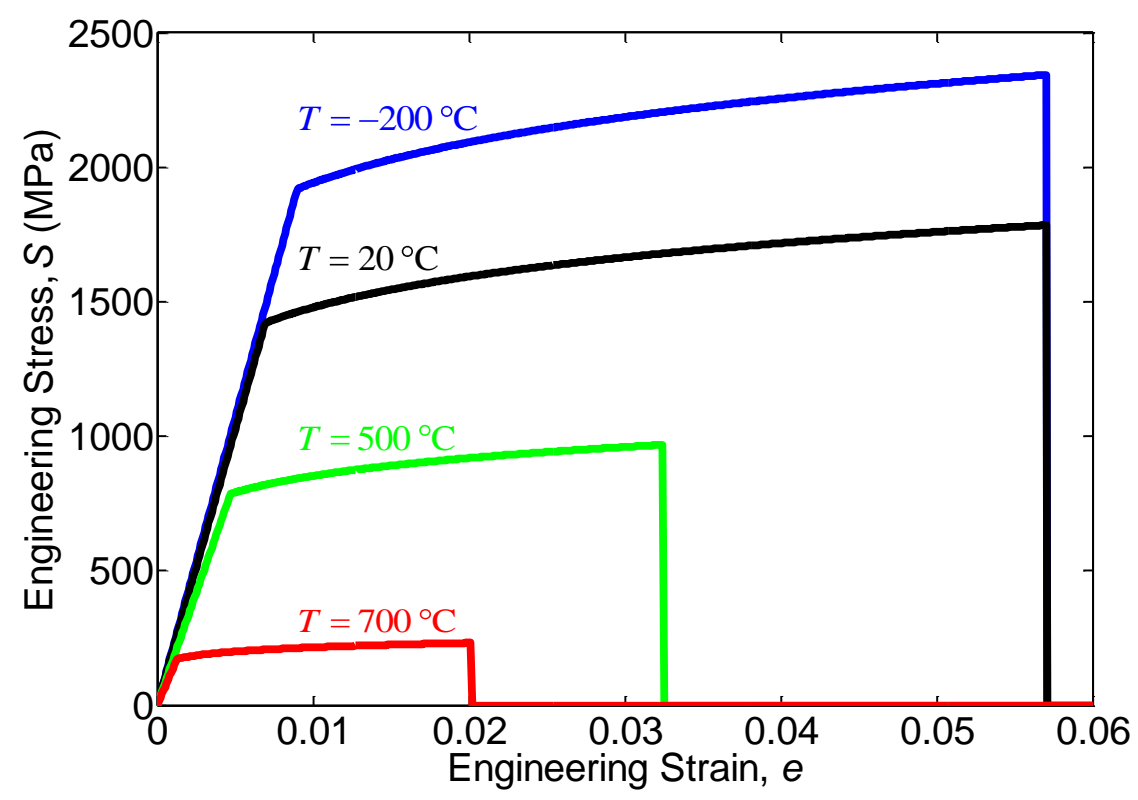

Figure 5: Engineering stress-strain curves for new wire at different temperatures.

The presence of moisture can cause surface flaws or cracks to initiate and propagate, producing stress concentrations and causing the wire to fail in a brittle manner with a reduced capacity. The engineering stress at which a cracked wire fails can be expressed as

$$
S_{c}=\frac{K_{C}}{Y\left(\frac{a}{d}\right) \sqrt{\pi a}}
$$

where $a$ is the crack depth, $d$ is the wire diameter, and $Y(a / d)$ is the normalized stress intensity factor for a wire in tension proposed by Mahmoud (2007):

$$
Y\left(\frac{a}{d}\right)=0.7282-2.1425\left(\frac{a}{d}\right)+18.082\left(\frac{a}{d}\right)^{2}-49.385\left(\frac{a}{d}\right)^{3}+66.114\left(\frac{a}{d}\right)^{4}
$$

The fracture toughness $K_{C}$ is approximated as a linear function of temperature below the nilductility transition (NDT) temperature, which is assumed to be $T_{N D T}=20^{\circ} \mathrm{C}$, and as approximately constant above the NDT temperature:

$$
K_{C}=\left\{\begin{array}{cc}
K_{C, 20}+\frac{d K_{C}}{d T}\left(T-20^{\circ} \mathrm{C}\right), & T<20^{\circ} \mathrm{C} \\
K_{C, 20}, & T \geq 20^{\circ} \mathrm{C}
\end{array}\right.
$$


where $K_{C, 20}$ is set to the room-temperature value of $65.7 \mathrm{MPa} \cdot \mathrm{m}^{1 / 2}$ reported by Mahmoud (2007) and a value of $d K_{C} / d T=0.1810 \mathrm{MPa} \cdot \mathrm{m}^{1 / 2} /{ }^{\circ} \mathrm{C}$ is used, based on linear regression of literature data from low-carbon structural steels (see Section 12.3.6). The fracture toughness $K_{C}$ decreases with decreasing temperature, reducing the strength $S_{c}$ of a cracked wire. Figure 6 shows a plot of the fracture toughness $K_{C}$ against temperature.

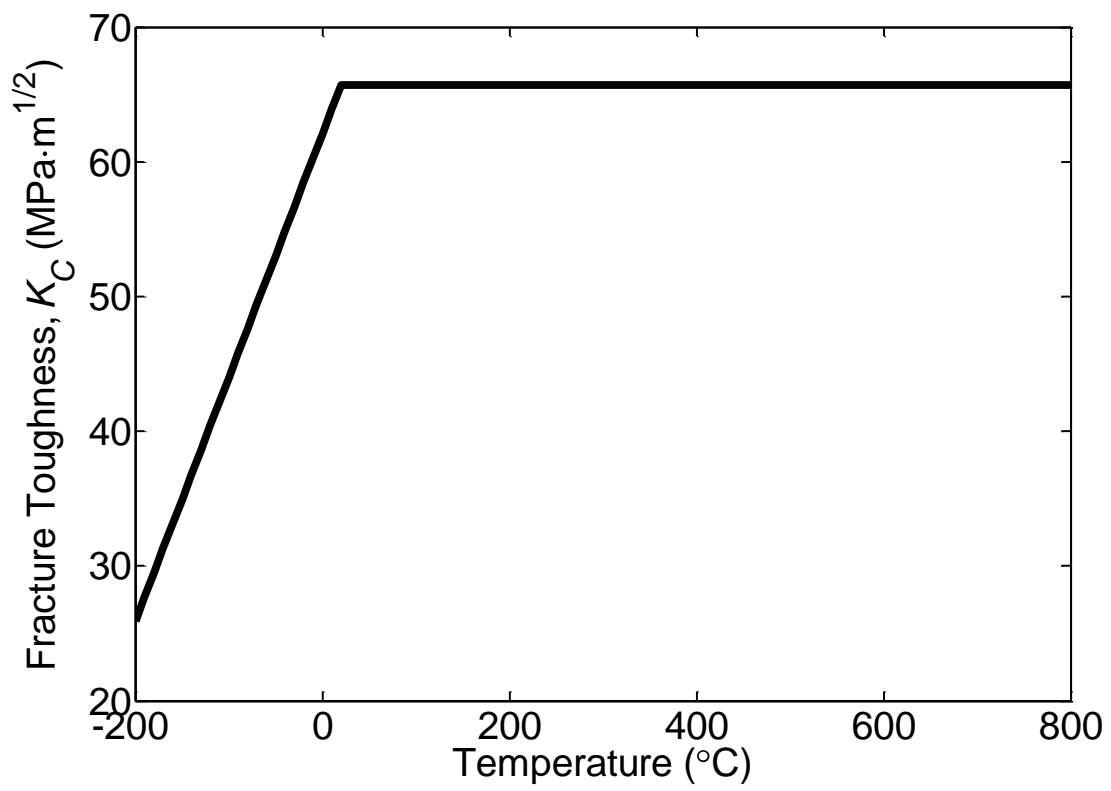

Figure 6: Variation of fracture toughness with temperature.

Using Eqs. (10) and (12) the strength of a cracked wire can be expressed as a function of temperature in terms of its strength at $20^{\circ} \mathrm{C}$, denoted $S_{c, 20}$, eliminating the explicit dependence on the flaw size in Eq. (10):

$$
S_{c}=\left\{\begin{array}{cc}
S_{c, 20}\left(1+\frac{d K_{C} / d T}{K_{C, 20}}\left(T-20^{\circ} \mathrm{C}\right)\right), & T<20^{\circ} \mathrm{C} \\
S_{c, 20}, & T \geq 20^{\circ} \mathrm{C}
\end{array}\right.
$$

Note that in some cases Eq. (13) predicts a strength $S_{c}$ that exceeds the ultimate strength $S_{u}$ from Eq. (9), corresponding to ductile failure. However, the strength of a cracked wire can never be larger than the strength without cracks. Therefore the engineering stress at fracture $S_{f}$ is obtained as the smaller of the two values: 


$$
S_{f}=\min \left(S_{u}, S_{c}\right)
$$

The stress-strain behavior is assumed to follow Eq. (1) until the fracture strength $S_{f}$ is reached, at which point failure occurs. Using Eq. (5), the engineering strain at fracture $e_{f}$ can be expressed as

$$
e_{f}=\left\{\begin{array}{cc}
\frac{S_{f}}{E}, & S_{f} \leq S_{y} \\
\left(\frac{S_{f}}{K_{e}}\right)^{1 / n_{e}}, & S_{f}>S_{y}
\end{array}\right.
$$

If the fracture strength is greater than the yield stress, $S_{f}>S_{y}$, then ductile behavior is observed before failure, as illustrated in Figure 7(a). If $S_{f} \leq S_{y}$, then the behavior is linearly elastic until fracture, representing a brittle failure, as illustrated in Figure 7(b). Figure 8 shows stress-strain curves for a cracked wire at different temperatures, using a representative room-temperature strength of $S_{c, 20}=0.7 S_{u}=1249 \mathrm{MPa}$ for the cracked wire. The stress-strain curves for $T=-200^{\circ} \mathrm{C}$ and $T=20^{\circ} \mathrm{C}$ in Figure 8 exhibit brittle failures, with a lower strength at $T=-200^{\circ} \mathrm{C}$ due to degradation in the fracture toughness at the reduced temperature. The stressstrain curves for $T=500{ }^{\circ} \mathrm{C}$ and $T=700^{\circ} \mathrm{C}$ exhibit ductile failure and are equivalent to those shown for new wire in Figure 5 (note the different scales on the ordinate and abscissa).

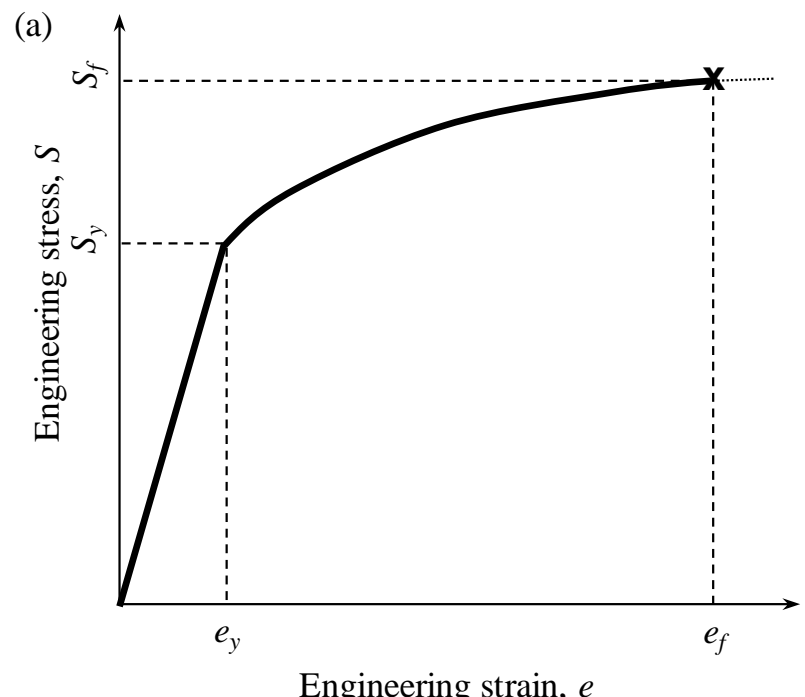

Engineering strain, $e$

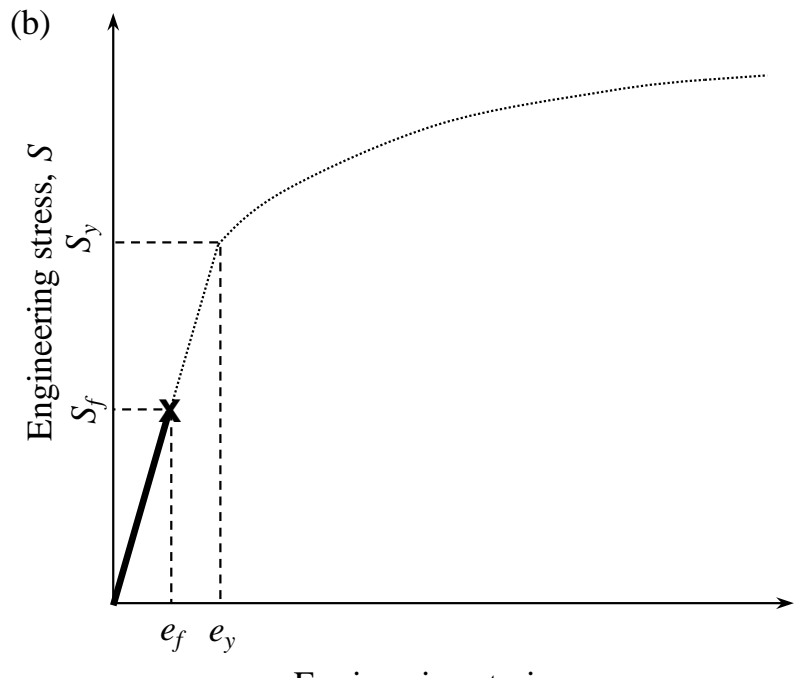

Engineering strain, $e$

Figure 7: Stress-strain behavior of steel wire up to fracture: (a) ductile failure $\left(S_{f}>S_{y}\right)$; (b) brittle failure $\left(S_{f} \leq S_{y}\right)$. 


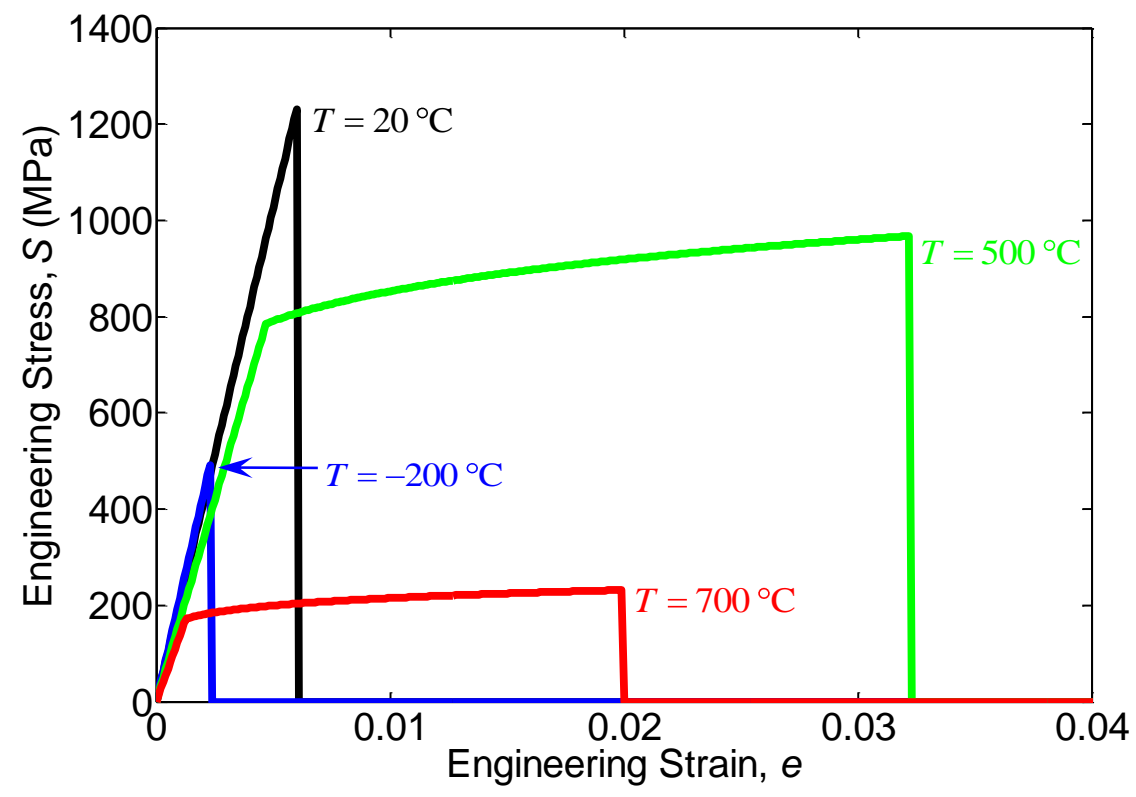

Figure 8: Engineering stress-strain curves for a cracked wire at different temperatures.

\section{Wire Strength Statistics}

Corrosion of in-situ wires leads to reductions in mean wire strength and increases in variability of wire strength. The National Cooperative Highway Research Program (NCHRP) Guidelines for Inspection and Strength Evaluation of Suspension Bridge parallel Wire Cables (Mayrbaurl and Camo 2004) define four stages of wire corrosion, with stages 1 and 2 corresponding to oxidization of the zinc wire coating and stages 3 and 4 corresponding to rusting of the steel wire itself. A significant fraction of the wires in stages 3 and 4 exhibit cracks that lead to brittle fractures with substantially reduced strengths, and the NCHRP Guidelines specify that cracked wires must be treated separately from uncracked wires in statistical strength analysis.

Strength statistics for cracked wires and for uncracked wires from the four corrosion stages are presented in Appendix A of the NCHRP Guidelines (Mayrbaurl and Camo 2004, Table A.3.1-1) for wires sampled from three different suspension bridges. Guided by these statistics, Table 3 presents representative mean and coefficient of variation (COV) values for the strength of cracked and uncracked wires. In the present analysis, uncracked wires from the four stages of corrosion are lumped together as a single group, with mean and COV values selected to represent the entire population of uncracked wires in a representative bridge cable. Note that while the statistics in Table A.3.1-1 of the NCHRP Guidelines correspond to the minimum wire strength over a length of $12.5 \mathrm{~m}$, the statistics in Table 3 correspond to specimens with a length of $30.5 \mathrm{~cm}$.

A lognormal probability distribution is used to represent the wire specimen strengths, as this distribution has the advantage of predicting only positive strength values. The shape parameter and 
location parameter of the lognormal distribution were calculated to match the mean and COV values reported in Table 3 for uncracked and cracked wires, with a mean ultimate strength of $S_{u, 20}=1784 \mathrm{MPa}$ for new wire, as obtained from room-temperature tensile tests. The resulting probability distributions are shown in Figure 9. The strength values for uncracked wires correspond to the ultimate strength at room temperature $S_{u, 20}$, and the temperature dependence of this ultimate strength is represented using Eq. (9). The strength values for cracked wires correspond to the fracture strength at room temperature $S_{c, 20}$, and the temperature dependence of this fracture strength is represented using Eq. (13).

Table 3: Strength statistics of uncracked and cracked wire specimens at room temperature.

\begin{tabular}{ccc}
\hline Wire Classification & $\begin{array}{c}\text { Mean Tensile Strength } \\
\text { (Fraction of New Wire Strength) }\end{array}$ & $\begin{array}{c}\text { Coefficient of } \\
\text { Variation }\end{array}$ \\
\hline uncracked & 0.95 & 0.04 \\
cracked & 0.75 & 0.13 \\
\hline
\end{tabular}

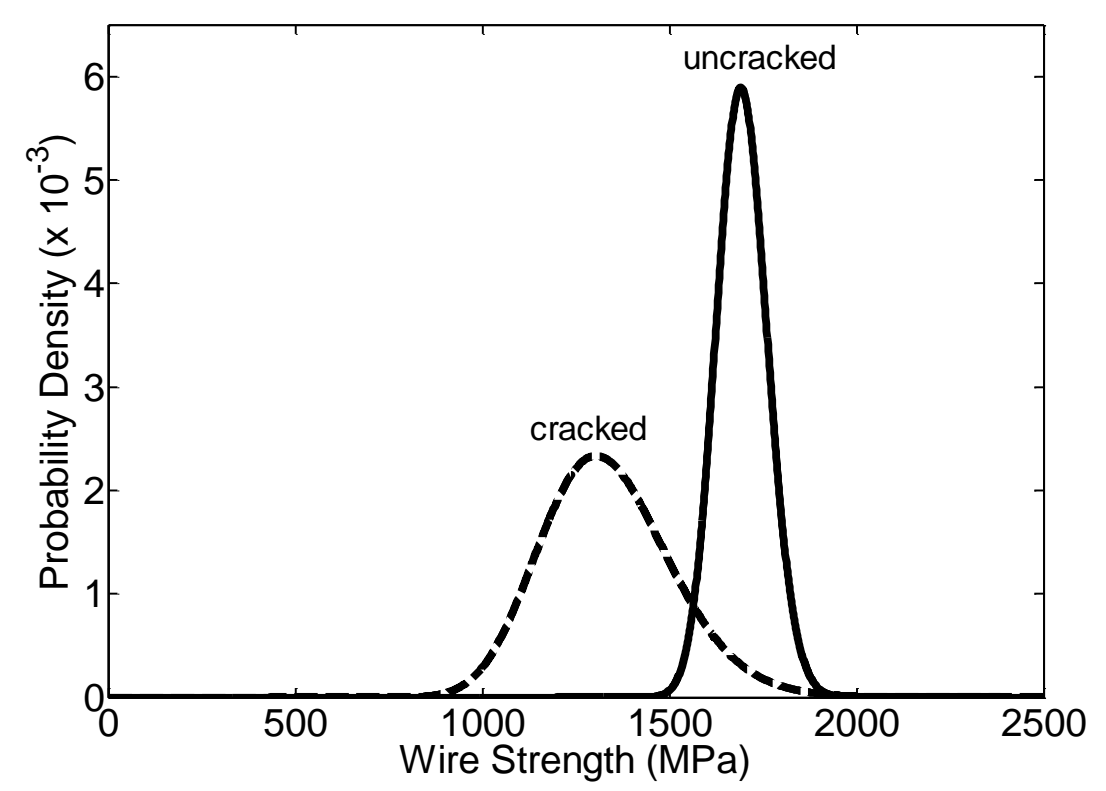

Figure 9: Probability distributions of wire specimen strengths at room temperature.

Shi et al. (2007) observed that wire strengths are substantially correlated along the length of a wire, with correlation above 0.8 at a separation of $3 \mathrm{~m}$. Previous models, including those presented in the NCHRP Guidelines (Mayrbaurl and Camo 2004) had assumed that the strength of adjacent wire segments with lengths of $30.5 \mathrm{~cm}$ were completely uncorrelated, and used extreme value distributions to estimate the "weakest link" strength for a wire of prescribed length. Accounting for correlation along the wire length using a random field model, Shi et al. (2007) ob- 
tained a strength estimate $13 \%$ larger than previous models, with a standard deviation $48 \%$ larger. It is noted that Shi et al. (2007) used the "ductile wire" strength model, which is known to be unconservative, to assess the total capacity of the cable.

In the present analysis, correlated wire strengths with lognormal marginal distributions are generated using the following procedure. Consider a wire divided into sequentially numbered segments of equal length, and let $S_{k}$ denote the ultimate strength of the $k$ th wire segment at room temperature. This quantity was previously denoted $S_{u, 20}$, but the additional subscripts are omitted here for clarity. Because strength is governed by a lognormal marginal distribution, the cumulative probability $p_{k}$ associated with the strength $S_{k}$ can be expressed as follows:

$$
p_{k}=\Phi\left(\frac{\ln S_{k}-\lambda_{u}}{\zeta_{u}}\right)
$$

where $\Phi()$ is the cumulative distribution function of the standard normal distribution, and $\lambda_{u}$ and $\zeta_{u}$ are the location parameter and shape parameter, respectively, of the lognormal distribution shown in Figure 9 for the ultimate strength of uncracked wires at room temperature. The strength $S_{k}$ of an initial segment in the wire is generated by drawing its cumulative probability $p_{k}$ from a uniform distribution over the interval $(0,1)$ :

$$
p_{k}=u_{(0,1)}
$$

where $u_{(0,1)}$ denotes a uniformly distributed random variable on the interval $(0,1)$. The strength $S_{k}$ is then calculated by inversion of Eq. (16):

$$
S_{k}=\exp \left(\lambda+\zeta \Phi^{-1}\left(p_{k}\right)\right)
$$

To generate a correlated strength $S_{k+1}$ for the subsequent wire segment, its cumulative probability $p_{k+1}$ is generated in a two-step process. First, an initial value $p_{k+1}^{0}$ is generated from a uniform distribution over the interval $\left(p_{k}-\alpha / 2, p_{k}+\alpha / 2\right)$, where $\alpha<2$ :

$$
p_{k+1}^{0}=p_{k}+\alpha\left(u_{(0,1)}-\frac{1}{2}\right)
$$

If the resulting value of $p_{k+1}^{0}$ does not fall within the interval $(0,1)$, it is then folded around the boundaries so that the resulting value of $p_{k+1}$ does fall within the required interval: 


$$
p_{k+1}=\left\{\begin{array}{cc}
-p_{k+1}^{0}, & p_{k+1}^{0}<0 \\
p_{k+1}^{0}, & 0 \leq p_{k+1}^{0} \leq 1 \\
2-p_{k+1}^{0}, & p_{k+1}^{0}>1
\end{array}\right.
$$

The strength $S_{k+1}$ is then calculated from Eq. (18). Cumulative probabilities for successive segments along the wire length are generated through repeated application of Eqs. (19) and (20), with corresponding strengths calculated from Eq. (18).

Eqs. (17), (19), and (20) represent a bivariate joint probability distribution for $p_{k}$ and $p_{k+1}$ that is illustrated in Figure 10. The marginal distributions for both $p_{k}$ and $p_{k+1}$ are uniform over the interval $(0,1)$, so that values of $S_{k}$ and $S_{k+1}$ calculated from Eq. (18) maintain a lognormal marginal distribution. The correlation of $S_{k}$ and $S_{k+1}$ can be adjusted by varying the parameter $\alpha$. A value of $\alpha=0.2$ was found to give fairly good agreement with the empirical strength correlation data presented by Shi et al. (2007) over the wire length of $6 \mathrm{~m}$ that is of interest in this study, as shown in Figure 11.

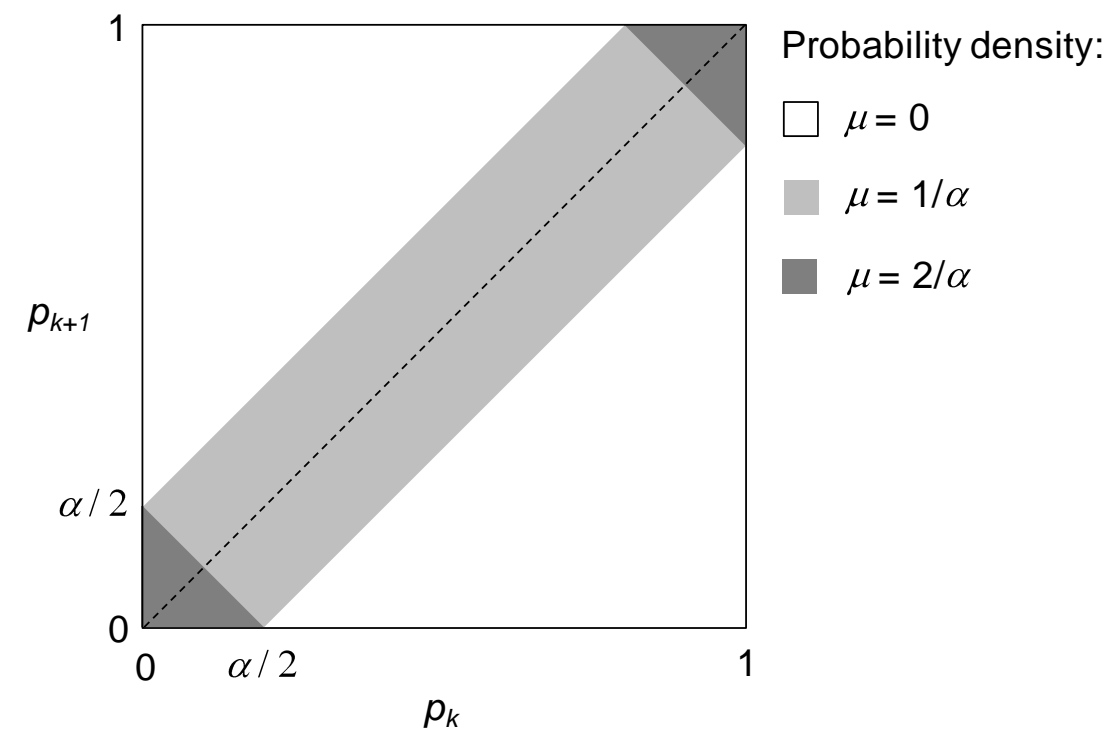

Figure 10: Bivariate joint probability density function for generating strengths of neighboring wire segments. 


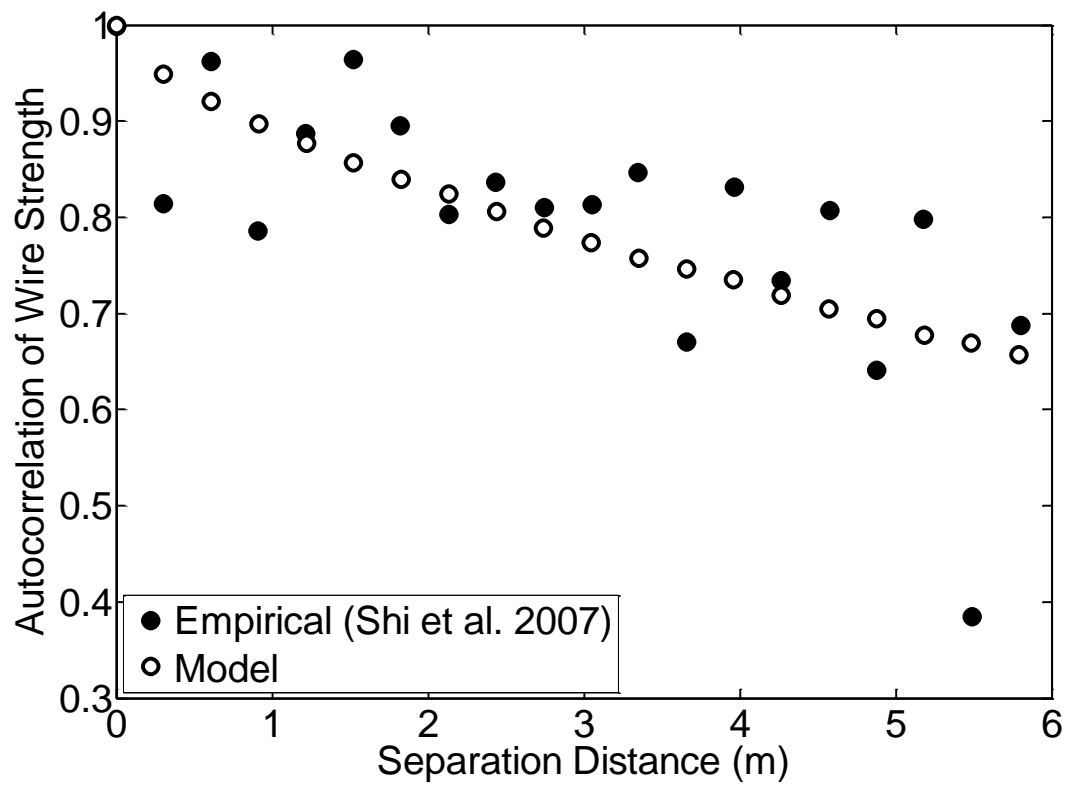

Figure 11: Autocorrelation of uncracked wire strength along cable axis.

Once values of the room-temperature ultimate strength $S_{u, 20}$ have been generated for each wire segment in the model, cracked wire segments are selectively introduced into the model. Cracks are introduced for the selected wire segments by generating values of the cracked strength at room temperature $S_{c, 20}$ from the lognormal distribution for cracked wires shown in Figure 9.

The NCHRP Guidelines (Mayrbaurl and Camo 2004, Section 1.4.2) note that cracks occur predominantly in the more corroded wires, with $5 \%$ to $20 \%$ of stage 3 wires and $60 \%$ of stage 4 wires exhibiting cracks. Because wires from stages 3 and 4 have lower mean strength values, this implies that cracks are more prevalent among lower strength wire specimens. To represent this in the model, cracks are introduced in all wire segments with strength $S_{u, 20}$ less than a certain threshold value. This threshold strength is determined by specifying a target fraction of wires in the cable bundle that should have at least one crack along the length.

The NCHRP Guidelines (Mayrbaurl and Camo 2004, Calculation Page EX1-19 in Appendix C) report that $13.6 \%$ of the wires in a selected panel of the Centennial Bridge had at least one crack in the panel length, and this value was used as the target fraction of cracked wires in the present analysis.

\section{Modeling of Parallel Wire Cable System}

In analyzing the behavior of a parallel wire cable system, a panel length $L$ of cable between cable bands is considered, with a cable band located at each end of the panel under consideration. The 
clamping action of the cable bands introduces substantial interwire friction that resists relative motion of the wires. In the present analysis, it is assumed that this interwire friction is adequate to completely restrain relative wire slippage at the cable bands, so that all wires in the panel length have the same total extension. No resistance to slippage between cable bands is considered. While wire wrapping has been found to introduce some additional interwire friction between cable bands, the NCHRP Guidelines note that this effect is ignored, in part because it is unquantifiable (Mayrbaurl and Camo 2004, Section C4.5). With interwire friction between cable bands considered negligible, it follows that the axial force in each wire is constant over the panel length.

Consider an individual wire within the parallel wire bundle. The wire, initially of length $L$, is divided into $n_{s}$ segments of initial length $\ell=L / n_{s}$, as illustrated in Figure 12. The extension of the $k$ th wire segment, denoted $\delta_{k}$, can be expressed as the sum of the thermal expansion and the mechanical extension:

$$
\delta_{k}=\delta_{k}^{t h}+\delta_{k}^{\text {mech }}
$$

Letting $T_{k}$ denote the temperature of the $k$ th wire segment, the thermal expansion of the segment can be represented as a cubic function of its temperature as follows (see Section 12.3 in Part 2):

$$
\delta_{k}^{t h}=\ell\left(a_{0}+a_{1} T_{k}+a_{2} T_{k}^{2}+a_{3} T_{k}^{3}\right)
$$

where $\quad a_{0}=-0.223 \times 10^{-2}, \quad a_{1}=4.337 \times 10^{-6} \mathrm{~K}^{-1}, \quad a_{2}=1.273 \times 10^{-8} \mathrm{~K}^{-2}, \quad$ and $a_{3}=-4.446 \times 10^{-12} \mathrm{~K}^{-3}$. The thermal strain $\delta^{\text {th }} / \ell$ is plotted as a function of temperature in Figure 13.

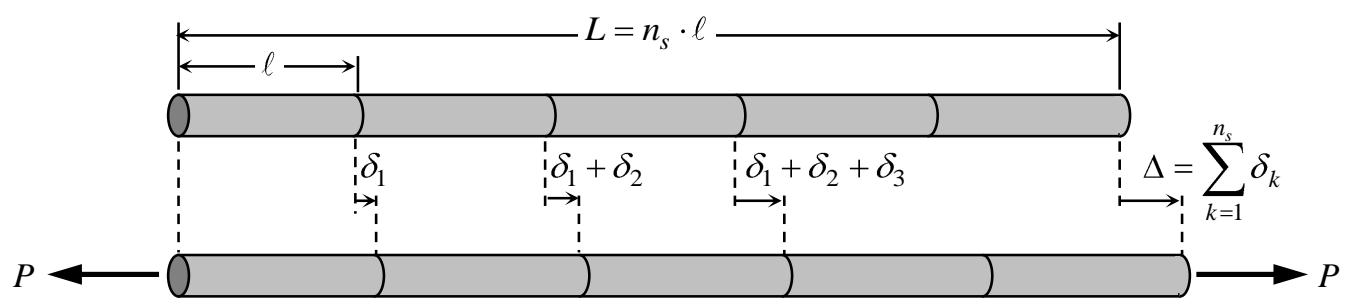

Figure 12: Extension of wire divided into segments initially of equal length. 


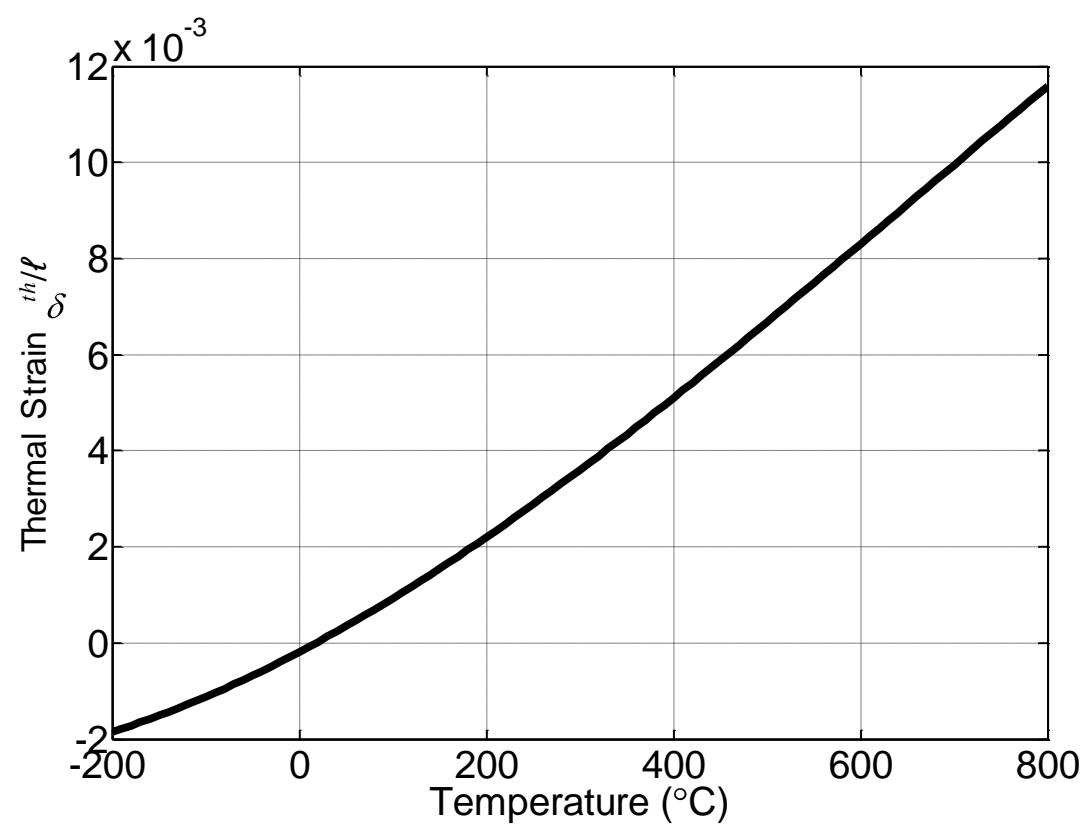

Figure 13: Thermal strain versus temperature.

Using Eq. (5), the mechanical extension of the $k$ th wire segment can be expressed as a function of the axial force $P$ as follows:

$$
\delta_{k}^{\text {mech }}(P)=\left\{\begin{array}{cc}
\frac{P \ell}{E\left(T_{k}\right) A_{w}}, & P \leq P_{y}\left(T_{k}\right) \\
\ell\left(\frac{P}{A_{w} K_{e}\left(T_{k}\right)}\right)^{1 / n_{e}} & ,
\end{array}\right.
$$

where $A_{w}$ denotes the initial cross-sectional area of the wire, and $P_{y}=S_{y} A_{w}$ and $P_{f}=S_{f} A_{w}$ denote the yield and failure loads of the wire, respectively. The dependence of parameters on the temperature $T_{k}$ has been indicated explicitly in Eq. (23). With interwire friction between cable bands neglected, the axial force in the wire is constant, so that all wire segments have the same axial force. As illustrated in Figure 12, the total extension of the wire can then be evaluated as a function of the constant axial force $P$, as follows:

$$
\Delta(P)=\sum_{k=1}^{n_{s}} \delta_{k}(P)
$$

Consider a bundle of $n_{w}$ parallel wires, each initially of length $L$, as illustrated in Figure 14. With the cable bands assumed to prevent relative slippage of the wires at both ends of the panel length, all wires in the bundle have the same total extension, denoted $\Delta$. The total axial force in the cable 
bundle at an extension $\Delta$ can then be obtained through summation of the axial forces in all wires at that extension:

$$
N(\Delta)=\sum_{i=1}^{n_{w}} P_{i}(\Delta)
$$

where the values of $P_{i}(\Delta)$, the wire forces at the desired extension, are obtained through numerical inversion of Eq. (24) for each wire.

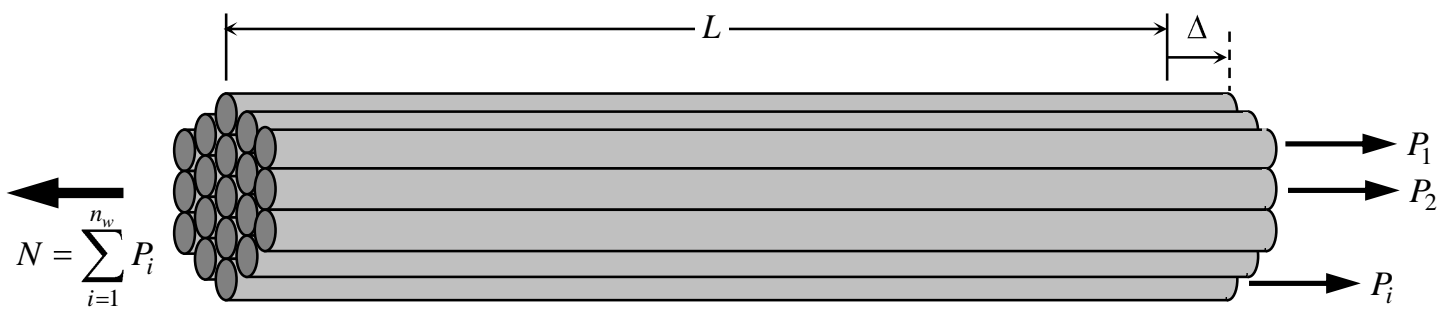

Figure 14: Extension of a wire bundle with all wires clamped together at both ends.

Figure 15 shows a plot of the total cable load $N$ against the total extension $\Delta$ of the cable bundle. A cable of diameter $D=508 \mathrm{~mm}$ with a panel length of $L=6.096 \mathrm{~m}$ is considered in the analysis, consisting of $n_{w}=9931$ parallel wires of diameter $d=4.85 \mathrm{~mm}$ and cross-sectional area $A_{w}=18.5 \mathrm{~mm}^{2}$. Each wire is divided into $n_{s}=20$ segments in the analysis. Based on 20 different realizations of the random wire strengths, a mean cable strength at room temperature of $N_{u l t}=245485 \mathrm{kN}$ was obtained, with a COV of $0.081 \%$. This level of variability compares reasonably well with the COV of $0.066 \%$ obtained by Shi et al. (2007) for the strength of a Williamsburg Bridge cable. The original cable strength can be estimated as $N_{u l t, 0}=S_{u, 20} A_{w} n_{w}=327500 \mathrm{kN}$, using $S_{u, 20}=1784 \mathrm{MPa}$ for new wire, which yields a value of $N_{u l t} / N_{u l t, 0}=0.750$ for the current cable strength as a fraction of the original strength. This value is consistent with those presented in Table 1, which were estimated using wire strength statistics from four suspension bridges. 


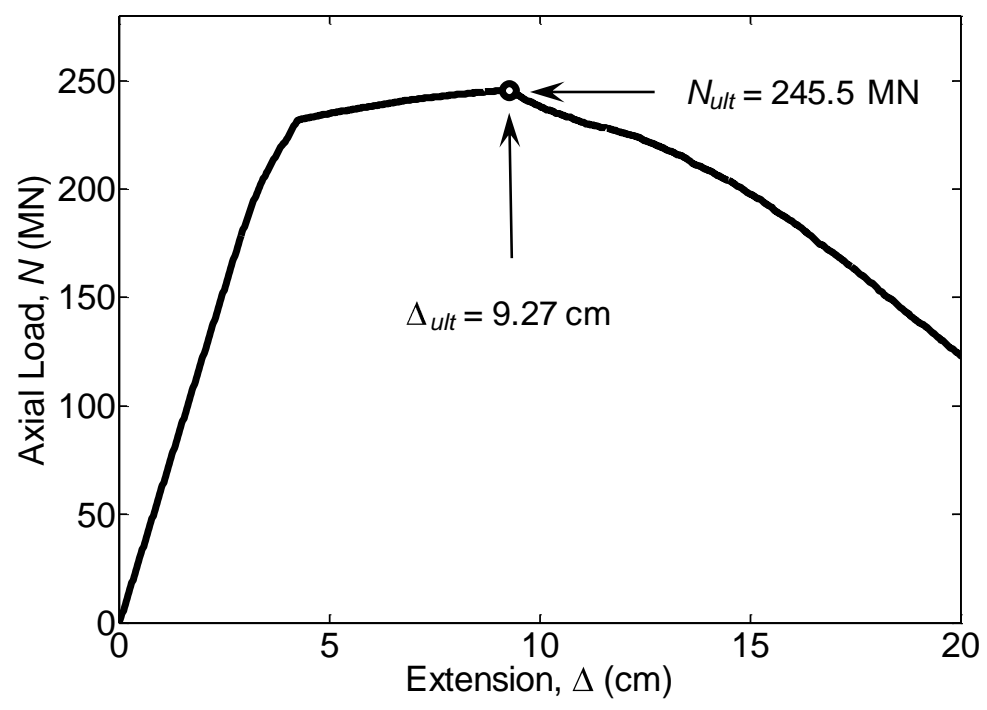

Figure 15: Total axial load versus axial extension for a representative cable.

\section{Heat Conduction Analysis}

This section describes the approaches used to analyze heat conduction in a parallel wire suspension bridge cable. Section 5.1 describes the approach used to obtain effective thermal properties for the bundle of parallel wires, approximating the bundle as a continuum. Section 5.2 presents an analytical solution for uniform axisymmetric heat conduction in a cylinder, which is used as a simple initial assessment of heat conduction in a bridge cable. This simple analytical solution assumes a uniform temperature on the outer surface of the cable and neglects any insulating effects of the exterior paint and wire wrapping layers. Section 5.3 discusses a finite element modeling approach to analyze heat conduction in a bridge, which allows for local, asymmetric heating and allows for explicit modeling of the paint and wire wrap layers. Section 5.4 summarizes the interpolation scheme used to obtain wire temperatures from nodal temperatures in the thermal finite element model.

\subsection{Effective Thermal Properties of Parallel Wire Bundle}

In the analysis of heat conduction, the bundle of parallel wires is represented as a continuum, with different thermal conductivities in the axial and radial directions to represent heat conduction along the wires and across the wires, respectively. In developing effective continuum properties for heat conduction in the wire bundle, and in the subsequent analysis of the cable system response in Section 6, a hexagonal packing configuration is assumed, as illustrated in Figure 16. As discussed by Gimseng (1983, Section 2.1) the hexagonal packing arrangement is typical for the wires in a suspension bridge cable. The interstitial voids between the wires are assumed to be 
filled with air. While the wires of some early suspension bridges were greased or oiled during spinning or compaction (Mayrbaurl and Camo 2004, Section 1.3.3.2), the potential presence of such a grease coating on the wires is assumed insufficient to fill the interstitial voids. Corrosioninhibiting pastes were used as a layer of protection under the exterior wrapping wires (Mayrbaurl and Camo 2004, Section 1.3.3.3), but not throughout the cable cross section.

Heat conduction of the parallel wire bundle in the radial direction is complex, depending on line contact between neighboring wires, with interstitial air pockets providing insulation. An effective conductivity in the radial direction was calculated using an analytical result for a hexagonal array of cylinders in contact (Perrins et al. 1979), which depends on the relative conductivities of the cylinders (steel wires) and the interstitial material (air). The conductivity in the axial direction was calculated as an average of the conductivities of steel and air, weighted by their respective volume fractions. With the assumed hexagonal packing configuration, the volume fraction of the wires is $\pi /(2 \sqrt{3}) \cong 0.9069$. The temperature-dependent thermal conductivity of air was calculated using equations from Lemmon and Jacobsen (2004) and is plotted in Figure 17.

The calculated effective conductivities of the wire bundle in the axial and radial directions are plotted against temperature in Figure 18, along with the conductivity of steel wire (see Section 12.2 in Part 2 of this report). The effective conductivity is significantly greater in the axial direction, as would be expected, because heat is conducted more efficiently along the wires than across them.

The specific heat capacity $C_{p}$ of the wire bundle at constant pressure was calculated as an average of the specific heat capacities of steel (see Section 12.1) and air (a temperature-independent value of $1012 \mathrm{~J} / \mathrm{kg} / \mathrm{K}$ was used), weighted by their respective mass fractions in the cable bundle. Because the mass fraction of air in the cable bundle is negligibly small, the resulting specific heat capacity of the wire bundle is virtually equivalent to that of steel. The specific heat capacity of the wire bundle, which is indistinguishable from that of steel, is plotted against temperature in Figure 19.

Thermal diffusivity is calculated as $\alpha=k /\left(\rho C_{p}\right)$, where $k$ is thermal conductivity, $\rho$ is density, and $C_{p}$ is the specific heat capacity at constant pressure. The effective density of the wire bundle is calculated as an average of the densities of steel and air, weighted by their respective volume fractions. The thermal diffusivity in both the axial and radial directions is plotted against temperature in Figure 20. The thermal diffusivity in the axial direction is indistinguishable from that of steel, because both $k$ and $\rho$ in this case were calculated as weighted averages based on volume fraction, and the volume fractions effectively cancel in the calculation of diffusivity. 


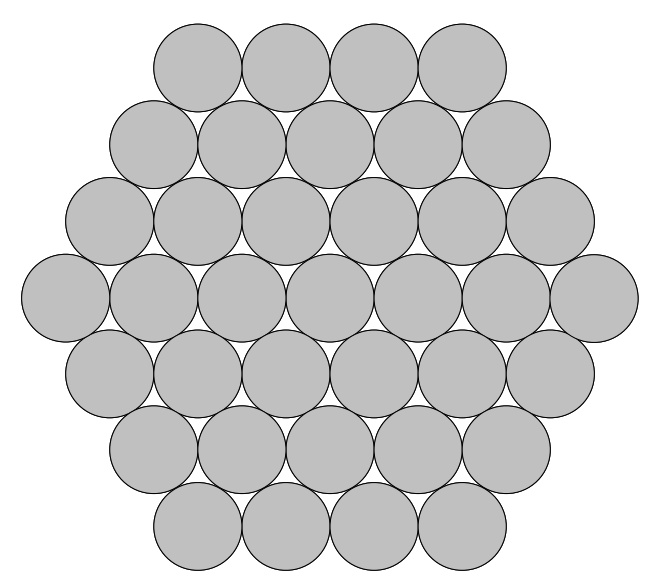

Figure 16: Assumed hexagonal packing configuration for parallel wires

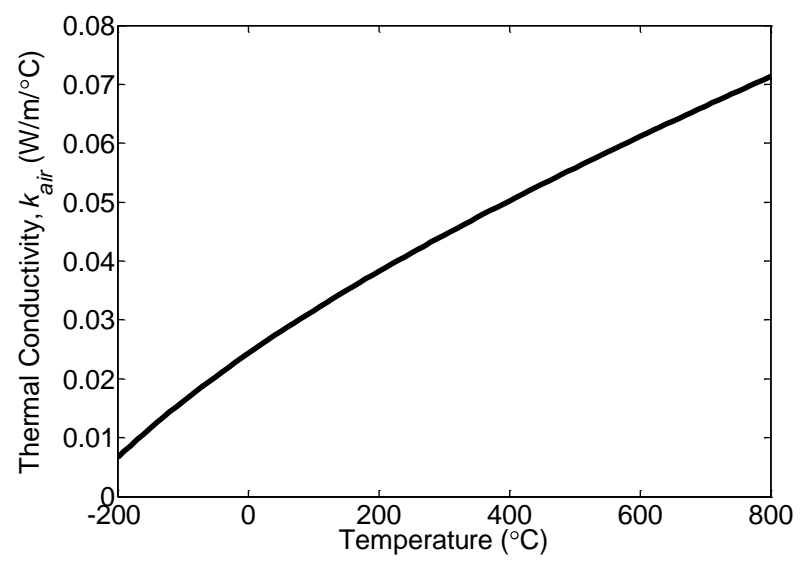

Figure 17: Thermal conductivity of air versus temperature.

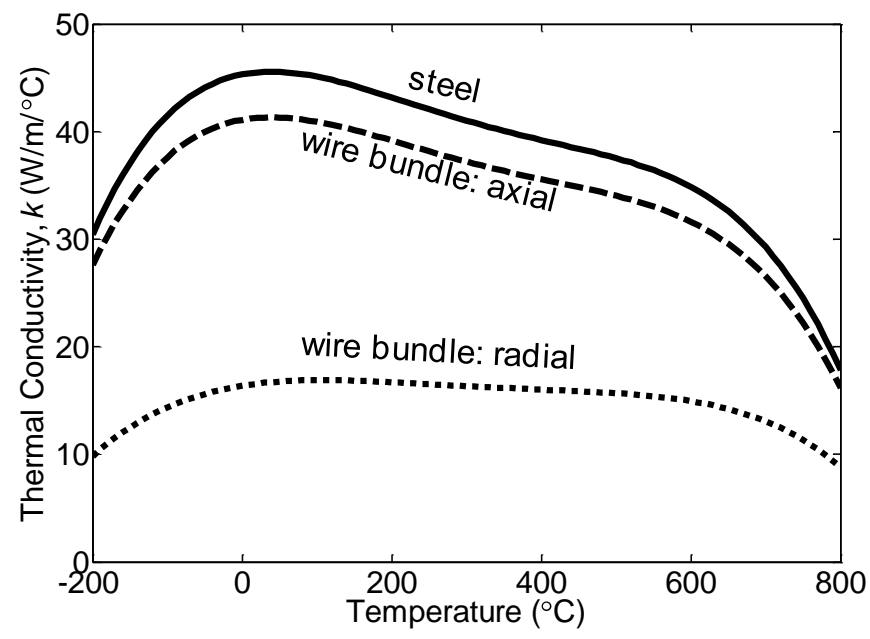

Figure 18: Thermal conductivity of wire bundle versus temperature. 


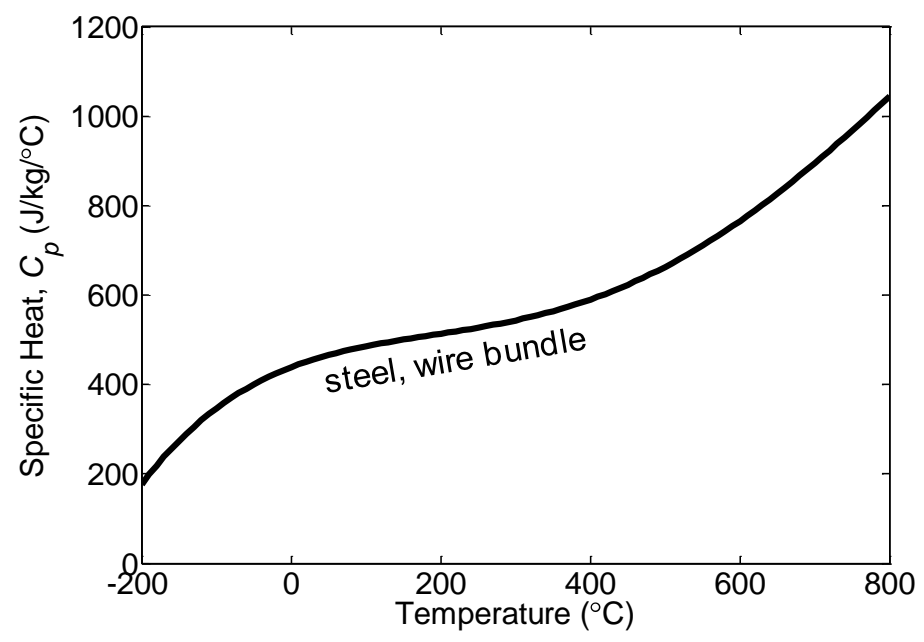

Figure 19: Specific heat capacity of wire bundle versus temperature.

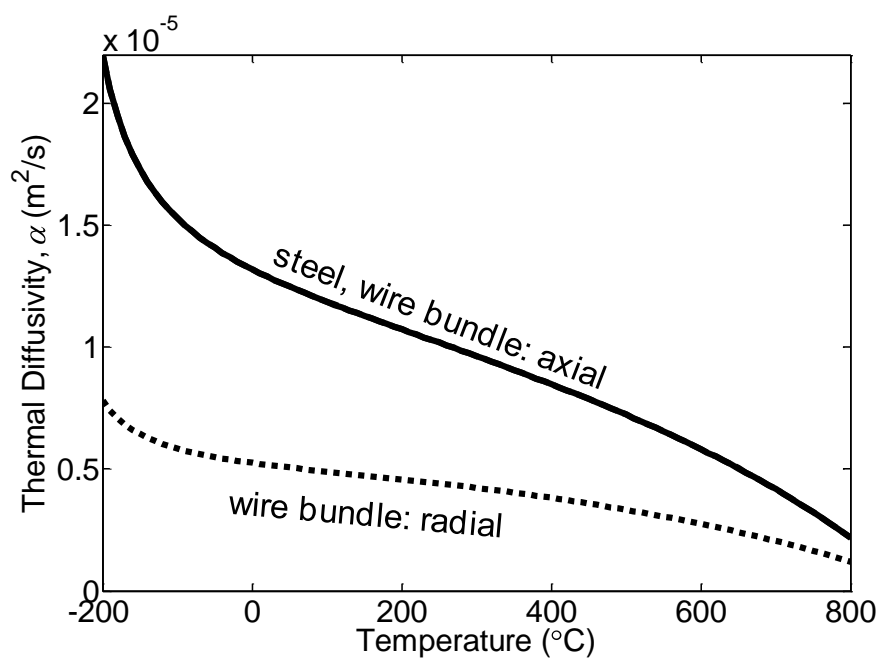

Figure 20: Thermal diffusivity of wire bundle versus temperature.

\subsection{Analytical Solution for Uniform Axisymmetric Heat Conduction}

As an initial assessment of the response of a suspension bridge cable to externally imposed temperatures, an analytical solution for axisymmetric heat conduction in a cylinder is considered (Antimonov, et al. 2008). A cylinder of radius $R$ with initial temperature $T_{o}$ is subjected to an external wall temperature $T_{w}$, uniform in the spanwise direction, beginning at time $t=0$. The time evolution of the solution as a function of the radial distance $r$ is illustrated in nondimensional form in Figure 21, where the Fourier number is defined as $\mathrm{Fo}=\alpha t / R^{2}$ and $\alpha$ is the thermal diffusivity, assumed to be independent of temperature. In Sections 6.1 and 6.2 this analytical so- 
lution is used to investigate the response of a cable to axisymmetric heating and cooling, respectively.

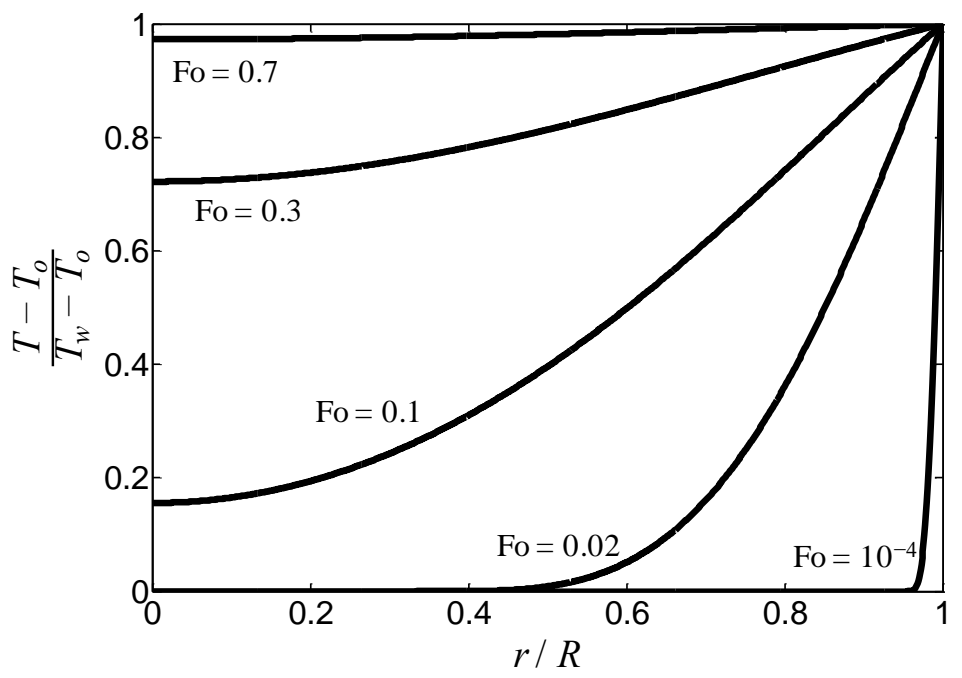

Figure 21: Solution to uniform axisymmetric heat conduction problem for a cylinder.

\subsection{Finite Element Modeling of Heat Conduction}

A more detailed analysis of heat conduction in a parallel wire suspension bridge cable is performed using a thermal finite element model that consists of solid elements representing the inner wire bundle, the exterior paint layer, and an intermediate layer of wire wrap and corrosioninhibiting paste. The solid element mesh for a $6.096 \mathrm{~m} \mathrm{(20} \mathrm{ft)} \mathrm{cable} \mathrm{segment} \mathrm{is} \mathrm{shown} \mathrm{in} \mathrm{Figure}$ 22. This length of cable was selected for analysis because this is the typical distance between cable bands, the locations at which the parallel wire bundles are clamped together and the vertical suspenders are attached. Constant boundary temperatures of $20{ }^{\circ} \mathrm{C}$ are applied at both ends of the cable segment, to represent the flow of heat into adjacent cable segments.

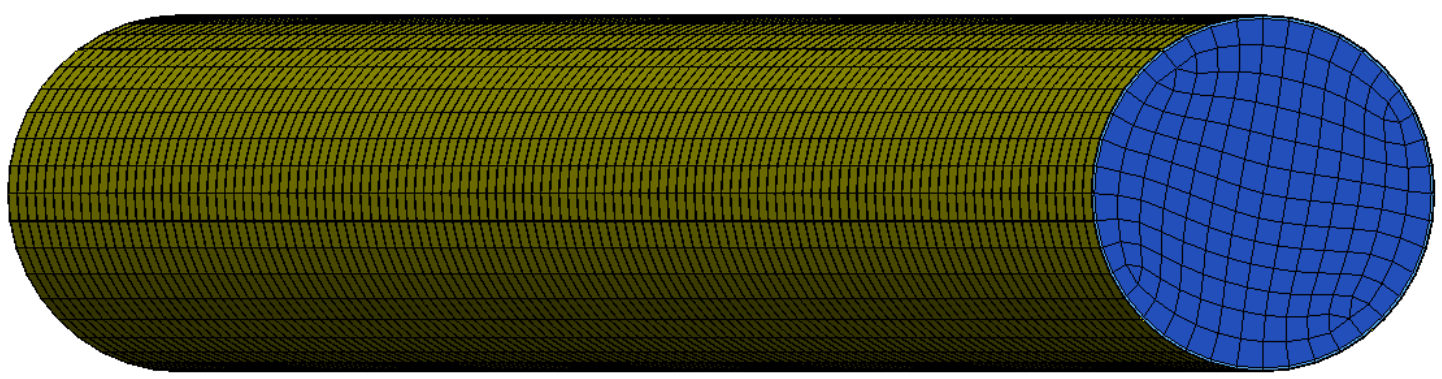

Figure 22: Finite element thermal model of cable.

In order to ensure that the solid element mesh used in the thermal model is adequately refined to accurately capture the thermal response, three meshes were created with different characteristic element sizes as shown in Figure 23. Results from test analyses using the three models were in- 
distinguishable, indicating that the coarsest mesh, with a characteristic element size of $40 \mathrm{~mm}$, is adequate. This coarsest mesh was therefore selected for use in subsequent simulations in order to minimize the time required for simulation.
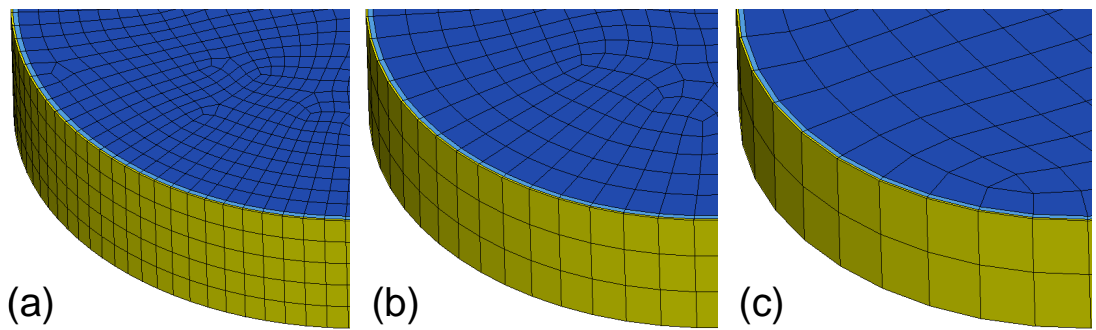

Figure 23: Portions of solid element meshes with three different characteristic element sizes: (a) $15 \mathrm{~mm}$; (b) $25 \mathrm{~mm}$; (c) $40 \mathrm{~mm}$.

The wire bundle is represented as a continuum in the thermal finite element model, using solid elements and an orthotropic material model with different thermal conductivities in the axial and radial directions to represent heat conduction along the wires and across the wires, respectively. The heat conduction properties used for the wire bundle were discussed in Section 5.1.

The exterior paint is represented in the thermal model using a single layer of solid elements with a thickness of $1.52 \mathrm{~mm}$ (0.060 in), corresponding to three layers of $0.508 \mathrm{~mm}$ (0.020 in) thickness each, as used on the New Carquinez Bridge in California, opened in 2003 (D. Khazem, personal communication). Thermal properties of paint reported by Sargent et al. (2006) were used in the model and are summarized as follows:

- Density of cured paint: $1620 \mathrm{~kg} / \mathrm{m}^{3}$

- Thermal conductivity of cured paint: $0.55 \mathrm{~W} / \mathrm{m} / \mathrm{K}$

- Specific heat capacity of cured paint: $1300 \mathrm{~J} / \mathrm{kg} / \mathrm{K}$

The temperature dependence of these thermal properties for paint is unknown, and the above values are simply treated as temperature-independent in the model.

Beneath the exterior paint is a single layer of wire wrap, with corrosion-inhibiting paste packed into the voids between the wire wrap and the parallel wire bundle. Traditionally, a red lead paste consisting of lead oxide powder $\left(\mathrm{Pb}_{2} \mathrm{O}_{3}\right)$ and raw linseed oil was used for corrosion prevention, while zinc-based pastes have been used recently. In the thermal model, a single layer of solid elements is used to represent both the wire wrap and the corrosion-inhibiting paste. A thickness of $3.77 \mathrm{~mm}(0.148 \mathrm{in})$ is used for this layer in the thermal model, corresponding to the diameter of the soft galvanized No. 9 wire used for wrapping.

The density and the specific heat capacity of the wire wrap layer can be estimated fairly directly using weighted averages based on the relative quantities of the constituent materials. Assuming a layer with uniform thickness equal to the diameter of the wrapping wires, the volume fraction of 
wrapping wires is $\pi / 4 \cong 0.785$, and the remaining volume is assumed to be completely filled with a material comparable to a zinc-based paste. Mayrbaurl and Camo (2004, p. 1-14) describe a zinc-based paste consisting of zinc, zinc oxide, corrosion inhibitors, and organic-based oil, which was used on several bridge rehabilitation projects in the United States. For the purposes of this thermal model, zinc-based paste with a composition by volume of $10 \%$ zinc, $60 \%$ zinc oxide, and $30 \%$ organic oil is assumed, from which a density of $4356 \mathrm{~kg} / \mathrm{m}^{3}$ and a specific heat capacity of $488 \mathrm{~J} / \mathrm{kg} / \mathrm{K}$ can be estimated as shown in Table 1 . (The density of the mixture is obtained by weighting the constituent densities by their respective volume fractions, and the specific heat capacity of the mixture is obtained by weighting the constituent heat capacities by their respective mass fractions.) Assuming a density of $7830 \mathrm{~kg} / \mathrm{m}^{3}$ and a specific heat capacity of $450 \mathrm{~J} / \mathrm{kg} / \mathrm{K}$ for the steel wires, the following effective properties for the wire wrap layer can be calculated:

- Effective density of wire wrap layer: $7080 \mathrm{~kg} / \mathrm{m}^{3}$

- Effective specific heat capacity wire wrap layer: $455 \mathrm{~J} / \mathrm{kg} / \mathrm{K}$

Table 4: Properties of zinc-based paste constituents and estimated properties of mixture.

\begin{tabular}{|c|c|c|c|c|c|}
\hline Constituent & $\begin{array}{l}\text { Density } \\
\left(\mathrm{kg} / \mathrm{m}^{3}\right)\end{array}$ & $\begin{array}{c}\text { Specific Heat } \\
\text { Capacity } \\
(\mathrm{J} / \mathrm{kg} / \mathrm{K})\end{array}$ & $\begin{array}{c}\text { Thermal Con- } \\
\text { ductivity } \\
(\mathrm{W} / \mathrm{m} / \mathrm{K})\end{array}$ & $\begin{array}{l}\text { Volume } \\
\text { Fraction }\end{array}$ & $\begin{array}{c}\text { Mass } \\
\text { Fraction }\end{array}$ \\
\hline zinc & $7140^{\mathrm{a}}$ & $387^{b}$ & $113^{\mathrm{c}}$ & 0.1 & 0.164 \\
\hline zinc oxide & $5606^{\mathrm{d}}$ & $397^{\mathrm{e}}$ & $21^{\mathrm{f}}$ & 0.6 & 0.772 \\
\hline organic oil & $929^{g}$ & $1840^{\mathrm{h}}$ & $0.173^{\mathrm{i}}$ & 0.3 & 0.064 \\
\hline mixture & $4356^{\mathrm{j}}$ & $488^{\mathrm{k}}$ & $1-2$ & 1.0 & 1.0 \\
\hline $\begin{array}{l}{ }^{a} \text { from http://en. } \\
{ }^{b} \text { from http://en. } \\
\text { at } 18^{\circ} \mathrm{C} \text { from } 1 \\
{ }^{d} \text { from http://en. } \\
{ }^{e} \text { from http://ww } \\
{ }^{f} \text { from http://en. } \\
{ }^{g} \text { for linseed oil } \\
\text { for linseed oil } \\
\text { for cottonseed } \\
\text { obtained by we }\end{array}$ & $\begin{array}{l}\text { pedia.org/v } \\
\text { ipedia.org/v } \\
\text { //www.gal } \\
\text { pedia.org/v } \\
\text { b.umich.ed } \\
\text { pedia.org/v } \\
5^{\circ} \mathrm{C} \text { from h } \\
\mathrm{h} \text { http://ww } \\
\text { rom http:// }\end{array}$ & $\begin{array}{l}\text { zi/Zinc } \\
\text { ki/Specific_heat } \\
\text { nizeit.org/showCo } \\
\text { ki/Zinc_oxide } \\
\text { dentlib/Dental_tab } \\
\text { i/List_of_thermal } \\
\text { ://www.simetric.c } \\
\text { engineeringtoolbo } \\
\text { p.fme.vutbr.cz/pre } \\
\text { ies of the constitu }\end{array}$ & $\begin{array}{l}\text { ent,302,346.cfm } \\
\text { s/Specheat.html } \\
\text { onductivities } \\
\text { uk/si_liquids.htm } \\
\text { com/specific-heat- } \\
\text { nety/thermomechar } \\
\text { ts by their respecti }\end{array}$ & d_151.h & \\
\hline
\end{tabular}

Thermal conduction through the wire wrap layer is complex, depending on point contacts between the parallel wire bundle and the circumferential wrapping wires, and strongly influenced by how completely the corrosion-inhibiting paste fills the voids between wires. In addition, as noted by Mayrbaurl and Camo (2004, p. 1-14), linseed oil polymerizes and shrinks with time, 
causing the paste to crack and become friable. These effects introduce air voids, which would reduce the conductivity of the paste. These complicating effects prevent a direct analytical estimation of the thermal conductivity of the wire wrap layer.

An estimate of the thermal conductivity of the zinc-based paste (prior to polymerization and cracking) can be achieved by comparison with silicone and zinc-oxide-based "thermal compounds," used to facilitate heat transfer from electronic components. These compounds have thermal conductivities ${ }^{2}$ between $0.7 \mathrm{~W} / \mathrm{m} / \mathrm{K}$ and $0.9 \mathrm{~W} / \mathrm{m} / \mathrm{K}$, much closer to that of the silicone oil medium (thermal conductivity $\left.{ }^{3} 0.1 \mathrm{~W} / \mathrm{m} / \mathrm{K}\right)$ than that of the zinc oxide filler $(21 \mathrm{~W} / \mathrm{m} / \mathrm{K})$. The thermal conductivity of the paste described in Table 4 might be expected to be somewhat higher than this range because the conductivity of organic oils $(0.17 \mathrm{~W} / \mathrm{m} / \mathrm{K})$ is somewhat larger than that of silicone oil $(0.1 \mathrm{~W} / \mathrm{m} / \mathrm{K})$, and because of the presence of more highly conductive metallic zinc $(113 \mathrm{~W} / \mathrm{m} / \mathrm{K})$. Thermal compounds with metal fillers, such as silver $(429 \mathrm{~W} / \mathrm{m} / \mathrm{K})$, can yield thermal conductivities ${ }^{4}$ as large as $3 \mathrm{~W} / \mathrm{m} / \mathrm{K}$. Therefore it is estimated that the initial thermal conductivity of the zinc-based corrosion-inhibiting paste might fall between $1 \mathrm{~W} / \mathrm{m} / \mathrm{K}$ and $2 \mathrm{~W} / \mathrm{m} / \mathrm{K}$. The overall conductivity of the wire wrap layer should be expected to be higher than this range, because approximately $78.5 \%$ of the volume of the layer is occupied by the more highly conductive steel wires $(45 \mathrm{~W} / \mathrm{m} / \mathrm{K})$. Conductivities as high as $10 \mathrm{~W} / \mathrm{m} / \mathrm{K}$ would seem realistic. However, uneven filling of the interstices and cracking of the paste would lead to significantly smaller values of thermal conductivity. A temperature-independent effective conductivity of $1.5 \mathrm{~W} / \mathrm{m} / \mathrm{K}$ for the wire wrap and paste layer is assumed in the finite element simulations, approximately one tenth of the room-temperature thermal conductivity of the wire bundle in the radial direction.

\subsection{Interpolation of Wire Temperatures from Finite Element Model}

Mapping of nodal temperatures from the thermal finite element model to wire segment temperatures in the mechanical model is accomplished using a weighted average interpolation scheme, in which greater weight is given to temperatures from nodes in closer proximity. Sample interpolation results are illustrated in Figure 24.

\footnotetext{
${ }^{2}$ http://www.heatsink-guide.com/content.php?content=compound.shtml

${ }^{3} \mathrm{http}: / /$ www.hukseflux.com/thermalScience/thermalConductivity.html

${ }^{4}$ http://en.wikipedia.org/wiki/Thermal_grease
} 

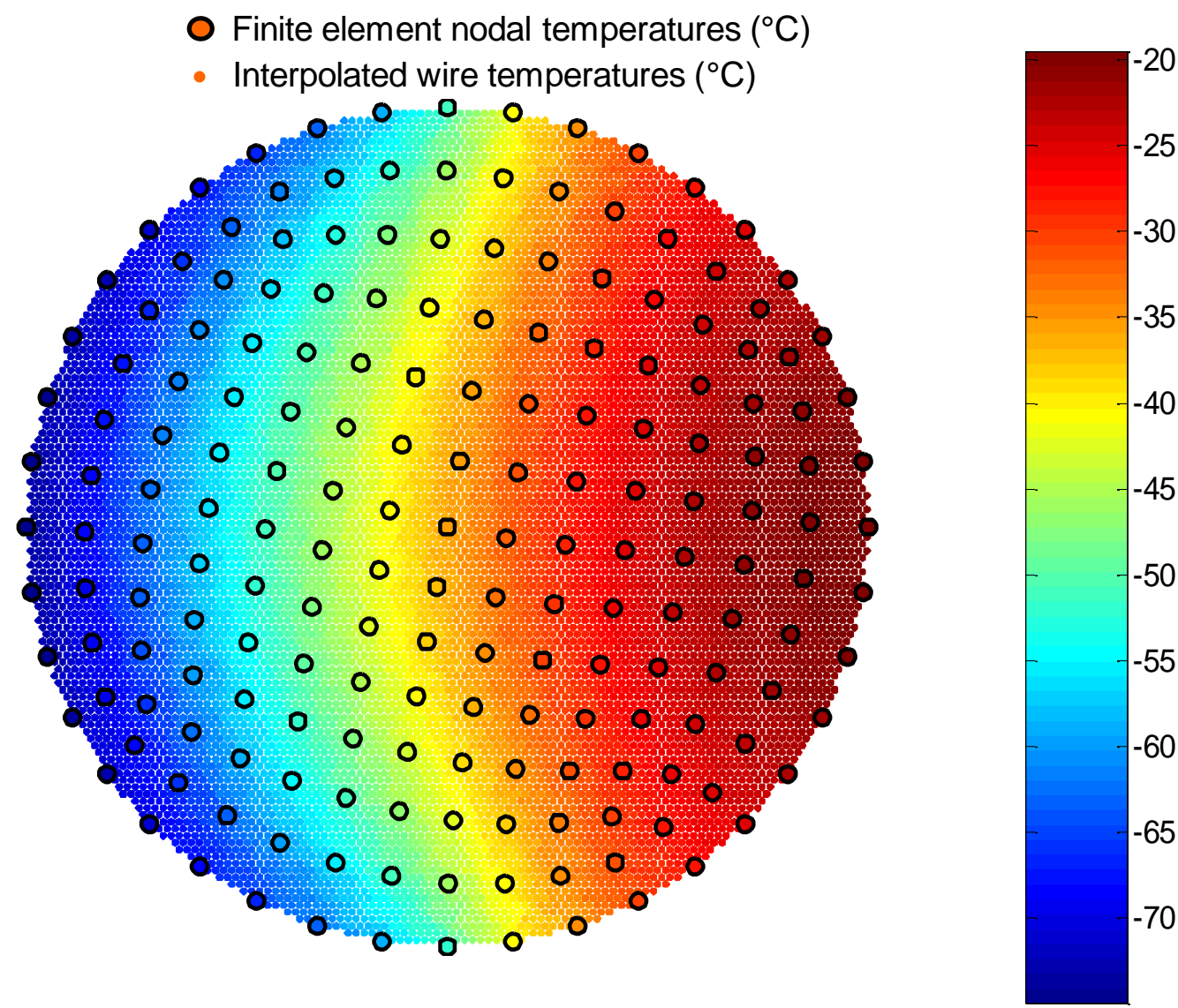

Figure 24: Interpolation of wire element temperatures from nodal temperatures.

\section{Response of Parallel Wire Cable}

This section presents results from analyses of parallel wire bridge cables subjected to four different prescribed surface temperature scenarios. Section 6.1 considers uniform axisymmetric cooling, with a uniform surface temperature of $-200{ }^{\circ} \mathrm{C}$ along the entire length of the cable segment. Because no significant loss in cable strength is observed even in this extreme case, no further analysis of surface cooling is presented.

The remaining scenarios in this section consider heating, with a surface temperature of $800{ }^{\circ} \mathrm{C}$ prescribed over different portions of the cable surface. Although fire temperatures in excess of $800{ }^{\circ} \mathrm{C}$ are conceivable, a surface temperature of $800{ }^{\circ} \mathrm{C}$ is selected because this is the upper limit for which material properties are available. At $800^{\circ} \mathrm{C}$, the ultimate strength of an uncracked wire is less than $5 \%$ of its room temperature strength (see Figure 4). Section 6.2 considers uniform axisymmetric heating, Section 6.3 considers local axisymmetric heating, and Section 6.4 considers local asymmetric heating. Cable failures are observed in each case, while the exposure time required to produce failure increases as the area exposed to high temperature decreases. 
In assessing the response of a parallel wire cable to prescribed surface temperatures, a service load in the cable equal to half of its ultimate capacity at room temperature ( $N_{\text {service }}=N_{\text {ult }} / 2=122742 \mathrm{kN}$ ) is selected, which corresponds to a safety factor of 2 . As noted in the Introduction, current safety factors for suspension bridges range between 2 and 3 .

The service load $N_{\text {service }}$ depends on the loads on the bridge and the geometry of the cable and is assumed to be negligibly affected by local thermal expansion or contraction of the cable segment being heated or cooled. For a representative suspension cable with a parabolic profile, a main span of $l=1000 \mathrm{~m}$, and a sag of $d=90 \mathrm{~m}$, a local thermal expansion of $10 \mathrm{~cm}$ would increase the sag by about $22 \mathrm{~cm}$. The service load $N_{\text {service }}$, which is proportional to $l^{2} / d$, would decrease by only about $0.24 \%$ as a consequence of this change in geometry.

\subsection{Uniform Axisymmetric Cooling}

To analyze the response of the parallel wire cable to embrittlement under low surface temperatures, the analytical solution discussed in Section 5.2 is employed, with a wall temperature of $T_{w}=-200{ }^{\circ} \mathrm{C}$ on the surface and an initial temperature of $T_{o}=20^{\circ} \mathrm{C}$. A temperatureindependent thermal diffusivity of $\alpha=5.986 \times 10^{-6} \mathrm{~m}^{2} / \mathrm{s}$ in the radial direction is used, which corresponds to an average value of the radial thermal diffusivity shown in Figure 20 over the temperature range of interest, between $-200{ }^{\circ} \mathrm{C}$ and $20{ }^{\circ} \mathrm{C}$. The resulting time evolution of the radial temperature profile is shown in Figure 25, and Figure 26 shows the mean and center temperatures of the cable plotted against time.

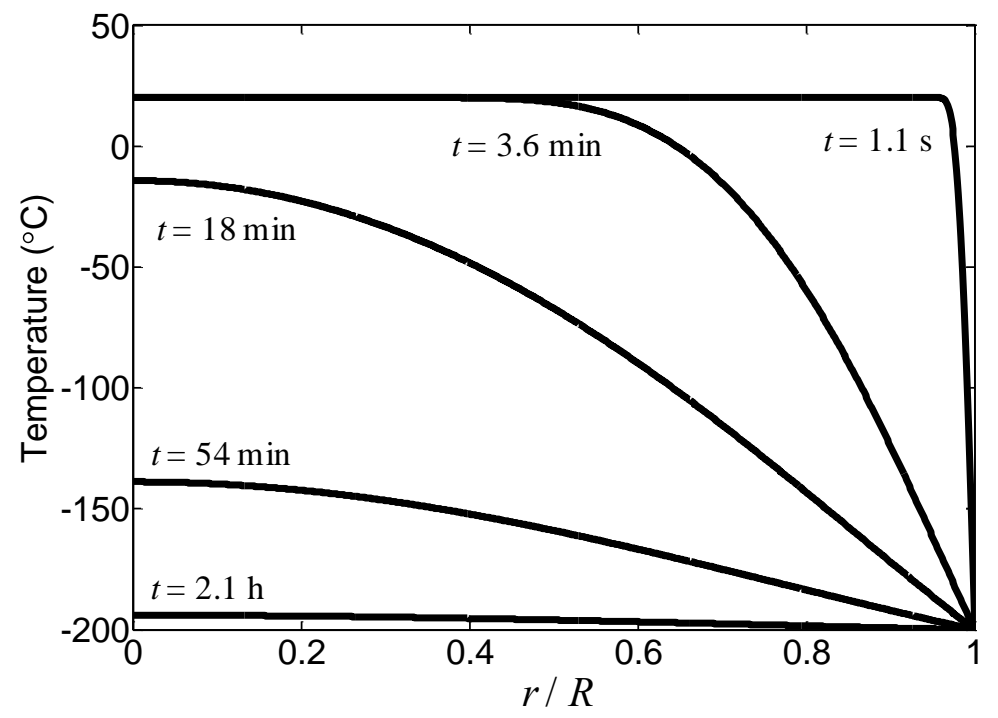

Figure 25: Time evolution of radial temperature profile for uniform axisymmetric cooling. 


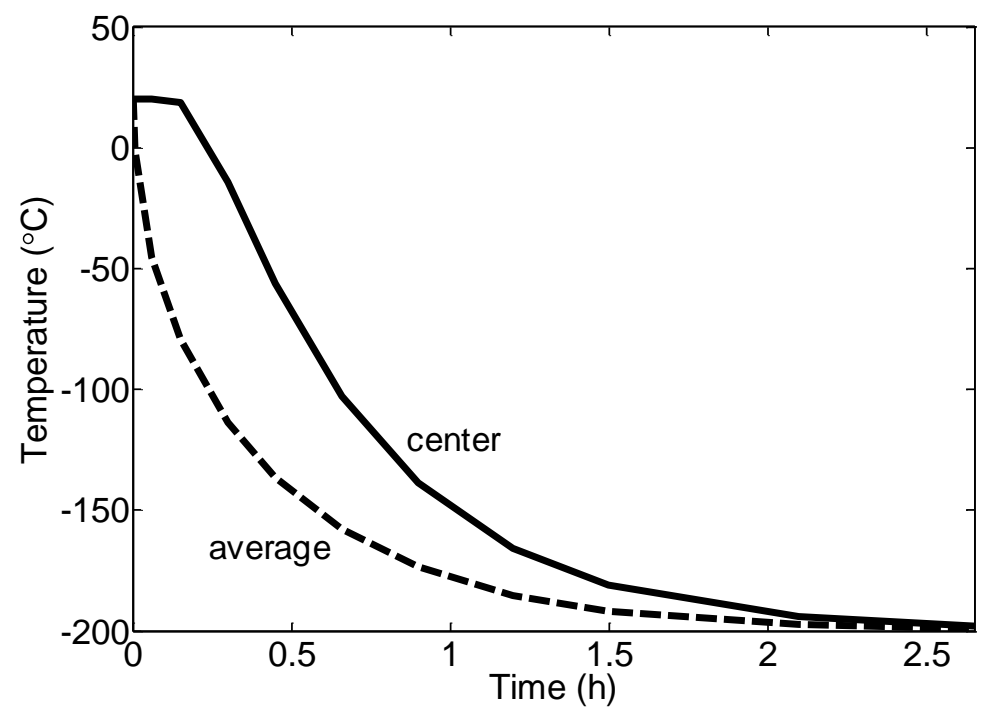

Figure 26: Time evolution of cable temperatures for uniform axisymmetric cooling.

The response of the parallel wire cable to low surface temperatures is illustrated in Figure 27 and Figure 28, in which wire temperatures (left column) and wire stresses (right column) are shown at subsequent instants in time. These figures illustrate how cooling of the outer wires results in increased stresses in these wires. The increased stresses result from thermal contraction, which causes the outer wires to carry a larger portion of the load relative to the inner wires.

The low temperatures also reduce the fracture strength of cracked wires, according to Eq. (13), which causes cracked wires to fracture as cooling and thermal contraction progress. Broken wires are indicated with hollow circles in Figure 27 and Figure 28, and an increasing fraction of broken wires is evident in these figures at subsequent times. Figure 29 shows the fraction of wires broken as a function of time, which increases fairly rapidly over the first hour of cooling and then stays relatively constant, reaching a maximum value of 0.136 at $t=2.7 \mathrm{~h}$, when the cable cross section has reached a fairly uniform temperature of about $-200{ }^{\circ} \mathrm{C}$. Note that 0.136 corresponds to the target fraction of cracked wires, as specified in Section 3. This indicates that essentially all of the cracked wires fracture at $-200{ }^{\circ} \mathrm{C}$, while the stresses in the uncracked wires remain in the elastic range. 

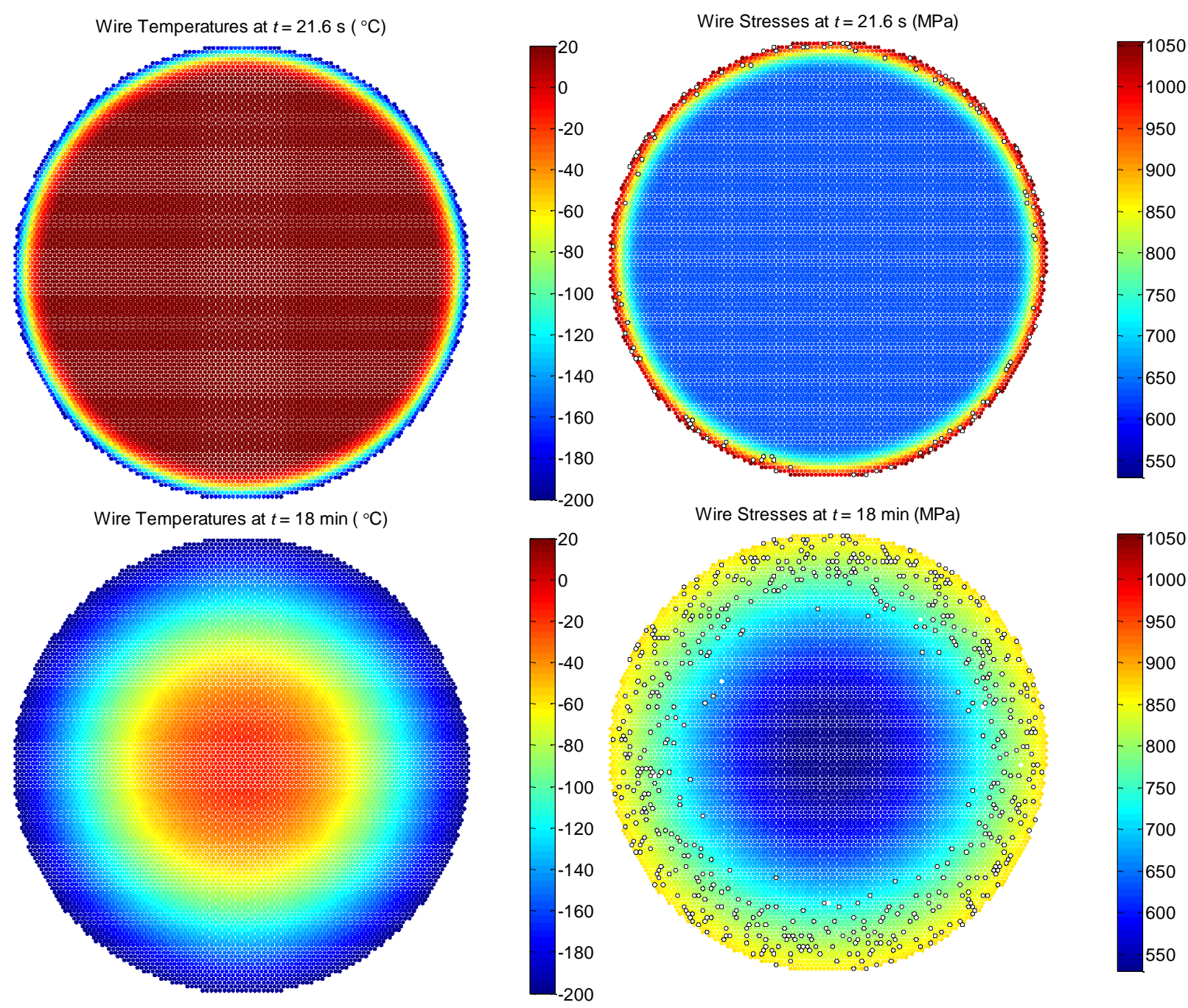

Figure 27: Contours of wire temperatures (left column) and stresses (right column) at subsequent times for uniform axisymmetric cooling. Hollow circles indicate broken wires. 

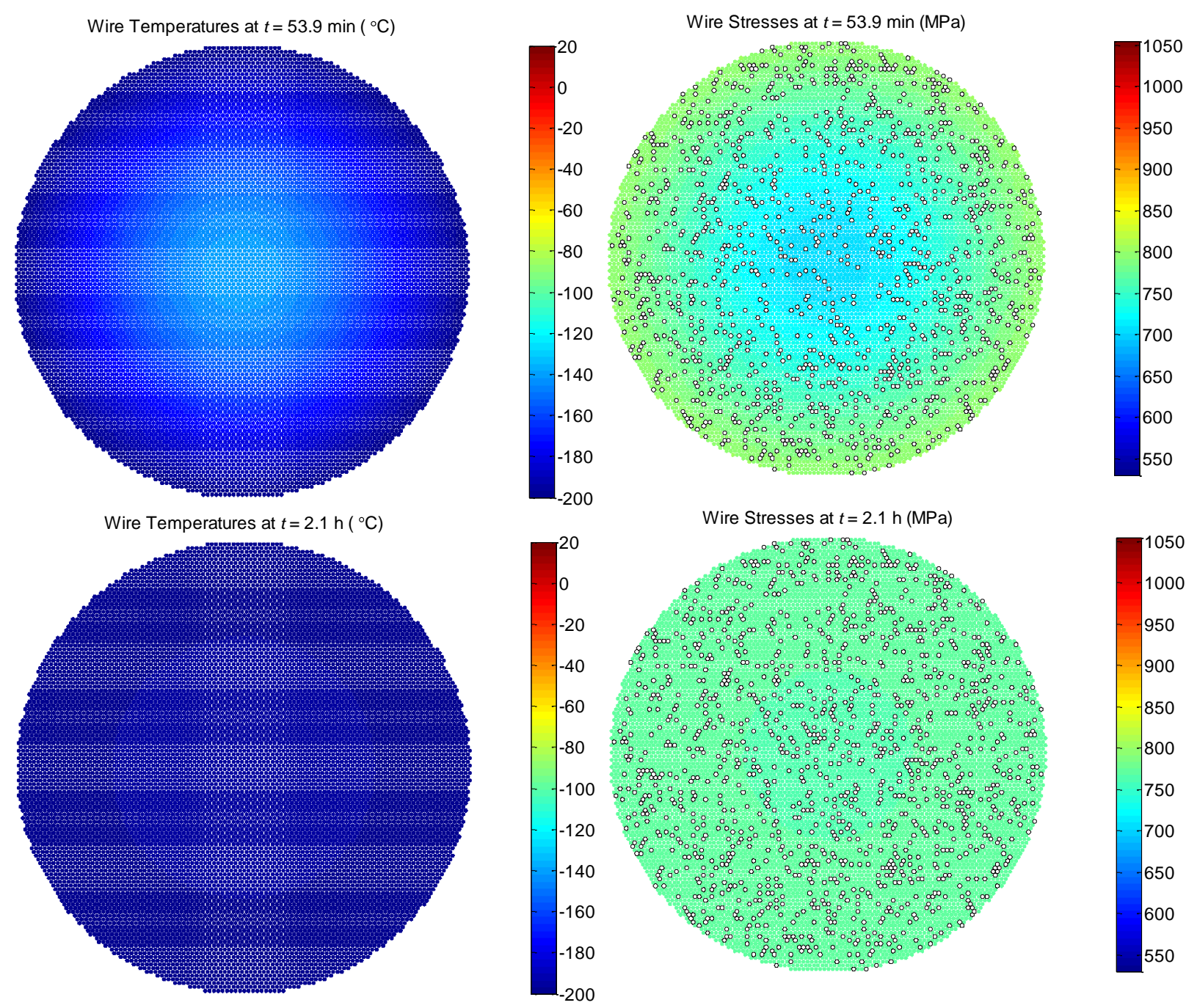

Figure 28: Contours of wire temperatures (left column) and stresses (right column) at subsequent times for uniform axisymmetric cooling. Hollow circles indicate broken wires. 


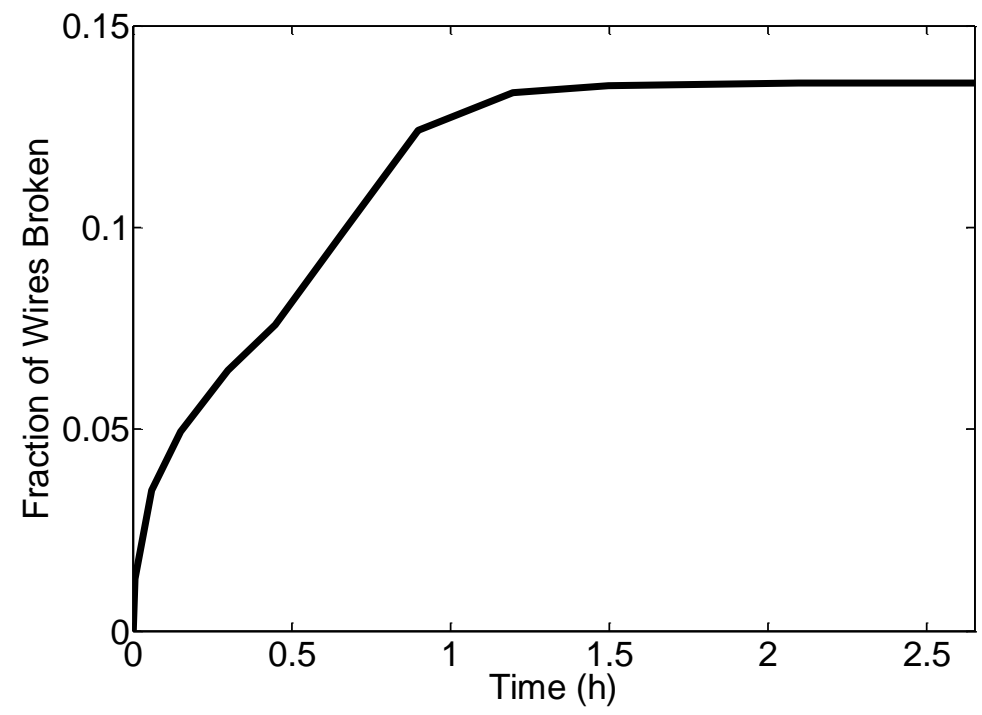

Figure 29: Time evolution of broken wire fraction for uniform axisymmetric cooling.

The results shown in Figure 27, Figure 28, and Figure 29 correspond to a constant axial load in the cable equal to the service load $N_{\text {service }}$. While the service load in the cable remains constant, the ultimate capacity of the cable changes due to thermal effects. The ultimate capacity of the cable can be assessed at each step in the analysis by imposing an increasing extension $\Delta$ until the ultimate load is achieved. Figure 30 shows curves of total cable load versus extension generated at different times in the analysis. In spite of the increasing fraction of broken wires, as shown in Figure 29, Figure 30 shows an increase in the ultimate capacity of the cable as cooling progresses. A reduction in the extension at zero load is also evident, which is a consequence of thermal contraction.

The increase in the ultimate capacity of the cable, as shown in Figure 30, results from increases in the ultimate stress of uncracked wires with decreasing temperature, as shown in Figure 4. An instantaneous safety factor against failure can be calculated by taking the ratio of the current ultimate capacity to the service load in the cable. As shown in Figure 31, this instantaneous safety factor increases with time from its initial value of 2, reaching a value of slightly more than 2.6 at $t=2.7 \mathrm{~h}$. If the cable is allowed to warm back to its initial temperature of $20^{\circ} \mathrm{C}$, its final capacity is found to be virtually equivalent to its capacity at $t=0$, and a safety factor very close to 2 is once again obtained. Exposure to low temperatures is thus found to have very little effect on the ultimate capacity of the cable, even though embrittlement caused essentially all of the cracked wires to fracture. This indicates that the cracked wires contributed very little to the ultimate capacity of the cable, because even at room temperature, the cracked wires would have failed at lower strains than the strain at which the ultimate capacity is obtained. 


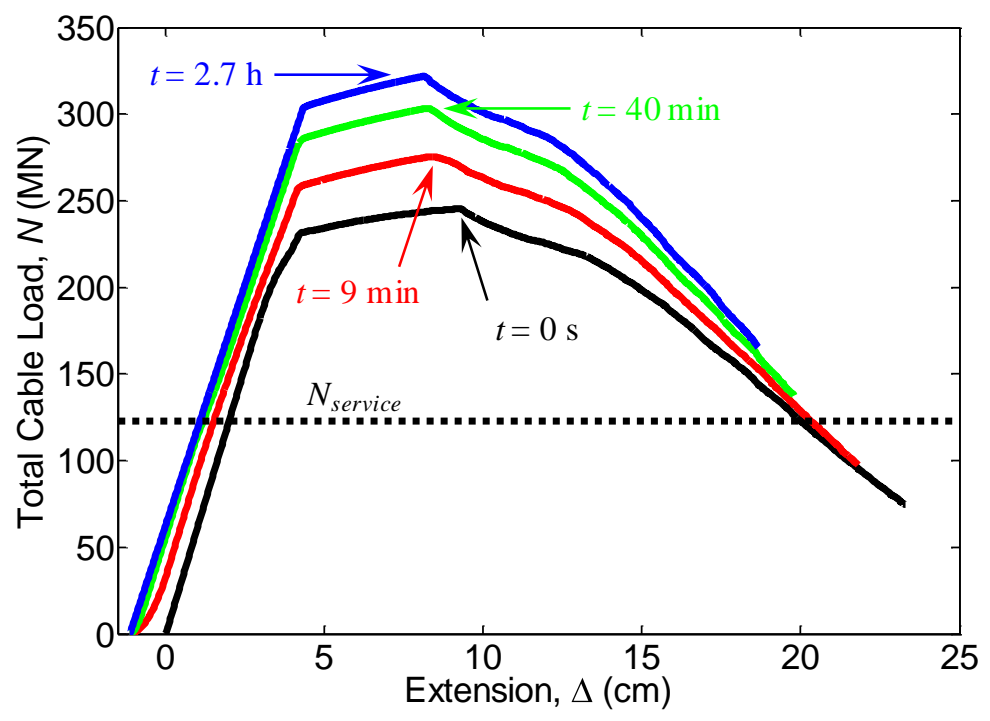

Figure 30: Total cable load versus extension curves for uniform axisymmetric cooling.

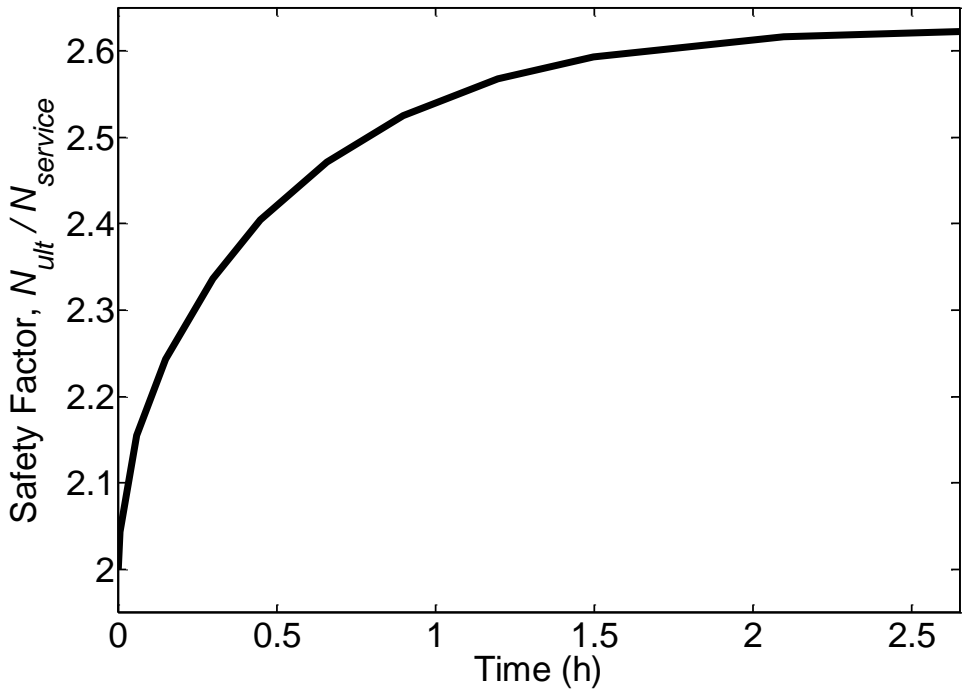

Figure 31: Time evolution of safety factor for uniform axisymmetric cooling. 


\subsection{Uniform Axisymmetric Heating}

To analyze the response of the parallel wire cable under exposure to high surface temperatures, the analytical solution discussed in Section 5.2 is employed, with a wall temperature of $T_{w}=$ $800{ }^{\circ} \mathrm{C}$ on the surface and an initial temperature of $T_{o}=20^{\circ} \mathrm{C}$. A temperature-independent thermal diffusivity of $\alpha=3.551 \times 10^{-6} \mathrm{~m}^{2} / \mathrm{s}$ in the radial direction is used, which corresponds to an average value of the radial thermal diffusivity shown in Figure 20 over the temperature range of interest, between $20^{\circ} \mathrm{C}$ and $800{ }^{\circ} \mathrm{C}$. The resulting time evolution of the radial temperature profile is shown in Figure 32, and Figure 33 shows the mean and center temperatures of the cable plotted against time. The temperature curves in Figure 33 terminate at about $35 \mathrm{~min}$ at which time failure of the cable occurred. The center temperature at the time of failure was $190{ }^{\circ} \mathrm{C}$.

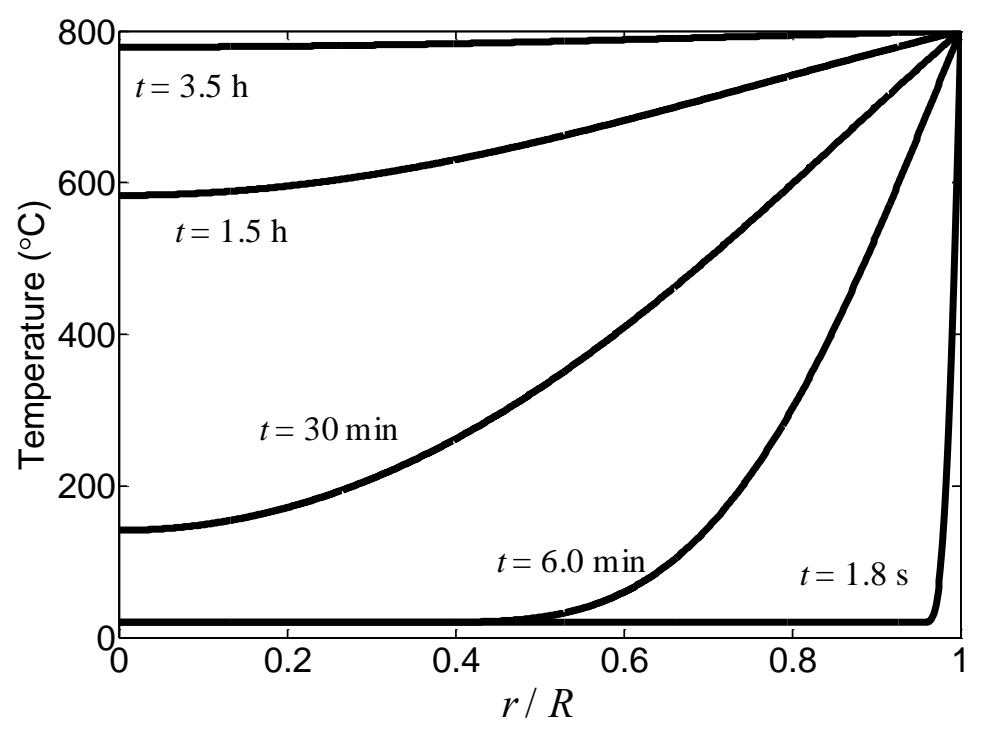

Figure 32: Time evolution of radial temperature profile for uniform axisymmetric heating. 


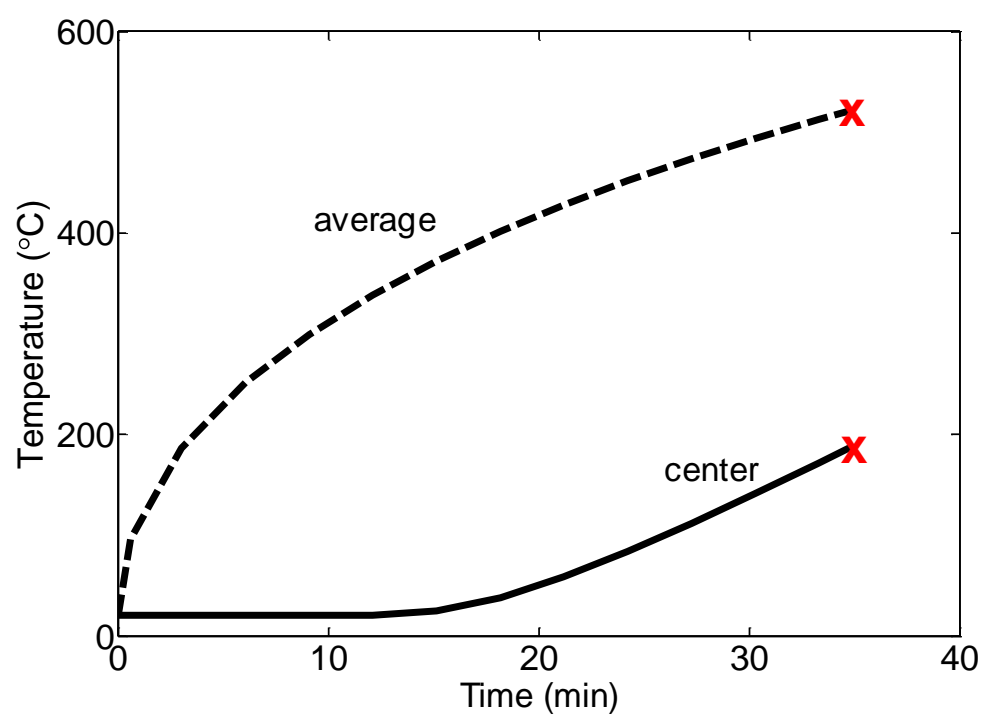

Figure 33: Time evolution of cable temperatures for uniform axisymmetric heating.

The response of the parallel wire cable to high surface temperatures is illustrated in Figure 34 and Figure 35, in which wire temperatures (left column) and wire stresses (right column) are shown at subsequent instants in time. These figures illustrate how heating of the outer wires results in reduced stresses in these wires. The reduced stresses result from thermal expansion, which causes the outer wires to shed load, redistributing load to the cooler inner wires.

Increasing temperatures reduce the ultimate strength of the wires, as shown in Figure 4, and as the inner wires begin to heat, while carrying the increased load redistributed from the outer wires, wire failures begin to occur. Broken wires are indicated with hollow circles in Figure 34 and Figure 35, and an increasing fraction of broken wires is evident in these figures at subsequent times. Figure 36 shows the fraction of wires broken as a function of time, which increases fairly rapidly to about 0.034 over the first $10 \mathrm{~min}$ of heating and then stays relatively constant for the next $25 \mathrm{~min}$, until failure occurs. 

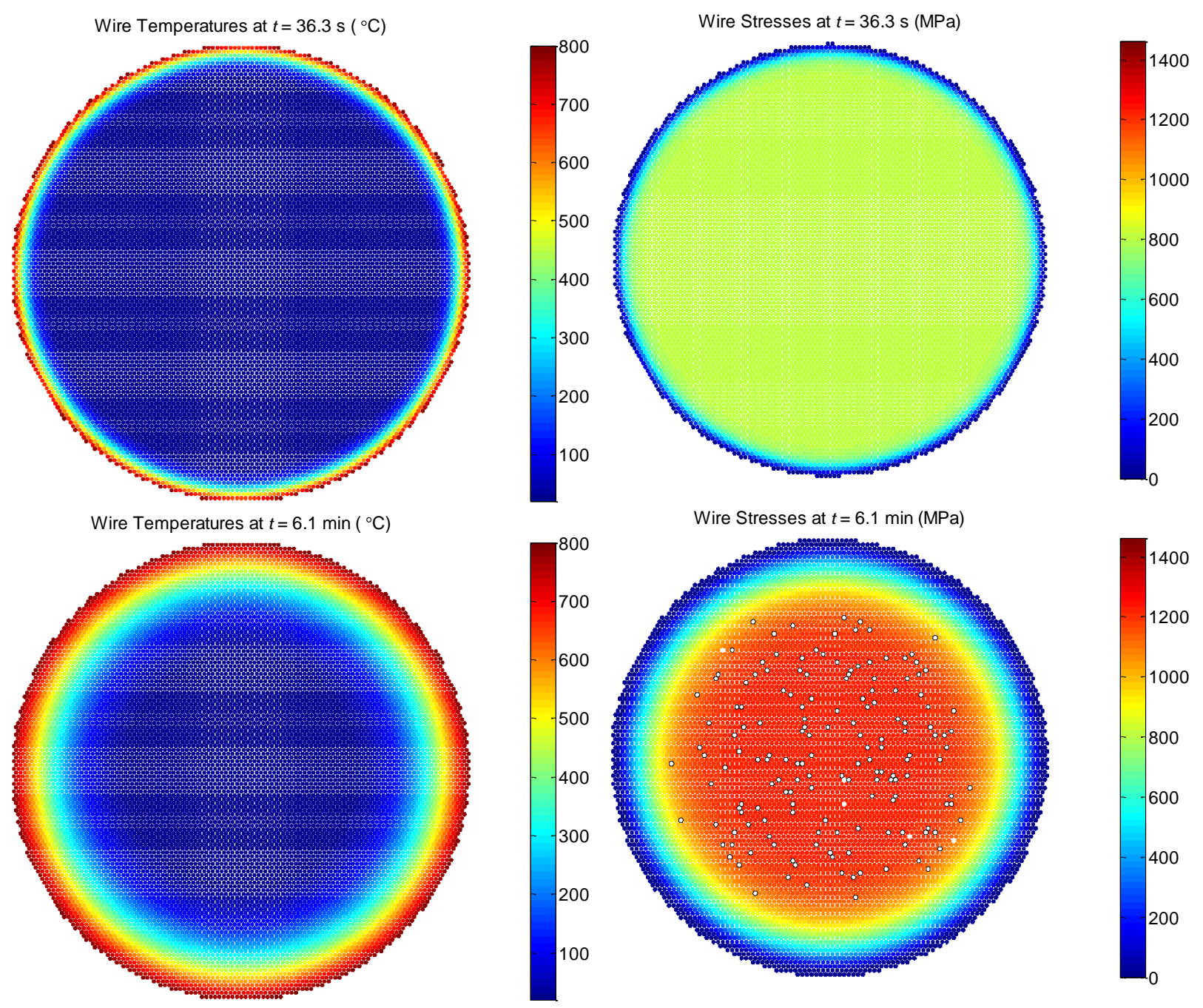

Figure 34: Contours of wire temperatures (left column) and stresses (right column) at subsequent times for uniform axisymmetric heating. Hollow circles indicate broken wires. 

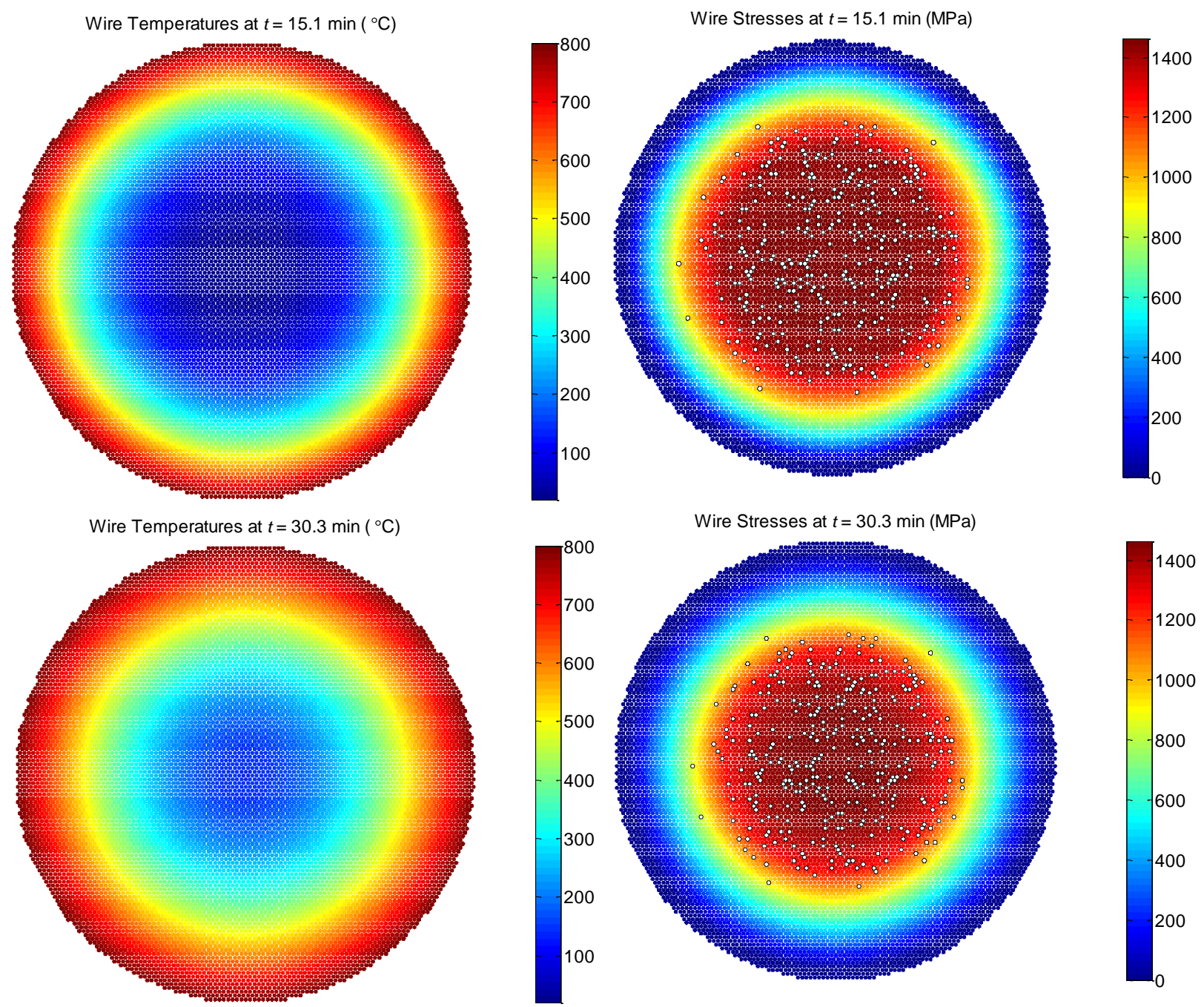

Figure 35: Contours of wire temperatures (left column) and stresses (right column) at subsequent times for uniform axisymmetric heating. Hollow circles indicate broken wires. 


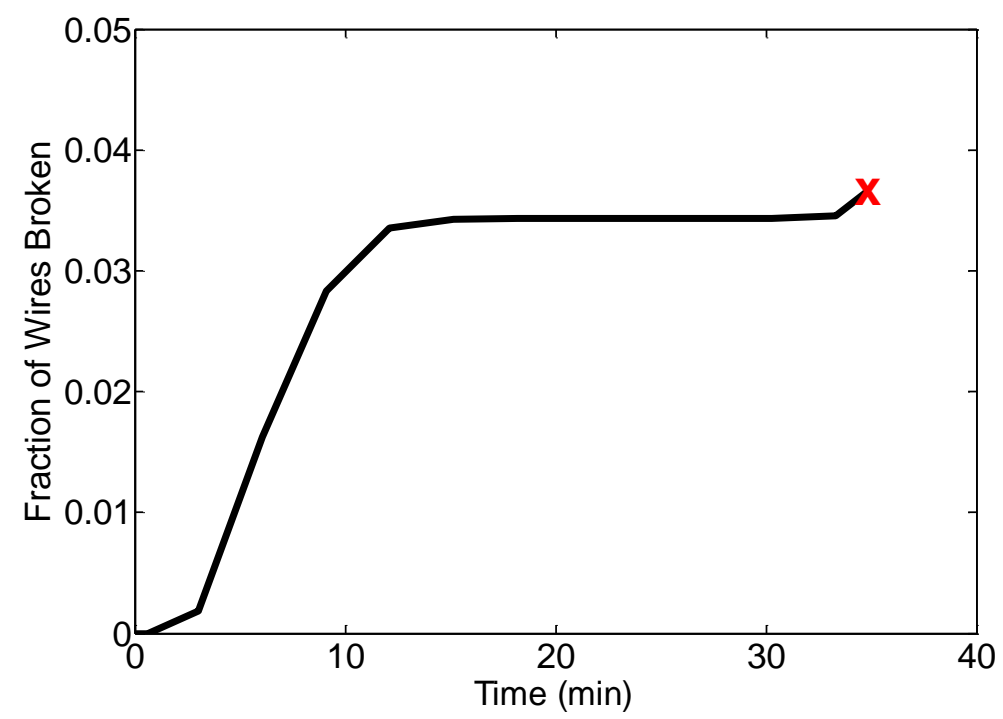

Figure 36: Time evolution of broken wire fraction for uniform axisymmetric heating.

The results shown in Figure 34, Figure 35, and Figure 36 correspond to a constant axial load in the cable equal to the service load $N_{\text {service }}$. While the service load in the cable remains constant, the ultimate capacity of the cable changes due to thermal effects. The ultimate capacity of the cable can be assessed at each step in the analysis by imposing an increasing extension $\Delta$ until the ultimate load is achieved. Figure 37 shows curves of total cable load versus extension generated at different times in the analysis, which reveal a reduction in the ultimate capacity of the cable as heating progresses. An increase in the extension at zero load is also evident, which is a consequence of thermal expansion.

An instantaneous safety factor against failure can be calculated by taking the ratio of the current ultimate capacity to the service load in the cable. As shown in Figure 38, this instantaneous safety factor decreases with time from its initial value of 2, reaching a value of unity at about $35 \mathrm{~min}$, at which point failure occurs. Exposure to high temperatures is thus found to have a significant effect on the ultimate capacity of the cable, potentially leading to failure in a fairly short period of time. 


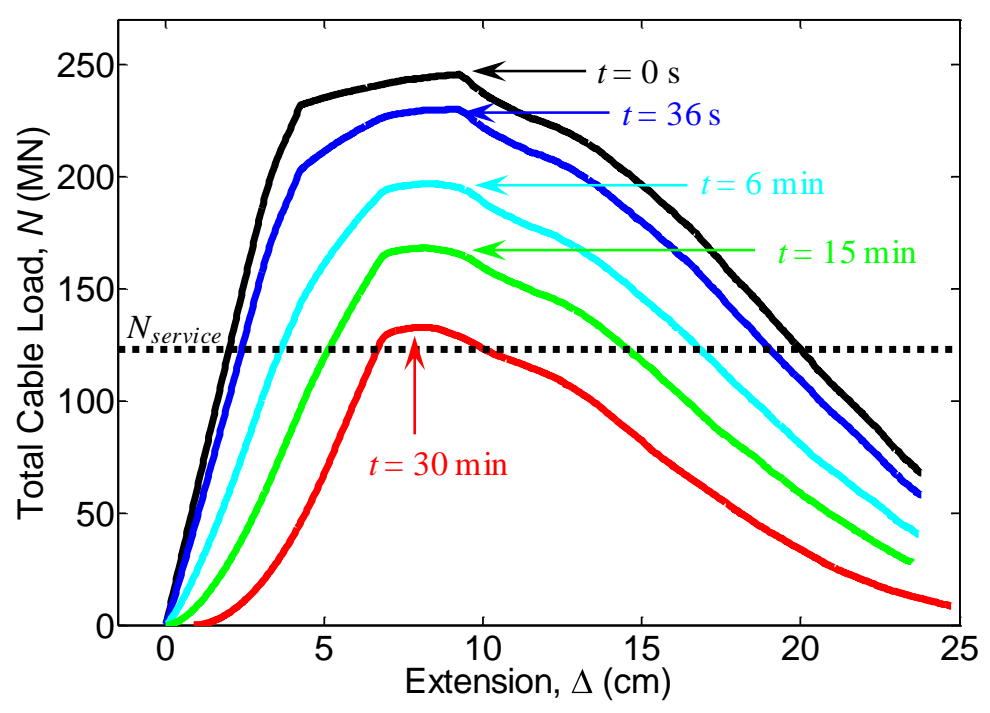

Figure 37: Total cable load versus extension curves for uniform axisymmetric heating.

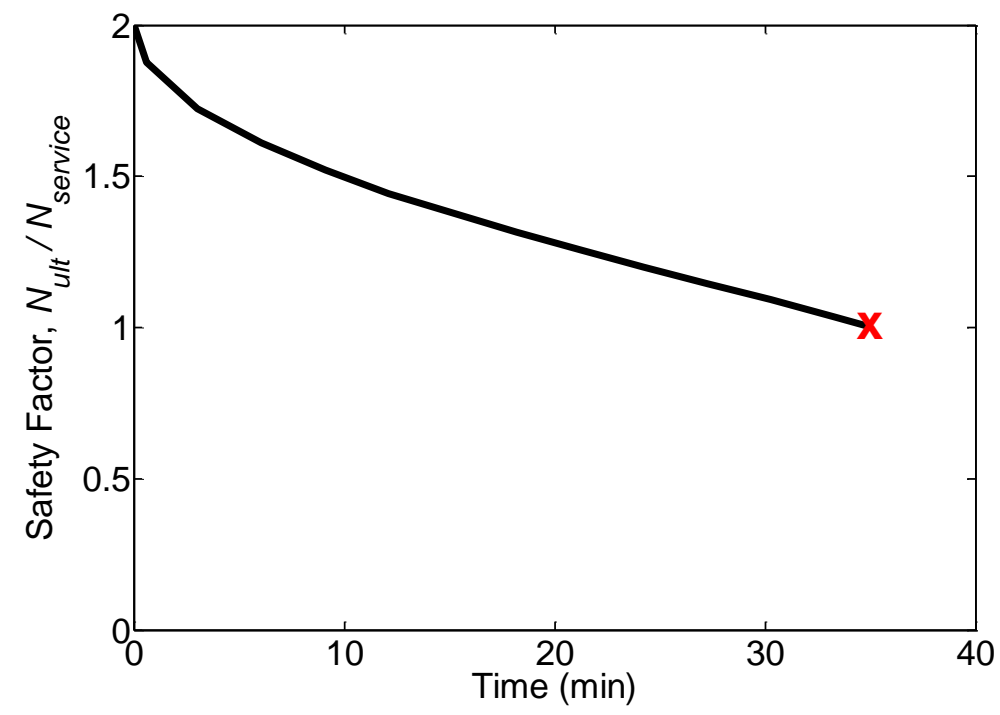

Figure 38: Time evolution of safety factor for uniform axisymmetric heating.

\subsection{Local Axisymmetric Heating}

While Section 6.2 considered uniform surface temperatures of $800{ }^{\circ} \mathrm{C}$ applied over the entire

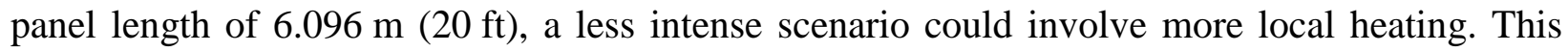
section considers a local axisymmetric heating scenario, in which a constant temperature of $800{ }^{\circ} \mathrm{C}$ is applied to the outer surface of the exterior paint layer over a length of $1 \mathrm{~m}$ at midlength of the panel. Temperatures in the parallel wire bundle obtained from the finite element thermal analysis are shown in Figure 39. Note that because of temperature gradients in the exte- 
rior paint and wire wrap layers, the temperatures shown on the outer surface of the wire bundle remain less than the $800{ }^{\circ} \mathrm{C}$ temperature imposed on the outer surface of the paint layer. The temperature contours in Figure 39 correspond to $t=1.2 \mathrm{~h}$, at which instant the ultimate capacity of the cable drops below the service load in the cable and failure occurs.

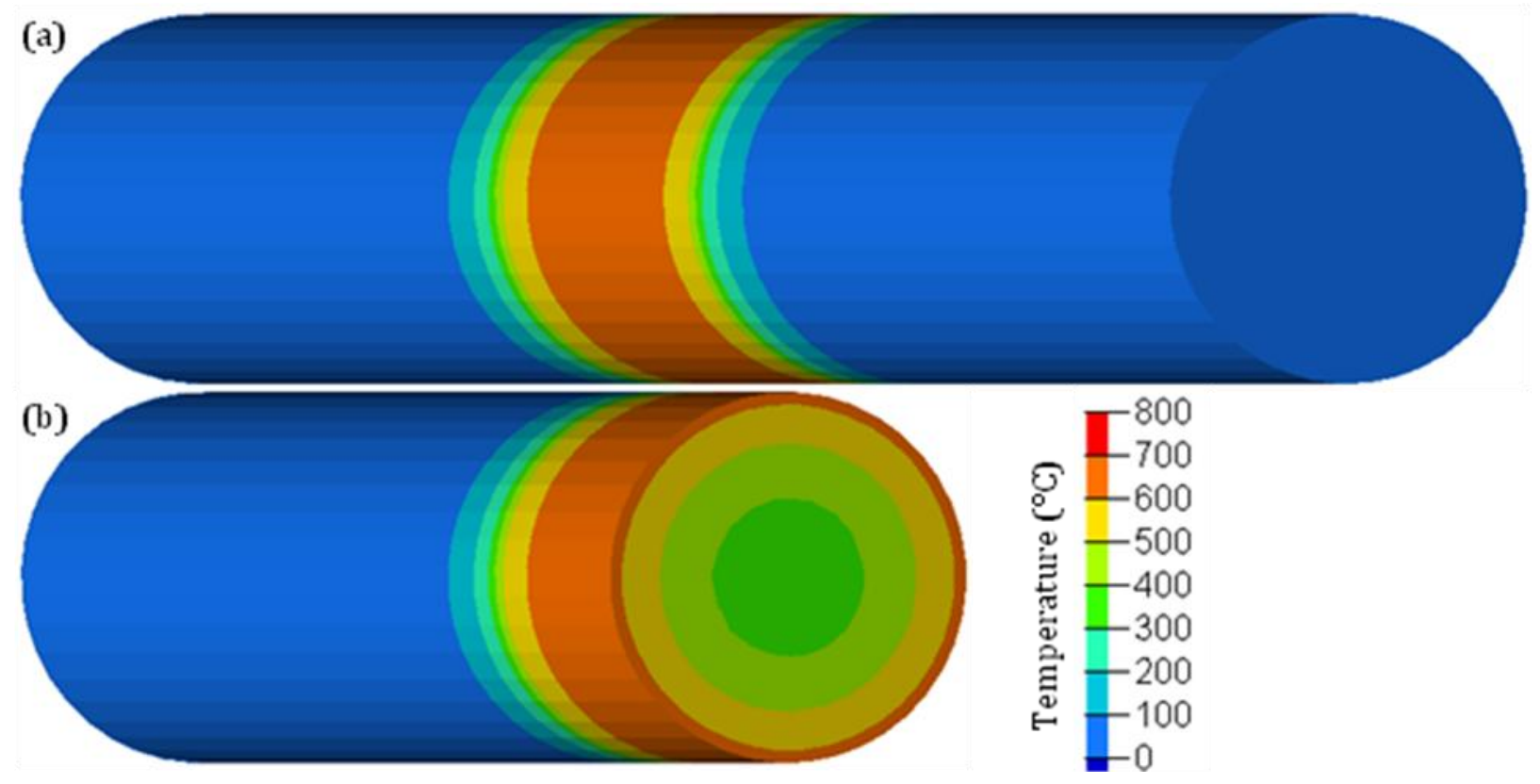

Figure 39: Contours of wire bundle temperatures from finite element model at $t=1.2 \mathrm{~h}$ : (a) entire panel length; (b) with section cut to show internal temperatures.

The response of the parallel wire cable to high local surface temperatures is illustrated in Figure 40 and Figure 41, in which wire temperatures (left column) and wire stresses (right column) at mid-length of the parallel wire bundle are shown at subsequent instants in time. These figures illustrate how heating of the outer wires leads to reduced stresses in these wires. The reduced stresses result from thermal expansion, which causes the outer wires to shed load, redistributing load to the cooler inner wires. However, in contrast with the case of uniform heating (see Figure 34 and Figure 35), the thermal expansion over a more local region is not sufficient to completely unload the outer wires. Rather, the outer wires continue to carry a reduced load, and it is the outer wires that begin to fail first, as increasing temperatures reduce the ultimate strengths of the outer wires. 
Mid-Length Wire Temperatures at $t=6 \min \left({ }^{\circ} \mathrm{C}\right)$

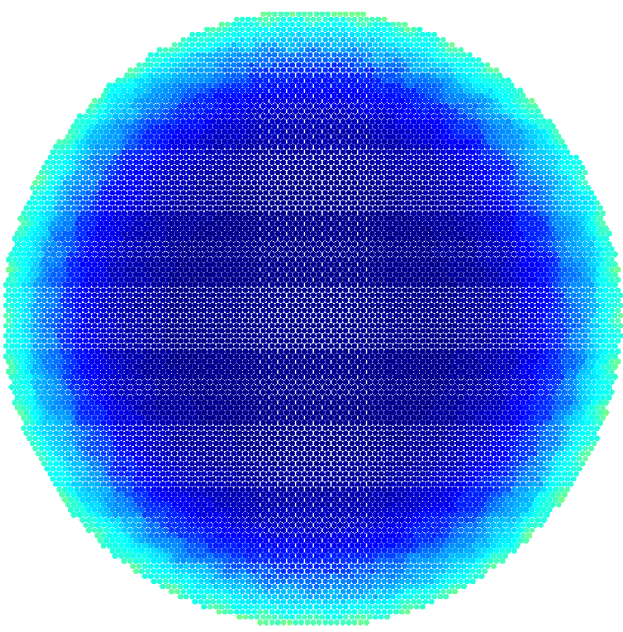

Mid-Length Wire Temperatures at $t=30 \min \left({ }^{\circ} \mathrm{C}\right)$

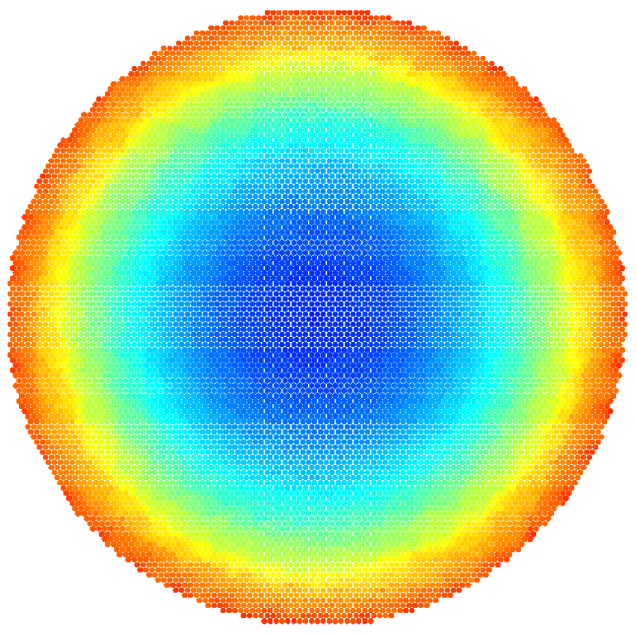

Wire Stresses at $t=6 \mathrm{~min}(\mathrm{MPa})$
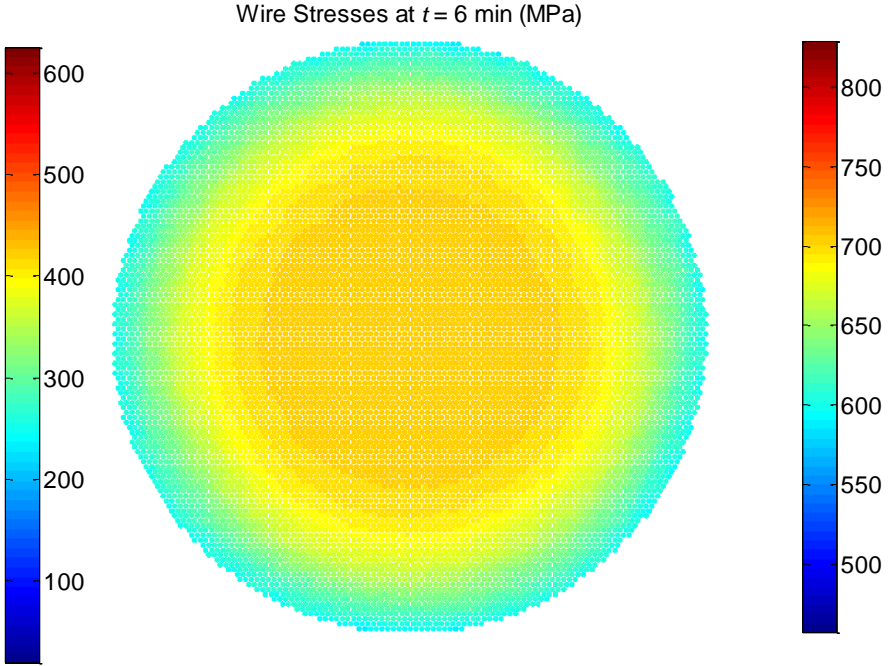

Wire Stresses at $t=30 \mathrm{~min}(\mathrm{MPa})$

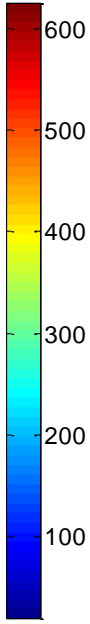

750

00

50

00

50

0

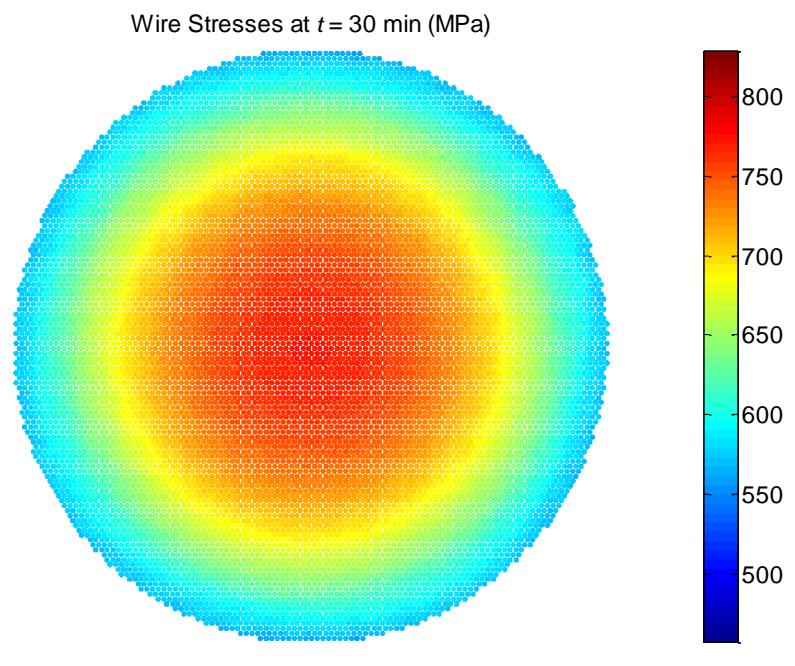

Figure 40: Contours of wire temperatures (left column) and stresses (right column) at subsequent times for local axisymmetric heating. 

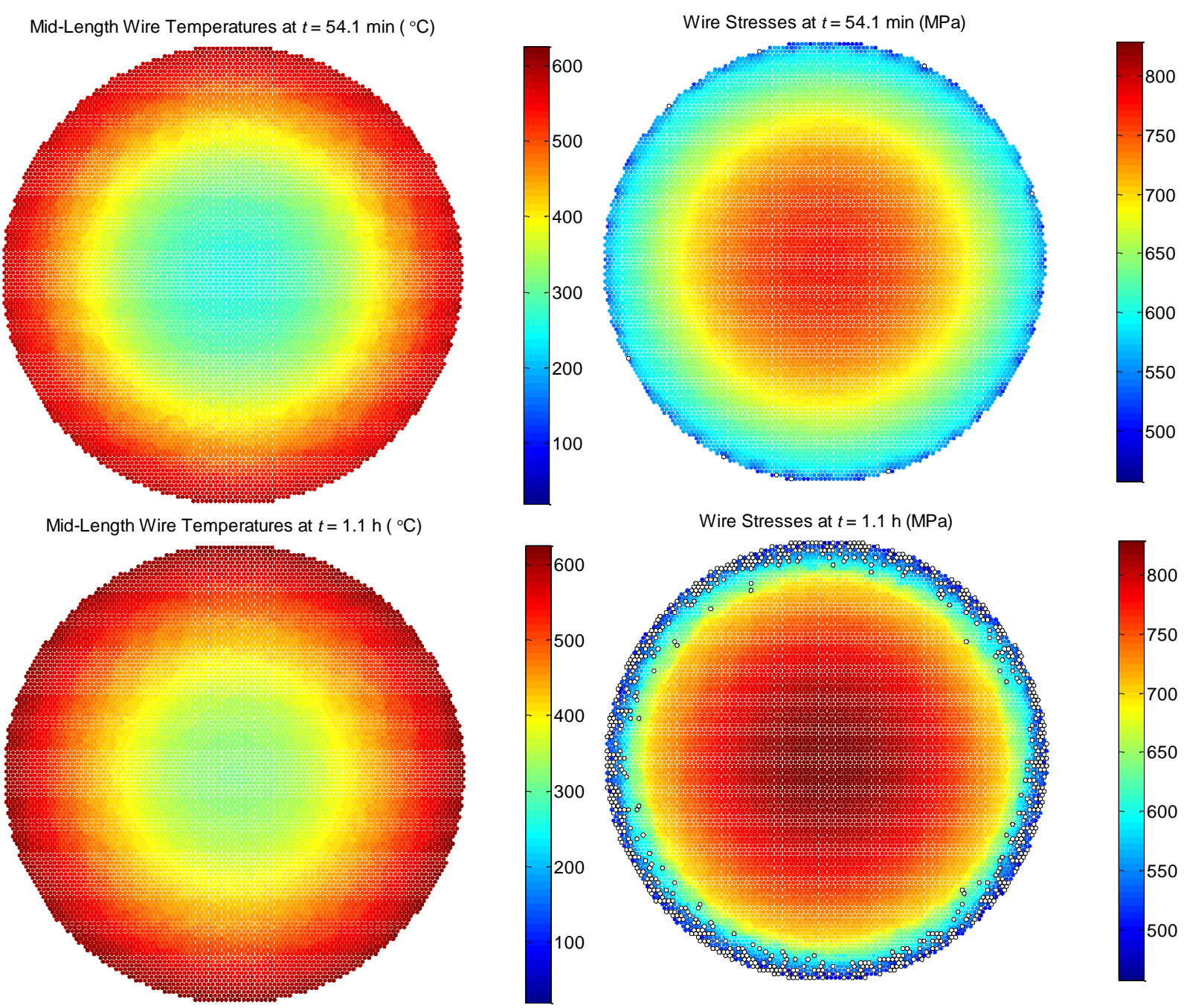

Figure 41: Contours of wire temperatures (left column) and stresses (right column) at subsequent times for local axisymmetric heating. Hollow circles indicate broken wires.

The results shown in Figure 40 and Figure 41 correspond to a constant axial load in the cable equal to the service load $N_{\text {service }}$. While the service load in the cable remains constant, the ultimate capacity of the cable changes due to thermal effects. The ultimate capacity of the cable can be assessed at each step in the analysis by imposing an increasing extension $\Delta$ until the ultimate load is achieved. Figure 42 shows curves of total cable load versus extension generated at different times in the analysis, which reveal a reduction in the ultimate capacity of the cable as heating progresses. A slight increase in the extension at zero load is also evident, which is a consequence of the local thermal expansion. Comparing the failure time for local axisymmetric heating (1.2 $\mathrm{h}$ ) with that for uniform axisymmetric heating (35 min), it is observed that failure takes approximately twice as long to occur under the more local heating scenario. Insulating effects of the paint and wire wrap layers also contribute to this increased time to failure. 


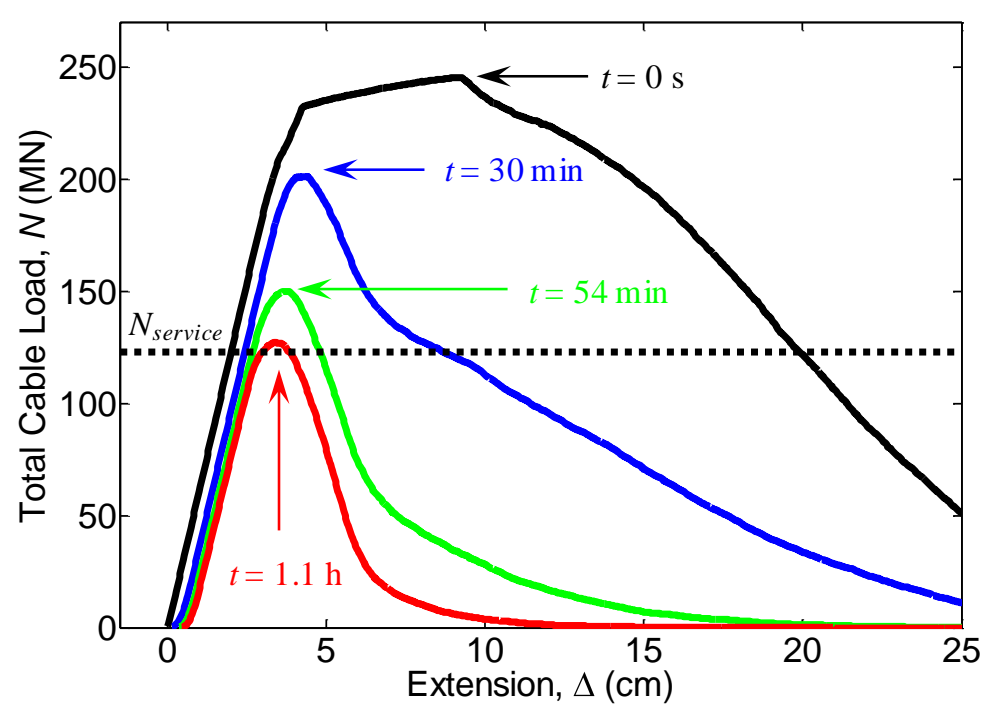

Figure 42: Total cable load versus extension curves for local axisymmetric heating.

\subsection{Local Asymmetric Heating}

While Section 6.3 considered axisymmetric surface temperatures of $800{ }^{\circ} \mathrm{C}$ applied around the entire circumference of the cable over a length of $1 \mathrm{~m}$, an even less severe scenario could involve heating applied primarily to one side of the cable. This section considers a local asymmetric heating scenario, in which a constant temperature of $800{ }^{\circ} \mathrm{C}$ is applied to the outer surface of the exterior paint layer on one side, over a length of $1 \mathrm{~m}$ at mid-length of the panel. Temperatures in the parallel wire bundle obtained from the finite element thermal analysis are shown in Figure 43. The temperature contours in Figure 43 correspond to $t=3.4 \mathrm{~h}$, at which instant the ultimate capacity of the cable drops below the service load in the cable and failure occurs. 


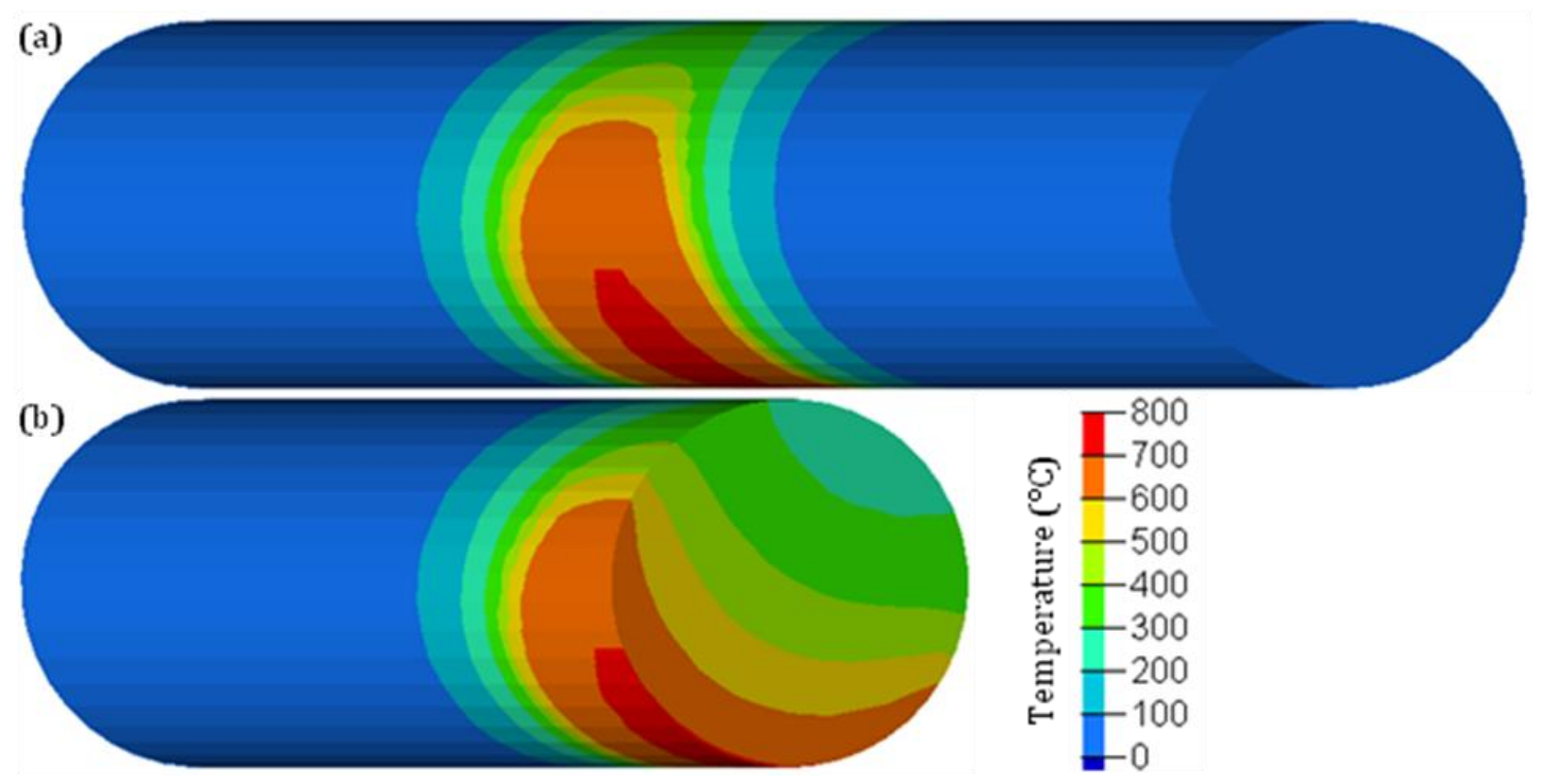

Figure 43: Contours of wire bundle temperatures from finite element model at $t=3.4 \mathrm{~h}$ : (a) entire panel; (b) with section cut to show internal temperatures.

The response of the parallel wire cable to local, asymmetric surface heating is illustrated in Figure 44 and Figure 45, in which wire temperatures (left column) and wire stresses (right column) at mid-length of the parallel wire bundle are shown at subsequent instants in time. These figures illustrate how heating of the wires on one side of the cable leads to reduced stresses in these wires. The reduced stresses result from thermal expansion, which causes the outer wires on one side of the cable to shed load, redistributing load to the cooler wires on the other side of the cable. However, as observed in Figure 40 and Figure 41 for the case of local axisymmetric heating, the local thermal expansion is not sufficient to completely unload the outer wires. Rather, the hottest wires continue to carry a reduced load, and it is the hottest wires that begin to fail first, as increasing temperatures reduce their ultimate strengths. 

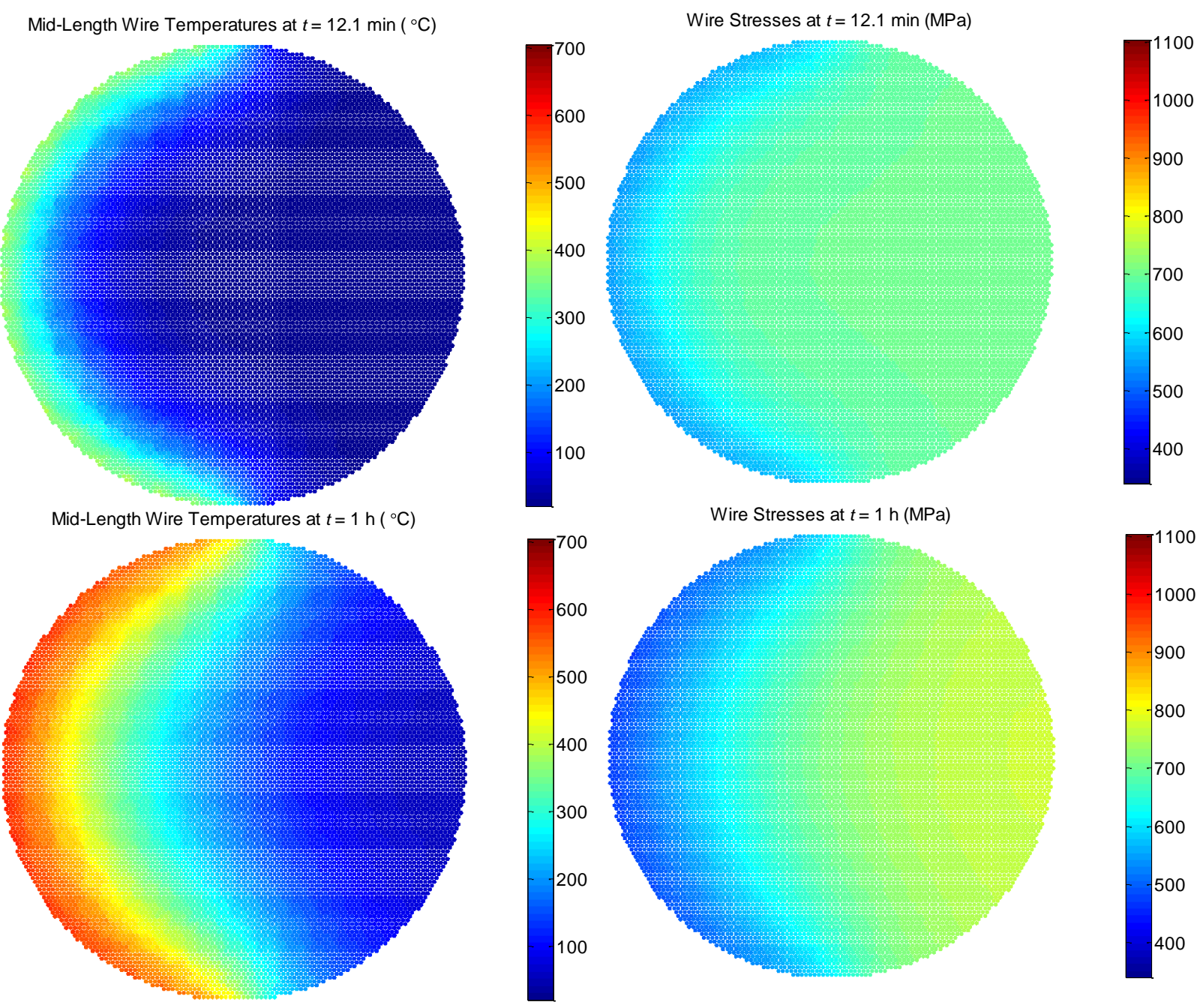

Figure 44: Contours of wire temperatures (left column) and stresses (right column) at subsequent times for local asymmetric heating. 

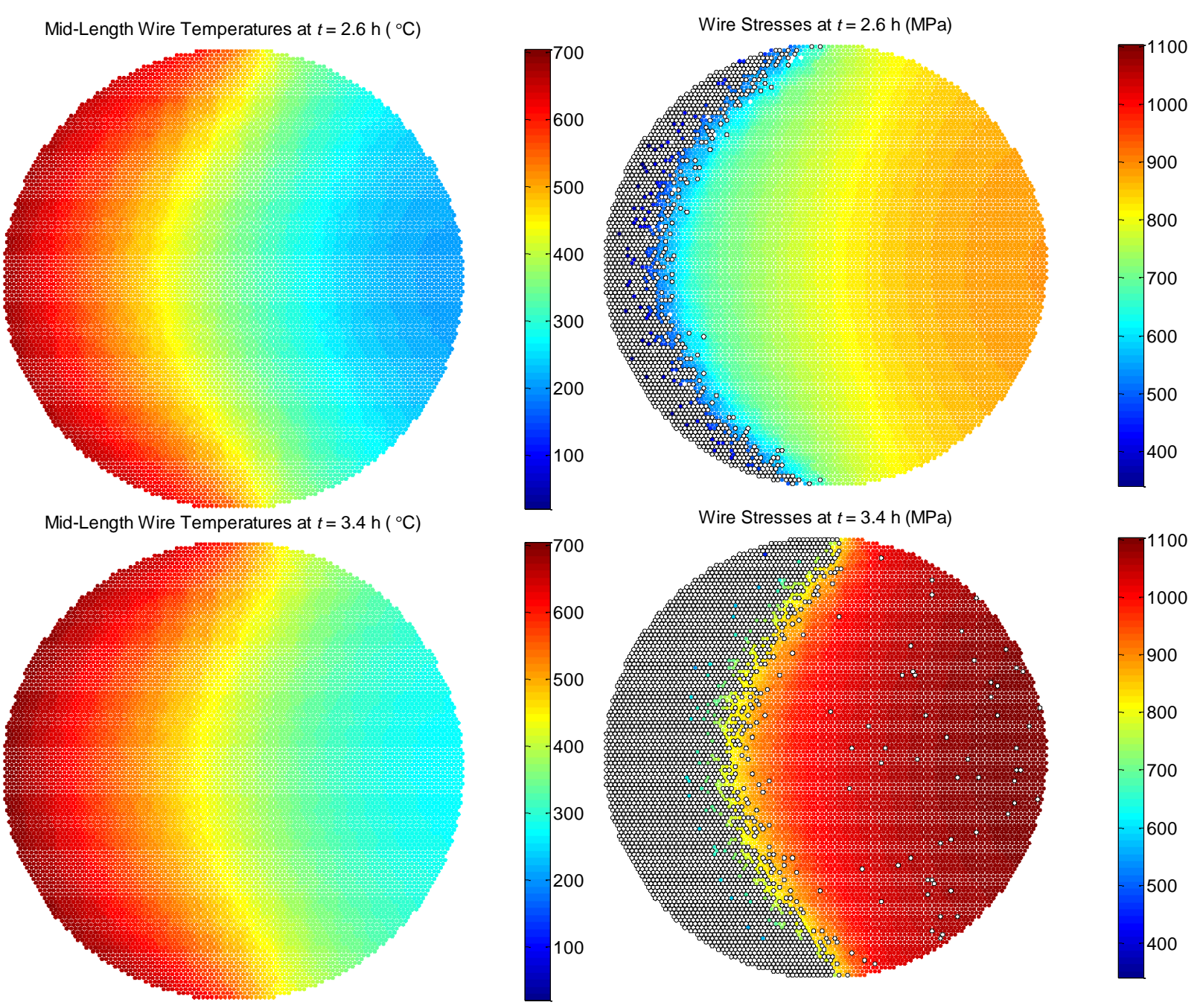

Figure 45: Contours of wire temperatures (left column) and stresses (right column) at subsequent times for local asymmetric heating. Hollow circles indicated broken wires.

The results shown in Figure 44 and Figure 45 correspond to a constant axial load in the cable equal to the service load $N_{\text {service }}$. While the service load in the cable remains constant, the ultimate capacity of the cable changes due to thermal effects. The ultimate capacity of the cable can be assessed at each step in the analysis by imposing an increasing extension $\Delta$ until the ultimate load is achieved. Figure 46 shows curves of total cable load versus extension generated at different times in the analysis, which reveal a reduction in the ultimate capacity of the cable as heating progresses. A slight increase in the extension at zero load is also evident, which is a consequence of the local thermal expansion. Comparing the failure time for local asymmetric heating $(3.4 \mathrm{~h})$ with that for local axisymmetric heating $(1.2 \mathrm{~h})$, it is observed that failure takes almost three times as long to occur under the asymmetric heating scenario. 


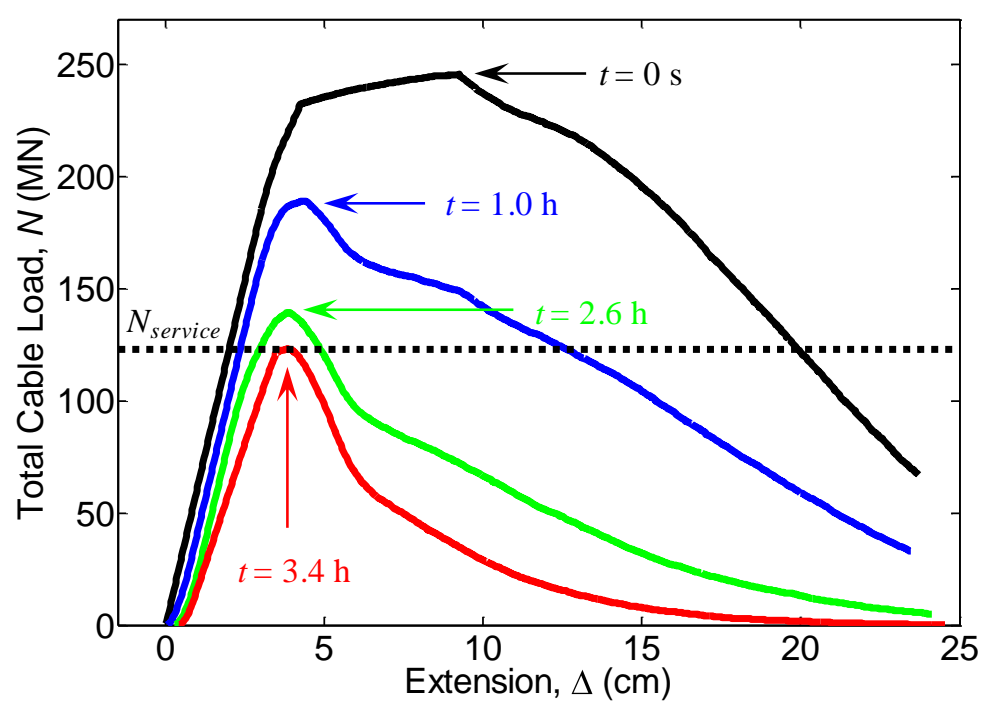

Figure 46: Total cable load versus extension curves for local asymmetric heating.

\section{$7 \quad$ Applicability of Results}

While the modeling approach described in Sections 2 through 5 could be used to analyze suspension bridge cables with a variety of different characteristics, the results presented in Section 6 correspond to a representative cable with the following specific characteristics:

- Cable diameter: $D=508 \mathrm{~mm}$

- Panel length between cable bands: $6.096 \mathrm{~m}$

- Fraction of wires with cracks: $13.6 \%$

- Resulting ultimate strength as a fraction of its initial value: $75.0 \%$

- Current safety factor: 2.0

- Uniform distribution of broken wires

- Standard exterior coating (wire wrap, corrosion inhibiting paste, exterior paint)

Based on the definition of the Fourier number (see Figure 21), it is noted that the time required for heat conduction to progress is approximately proportional to the square of the cable diameter. Therefore, larger diameter cables could require substantially longer to heat or cool, while smaller diameter cables could heat or cool much more quickly. While a maximum surface temperature of $800{ }^{\circ} \mathrm{C}$ was considered in the heating scenarios, higher temperatures are certainly conceivable in combustion scenarios. Higher temperatures would result in more rapid heating as indicated by the nondimensional curves in Figure 21.

Comparison with Table 1 shows that some bridge cables have ultimate strengths as little as $68 \%$ of their original strengths, which would correspond to a somewhat larger fraction of cracked 
wires than considered here. However, with a safety factor of 2.0, which corresponds to the lowest value reported in Table 1, the fraction of cracked wires would need to reach about $50 \%$ in order for failure of the cable to occur after exposure to low temperatures. Published wire strength data does not suggest such severe levels of degradation in suspension bridge cables. In some bridge cables, cracked wires may be concentrated near the outer surface of the cable, rather than uniformly distributed through the cross section, as assumed here. In such cases, the cracked wires would break more quickly upon exposure to low temperatures. However, the fraction of cracked wires would still need to reach about $50 \%$ for failure of the cable to occur.

It is noted that the factor of safety against failure actually varies along the bridge span, due to the

variation of the service load in the cable $N_{\text {service }}$ with position. While its horizontal component is constant, the axial force in the cable increases with increasing slope, being smallest at midspan and largest at the tower tops or in the back stays. The factor of safety against failure thus varies along the span as well, being largest at midspan and smallest at the tower tops or in the back stays. The factors of safety considered here and in Table 1 correspond to the smallest value over the span length. Higher factors of safety would be appropriate for some exposure locations, such as midspan, which would increase the time required to fail the cable under a high-temperature exposure scenario.

While a standard exterior coating was considered here, consisting of wire wrap, corrosion inhibiting paste, and exterior paint, provision of additional insulating layers would slow the heating or cooling of the cable. Cable protection systems have been installed on the main cables of several major suspension bridges, and the thermal performance of such systems could be evaluated using the approach outlined herein.

\section{Conclusions}

A modeling approach to analyze the response of a parallel wire suspension cable to prescribed surface temperatures has been developed. Analysis results showed that embrittlement due to low temperature exposure does not significantly reduce the ultimate capacity of a suspension bridge cable. Although embrittlement at low temperatures can cause the wires with initial cracks to fracture, these cracked wires are brittle even at room temperature, and it is primarily the ductile, uncracked wires that determine the ultimate capacity of the cable.

It was found that exposure to high temperatures, on the other hand, could result in failure of the cable, due to thermal softening of the steel wires and thermal expansion, which caused heated wires to shed load. In the case of a uniform surface temperature of $800{ }^{\circ} \mathrm{C}$ applied over the entire $6 \mathrm{~m}$ length of the cable segment, the exposure time required to produce failure was $35 \mathrm{~min}$. When surface temperatures of $800{ }^{\circ} \mathrm{C}$ were applied only over a $1 \mathrm{~m}$ segment centered at midlength, the exposure time required to produce failure increased to $1.2 \mathrm{~h}$. When surface tempera- 
tures of $800{ }^{\circ} \mathrm{C}$ were applied to only one side of the cable over a length of $1 \mathrm{~m}$, the exposure time required to produce failure increased further to $3.4 \mathrm{~h}$. It was thus observed that reducing the surface area exposed to high temperatures increases the exposure time required to produce failure.

\section{References}

Anitomonov, M.S., Kudinow, V.A., Stefanyuk, E.V. (2008). "Analytical solutions to the heat conduction problems for a cylinder and a ball based on determining the temperature perturbation front." Computational Mathematics and Mathematical Physics, 48(4), 648-658.

Bennet, J.A., Mindlin, H. (1973). "Metallurgical Aspects of the Failure of the Point Pleasant Bridge." Journal of Testing and Evaluation, 1(2), 152-161.

Camo, S. (2003). "Probabilistic strength estimates and reliability of damaged parallel wire cables." Journal of Bridge Engineering, 8(5), 297-311.

Gimseng, N.J. (1983). Cable Supported Bridges: Concept and Design, John Wiley \& Sons, New York.

Haight, R.Q., Billington, D.P., Khazem, D. (1997). "Cable safety factors for four suspension bridges." Journal of Bridge Engineering, 2(4), 157-167.

Luecke, W.E., McColskey, J.D., McCowan, C.N., Banovic, S.W., Fields, R.J., Foecke, T., Siewert, T.A., Gayle, F.W. (2005). Federal Building and Fire Safety Investigation of the World Trade Center Disaster: Mechanical Properties of Structural Steel, NCSTAR 1-3D, National Institute of Standards and Technology. <wtc.nist.gov/NCSTAR1/PDF/NCSTAR\%2013D\%20Mechanical\%20Properties.pdf >

Mahmoud, K.M. (2007). "Fracture strength for a high strength steel bridge cable wire with a surface crack." Theoretical and Applied Fracture Mechanics, 48, 152-160.

Mayrbaurl, R.M., Camo, S. (2004). Guidelines for Inspection and Strength Evaluation of Suspension Bridge Parallel Wire Cables, NCHRP (National Cooperative Highway Research Program) Report 534, Transportation Research Board, Washington, DC. <http://onlinepubs.trb.org/onlinepubs/nchrp/nchrp_rpt_534.pdf>

National Transportation Safety Board (1971). Collapse of U.S. 35 Highway Bridge, Point Pleasant, West Virginia, December 15, 1967. NTSB Report Number HAR-71-01.

Perrins, W.T., McKenzie, D.R., McPhedran, R.C. (1979). “Transport properties of regular arrays of cylinders." Proc., Royal Soc. Lond. A, 369, 207-225. 
Sargent, J.P., Almond, D.P., Gathercole, N. (2006). "Thermal wave measurement of wet paint film thickness." J. Mater. Sci., 41, 333-339. <www.springerlink.com/content/f830682319823879/fulltext.pdf>

Shi, Y., Deodatis, G., Betti, R. (2007). "Random field-based approach for strength evaluation of suspension bridge cables." Journal of Structural Engineering, 133(12), 1690-1699.

Stahl, F.L., Gagnon, C.P. (1996). Cable Corrosion in Bridges and Other Structures, ASCE Press, New York. 


\title{
Part 2.
}

\section{Data summary, analysis and recommended values: Mechanical properties of suspension bridge cable wire}

\author{
William E. Luecke \\ Metallurgy Division, Materials Science and Engineering Laboratory \\ National Institute of Standards and Technology, \\ 100 Bureau Drive Stop 8553, Gaithersburg, Md 20899 USA
}

\section{Executive Summary}

This document recommends the values for important thermal and mechanical properties necessary to model failure of suspension bridge wire. It documents the computations and sources for each recommendation. This executive summary is a quick reference to the equations that describe the recommendations.

- Recommended value for specific heat: Eq.27

- Recommended value for thermal conductivity: Eq. 31]

- Recommended value for thermal expansion coefficient: Eq. (32]

- Recommended value for elastic modulus: Eq.554

- Recommended values for stress-strain behavior below room temperature: Eq. 40 and Eq. 41

- Recommended values for stress-strain behavior above room temperature: Eq. 55 and Eq. 56 .

- Recommended value for toughness below room temperature: Eq. 62 (62)

\section{Introduction}

This report comprises two parts. The first part recommends values for three thermal properties: specific heat, $C_{p}$, thermal conductivity, $k$, and thermal expansion coefficient, $\alpha$, evaluated completely from published sources. The second part recommends values for mechanical properties such as stress-strain behavior, ductility, and fracture toughness. Recommended values for stressstrain behavior below room temperature were developed from mechanical property tests. Recommended values for stress-strain behavior above room temperature, for conditions relevant to fire, were developed from published sources. 


\section{Thermal Properties}

The thermal properties of the bridge wire, including heat capacity, thermal conductivity, and thermal expansion coefficient were estimated from published data.

\subsection{Heat Capacity}

The specific heat at constant pressure is defined as

$$
C_{p}=\left(\frac{d q}{d T}\right)_{p}
$$

where $q$ is the heat added per unit mass. To a first approximation, the molar specific heat of elements and mixtures at room temperature and above is a constant approximately $3 R=24.94 \mathrm{~J} /(\mathrm{mol} \cdot \mathrm{K})$, which is the so-called law of Dulong and Petit. At the $\alpha-\gamma$ phase transformation (above about $720{ }^{\circ} \mathrm{C}$ in carbon steels) the heat capacity is effectively infinity, since all added energy goes into transforming the phase rather than raising the temperature.

Even though the wire for the cable strands has the eutectoid composition $(0.77 \%$ mass fraction C) the heat capacity is still quite similar to that of pure iron. Figure 47 compares some values taken from Touloukian[1] p.p. 102ff, Specification Tables 26, 173, and 128, for pure iron, steel with composition similar to the bridge wire, and cementite $\left(\mathrm{Fe}_{3} \mathrm{C}\right)$ and Umemoto[ [2, 3] for cementite. No data exist for steel for temperatures below room temperature, unfortunately. Note that the curves for steel, which is a mixture of $\mathrm{Fe}$ and $\mathrm{Fe}_{3} \mathrm{C}$ lie above the curve for pure $\mathrm{Fe}$ until the heat capacity for $\mathrm{Fe}_{3} \mathrm{C}$ decreases as it passes through its Curie temperature. If necessary, a rule of mixtures approach could be used to estimate the specific heat of the bridge wire by treating it as a two-phase mixture of $\mathrm{Fe}$ and $\mathrm{Fe}_{3} \mathrm{C}$.

\subsubsection{Recommended Value}

Given the other uncertainties in the calculation, using the heat capacity of pure Fe will not change the results significantly. The recommended values are shown in Figure 48 . A fourth-order polynomial represents the data well in the range $(-183<T<720)^{\circ} \mathrm{C}$.

$$
C_{p}(T)=c_{0}+c_{1} T+c_{2} T^{2}+c_{3} T^{3}+c_{4} T^{4}
$$

where

$$
\begin{aligned}
& c_{1}=-1.784852 \times 10^{+1} \mathrm{~J} /\left(\mathrm{kg} \cdot \mathrm{K}^{1}\right) \\
& c_{2}=+3.158695 \times 10^{+0} \mathrm{~J} /\left(\mathrm{kg} \cdot \mathrm{K}^{2}\right) \\
& c_{3}=-7.311092 \times 10^{-3} \mathrm{~J} /\left(\mathrm{kg} \cdot \mathrm{K}^{3}\right) \\
& c_{4}=+7.493023 \times 10^{-6} \mathrm{~J} /\left(\mathrm{kg} \cdot \mathrm{K}^{4}\right) \\
& c_{5}=-2.388687 \times 10^{-9} \mathrm{~J} /\left(\mathrm{kg} \cdot \mathrm{K}^{5}\right)
\end{aligned}
$$




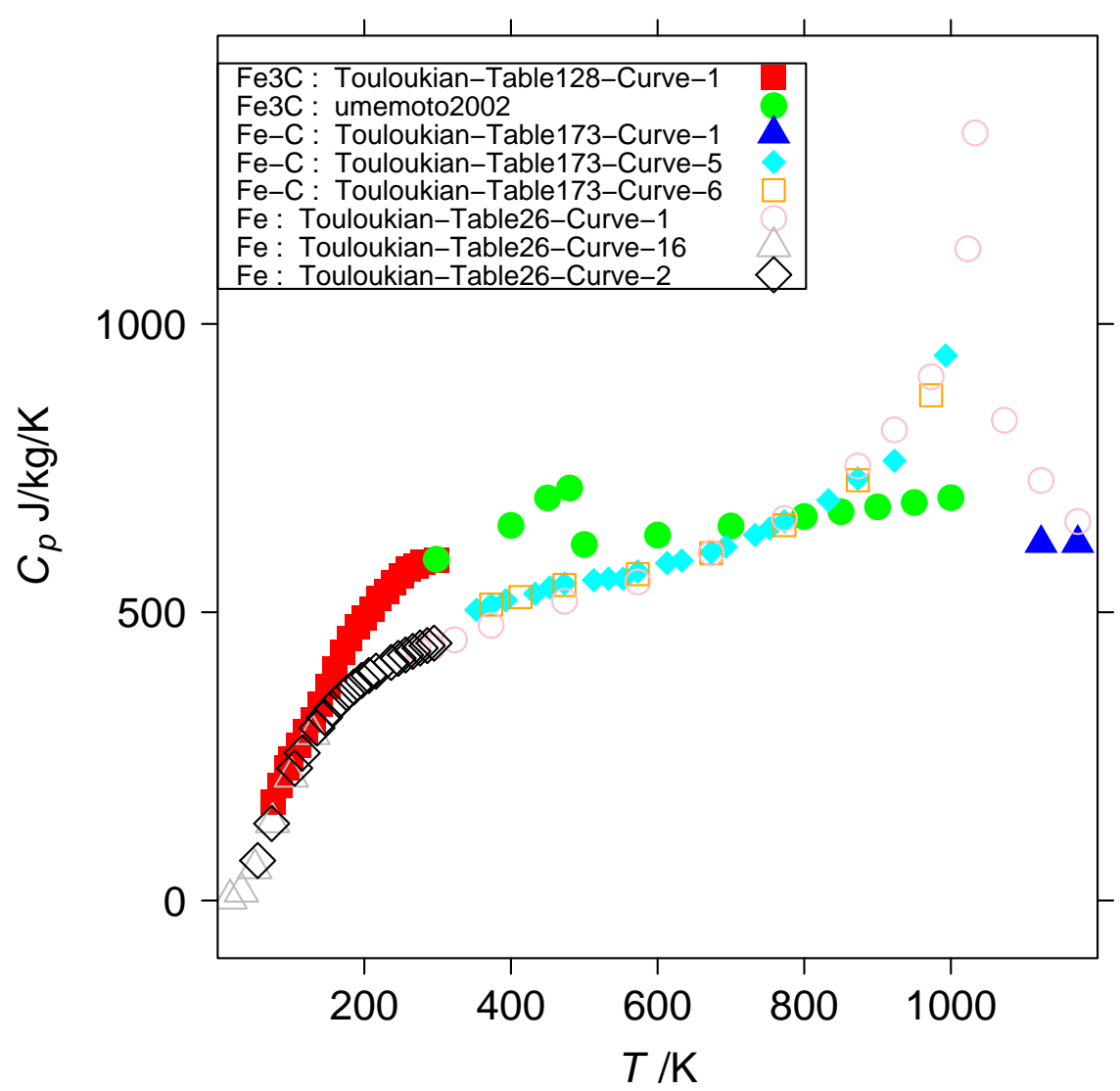

Figure 47: Specific heat, $C_{p}$, of pure iron $(\mathrm{Fe})$, steel with composition similar to the bridge wire (Fe-C), and cementite $\mathrm{Fe}_{3} \mathrm{C}$. Data sources: Touloukian:[1], umemoto2002:[2].

\subsection{Thermal Conductivity}

For one-dimensional heat flow, the thermal conductivity, $k$, relates the quantity of heat per unit time, $Q$, transported per unit area, $A$, to the temperature gradient, $d T / d x$ :

$$
\frac{Q}{A}=k\left(\frac{d T}{d x}\right)
$$

where $k$ has units of $\mathrm{W} /(\mathrm{mK})$. For one-dimensional situations where the temperature depends on time, the thermal diffusivity, $\alpha$, is appropriate:

$$
\frac{d T}{d t}=\alpha \frac{d^{2} T}{d x^{2}}
$$

The thermal diffusivity, $\alpha$,

$$
\alpha=\frac{k}{\rho C_{p}}
$$

is the ratio of the thermal conductivity, $k$, to the density, $\rho$, and specific heat $C_{p}$. It has units of a diffusion coefficient: $\mathrm{m}^{2} / \mathrm{s}$. Unlike the other thermal properties (modulus, thermal expansion 


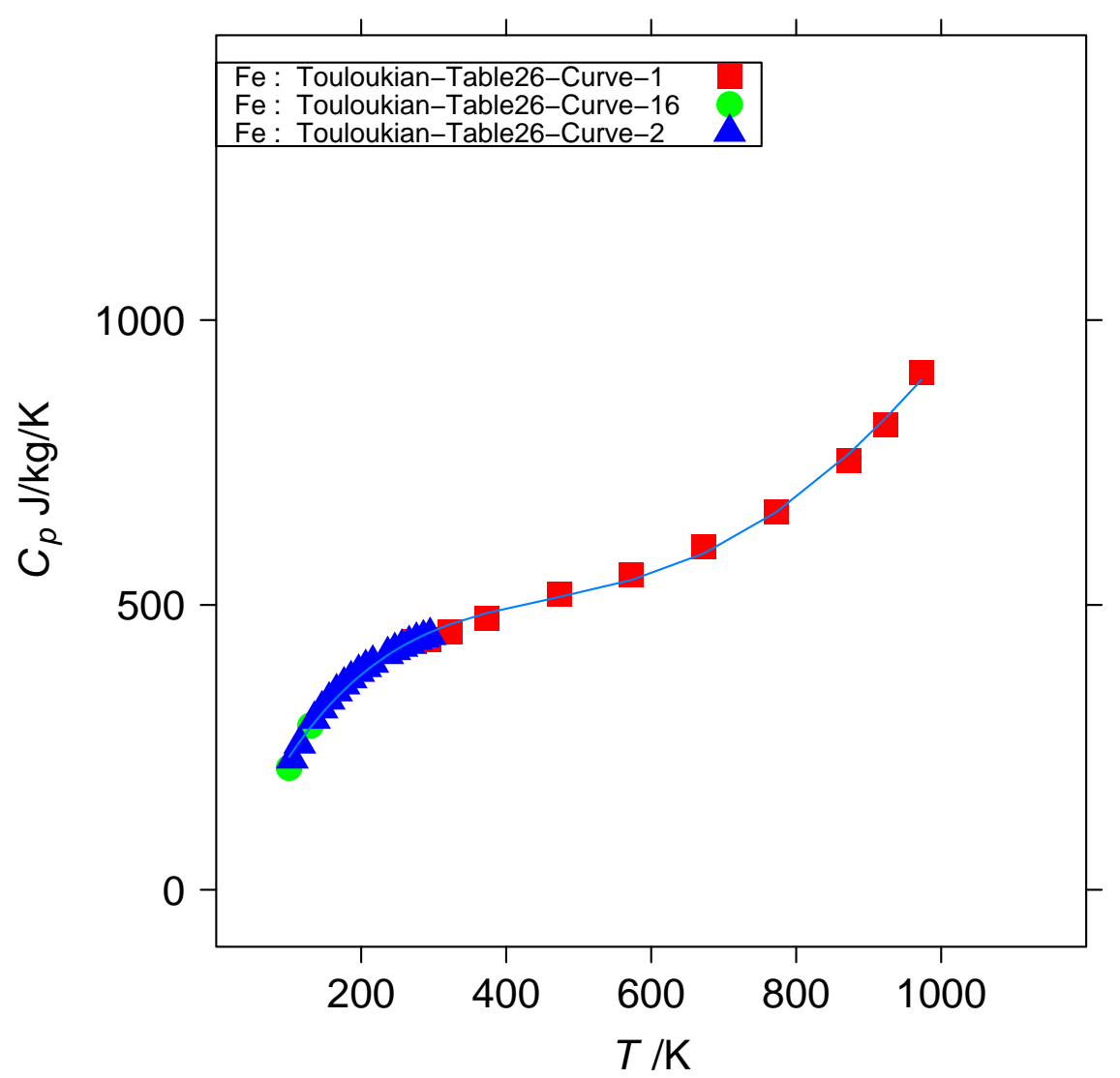

Figure 48: Fitted fourth-order polynomial and the specific heat data. Data source: Touloukian:[1]

coefficient, specific heat), the microstructure of the steel affects the thermal conductivity. Identical chemistries processed differently will yield steels with different thermal conductivities. Because the various alloying elements and processing steps modify the microstructure, there is no generic relation between grade of steel and thermal conductivity. For instance, Figure 49 plots the thermal conductivity, taken from Touloukian[4] Specification Table 322, as a function of temperature for steels whose compositions are similar to the bridge wire steel composition. The spread in the data demonstrates the uncertainty.

\subsubsection{Recommended Value}

The general behavior of the thermal conductivity, $k$, as a function of temperature, $T$, can also be expressed as a fourth-order polynomial:

$$
k(T)=k_{0}+k_{1} T+k_{2} T^{2}+k_{3} T^{3}+k_{4} T^{4}
$$




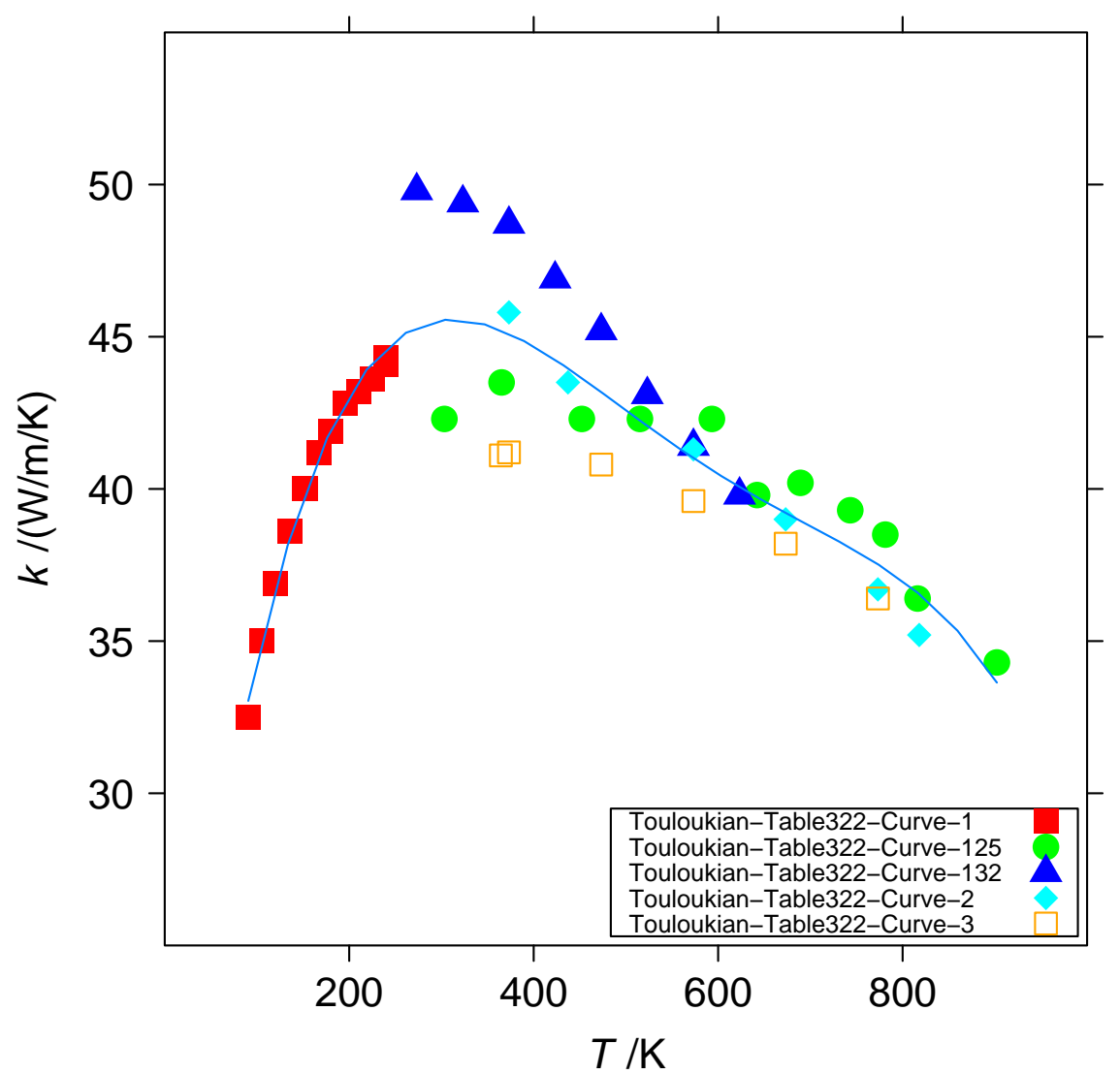

Figure 49: Thermal conductivity, $k$, of steels with carbon content similar to the bridge steel wire. The solid line is the fit to the subset of the thermal conductivity data in the range $(90.2<T<$ 1000) K using Eq,31. Data source: Touloukian:[4]

where

$$
\begin{aligned}
& k_{1}=+1.544991 \times 10^{+1} \mathrm{~W} /\left(\mathrm{m} \cdot \mathrm{K}^{1}\right) \\
& k_{2}=+2.540191 \times 10^{-1} \mathrm{~W} /\left(\mathrm{m} \cdot \mathrm{K}^{2}\right) \\
& k_{3}=-7.352568 \times 10^{-4} \mathrm{~W} /\left(\mathrm{m} \cdot \mathrm{K}^{3}\right) \\
& k_{4}=+8.503279 \times 10^{-7} \mathrm{~W} /\left(\mathrm{m} \cdot \mathrm{K}^{4}\right) \\
& k_{5}=-3.576576 \times 10^{-10} \mathrm{~W} /\left(\mathrm{m} \cdot \mathrm{K}^{5}\right)
\end{aligned}
$$

The upper temperature limit is the eutectoid temperature. Figure 49 also plots the fit overlaid on the data. 


\subsection{Thermal expansion}

\subsubsection{Recommended value}

Touloukian[5] recommends an expression for the fractional length change as a function of temperature for all steels with carbon content in the range $0.7 \%<[\mathrm{C}]<1.4 \%$, where the carbon is measured in percent by mass.

$$
\frac{\delta L}{L_{0}}=a_{0}+a_{1} T+a_{2} T^{2}+a_{3} T^{3}
$$

where

$$
\begin{aligned}
& a_{0}=-0.223 \times 10^{-2} \\
& a_{1}=+4.337 \times 10^{-6} \mathrm{~K}^{-1} \\
& a_{2}=+1.273 \times 10^{-8} \mathrm{~K}^{-2} \\
& a_{3}=-4.446 \times 10^{-12} \mathrm{~K}^{-3}
\end{aligned}
$$

The expression is accurate to $\pm 7 \%$ over the range $(50<T<1000) \mathrm{K}$. The instantaneous coefficient of thermal expansion is

$$
\alpha=\frac{1}{L}\left(\frac{d L}{d T}\right)
$$

Differentiating Equation (32) yields an expression for the instantaneous thermal expansion coefficient that can be used to calculate the thermal expansion between any two temperatures:

$$
\alpha=\frac{a_{1}+2 a_{2} T+3 a_{3} T^{2}}{1+a_{0}+a_{1} T+a_{2} T^{2}+a_{3} T^{3}}
$$

where the temperatures are again expressed in kelvin.

\section{Mechanical Properties}

The mechanical properties of the bridge wire were evaluated using a combination of experimental measurements for low-temperature stress strain and published literature data for high-temperature stress-strain, ductility, and toughness. Some references [6, 7, 8, 9, 10, 11] provide additional data on suspension bridge wire mechanical properties.

\subsection{Experimental Procedure}

\subsubsection{Material}

Dr. Raimondo Betti of the Columbia University Civil Engineering department and Dyab Khazem of Parsons, Inc donated the bridge wire in January, 2008. It was supplied as a $30 \mathrm{~m}$ coil with diameter $D_{c} \approx 2 \mathrm{~m}$, which resulted from the cast created by the original drawing operation. The wire itself had nominally $d=4.92 \mathrm{~mm}(d=0.196 \mathrm{in})$, and was zinc coated. The wire is used in their long-term study of condition assessment of suspension bridge cables.[12] Table 5] summarizes the chemical composition of the wire. 
Table 5: Chemical composition of the bridge wire.

\begin{tabular}{lcc} 
& Element & w/o \\
\cline { 2 - 3 } & $\mathrm{C}$ & 0.82 \\
$\mathrm{Mn}$ & 0.69 \\
$\mathrm{P}$ & 0.01 \\
$\mathrm{~S}$ & 0.01 \\
$\mathrm{Si}$ & 0.16 \\
$\mathrm{Ni}$ & 0.04 \\
$\mathrm{Cr}$ & 0.02 \\
$\mathrm{Mo}$ & $<0.01$ \\
$\mathrm{Cu}$ & 0.04 \\
$\mathrm{Al}$ & 0.04 \\
$\mathrm{Va}$ & 0.02 \\
$\mathrm{Nb}$ & $<0.005$ \\
$\mathrm{Zr}$ & $<0.005$ \\
$\mathrm{~B}$ & $<0.0005$ \\
$\mathrm{~N}$ & 0.01 \\
Source: Chicago Spectro report F7745 PO R1749 \\
C, S by ASTM E1019 all others by ASTM E415 \\
Date 05/06/08
\end{tabular}

\subsubsection{Tensile testing}

Figure 50 shows the tensile test setup for the low-temperature tests both before and after a typical test. The upside-down "U"-shaped liquid nitrogen diffuser is in the foreground. Behind that, clipped to the specimen, is the extensometer. Note the silver-colored aluminum spacer that extends the gage length to approximately $24 \mathrm{~mm}(=5 D)$. The center control thermocouple is wired to the specimen between the contact points of the extensometer. The two other thermocouples are wired to the specimen just above and below the specimen grips.

Gripping the specimen for the low temperature tests was a significant experimental difficulty. Because the strength typically increases with decreasing temperature, it is not possible to grip the wire specimen outside the refrigerated section. The specimen grips used serrated wedges made for gripping cylindrical test specimens. The strength and hardness of the wire is comparable to the steel of the wedges, which caused the specimen to frequently slip on loading. A solution that worked at most temperatures was to cut a 10-32 thread onto the last $6 \mathrm{~mm}$ of both ends of the wire using carbide tooling in a lathe. A nut threaded onto this section bears on the back ends of the wedges, and provides extra force to push the wedges together on loading. The sliding faces of the wedges were greased before each test.

\subsubsection{Temperature control and cooling}

Each test employed three K-type thermocouples. One was wired to the specimen center between the extensometer arms. The other two sat in the groove between the wedges at the top and bottom of the specimen, and measured the temperature of the specimen where it entered the wedge. 


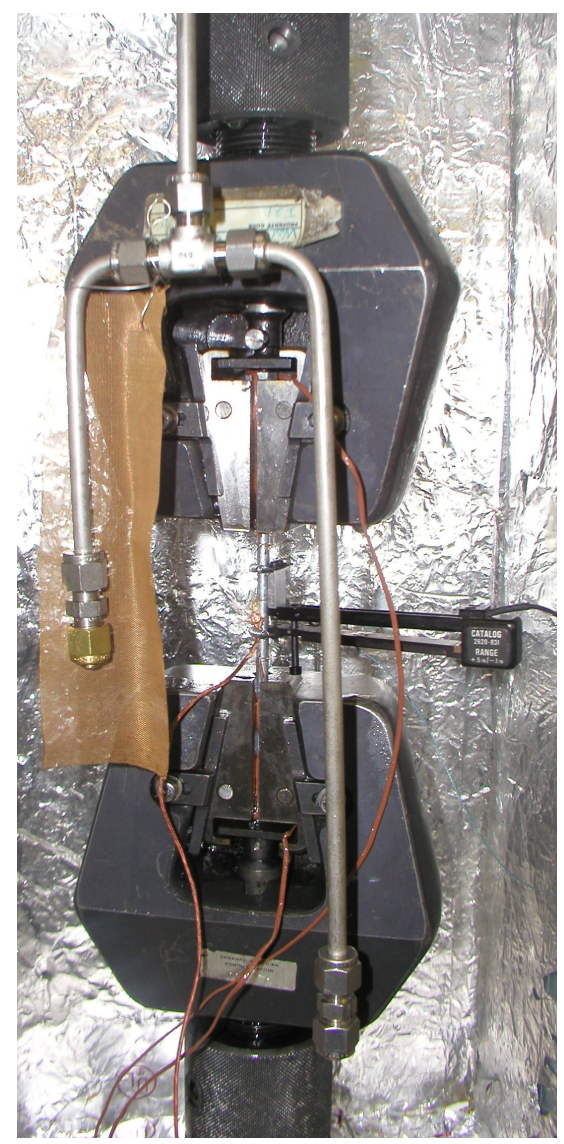

(a) Before test

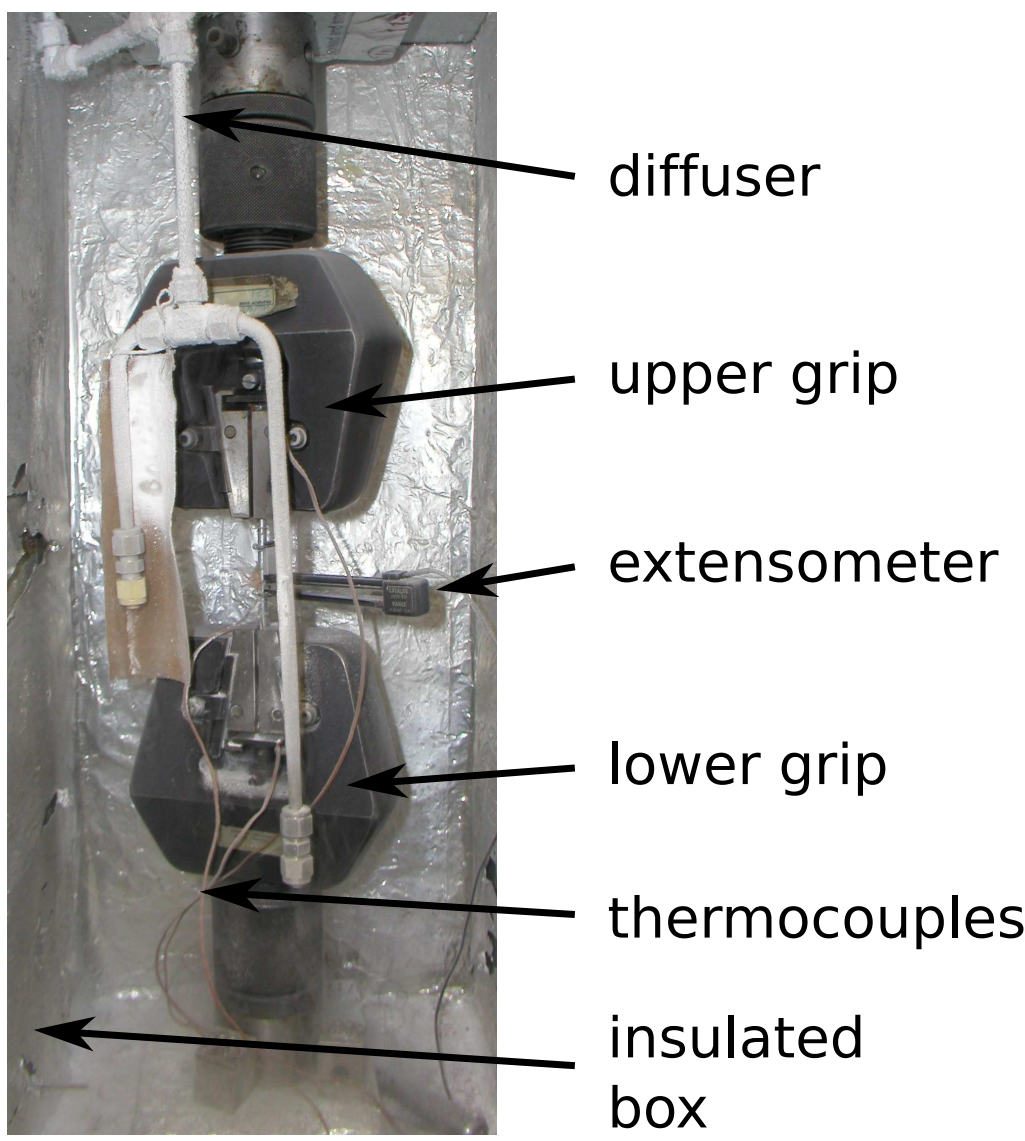

(b) After test

Figure 50: Test setup from test 2008071001.

The center thermocouple controlled the temperature. When the sample temperature was above the desired setpoint, the temperature controller opened a low-temperature solenoid valve to allow liquid nitrogen to flow from a $100 \mathrm{~L}$ dewar through the diffuser and into the sample chamber. The diffuser primarily sprayed onto the massive specimen grips, rather than the specimen, in an effort to make the temperature along the specimen as uniform as possible by conduction. The entire load train was surrounded by an insulated box made from expanded polystyrene foam, approximately $50 \mathrm{~mm}$ thick. Some early tests used a cooling system that expands $\mathrm{CO}_{2}$ gas in the chamber. This system was much less effective than the liquid nitrogen system, and was not used for many tests.

\subsubsection{Strain measurement}

Strain measurement was by an extensometer clipped to the specimen. It was modified to extend its gage length to be $G \approx 5 D$. For the early tests $G=24.0 \mathrm{~mm}$; in later test $G=25.4 \mathrm{~mm}$. The calibration of the extensometer was verified as a function of temperature by checking it against the motion of the actuator at four temperatures in the range $(-120<T<-40){ }^{\circ} \mathrm{C}$. In the verification, the extensometer was clipped to a broken specimen solidly mounted in the grips. After stabilizing at temperature, the actuator was cycled over $\pm 2 \mathrm{~mm}$ amplitude, while the data 


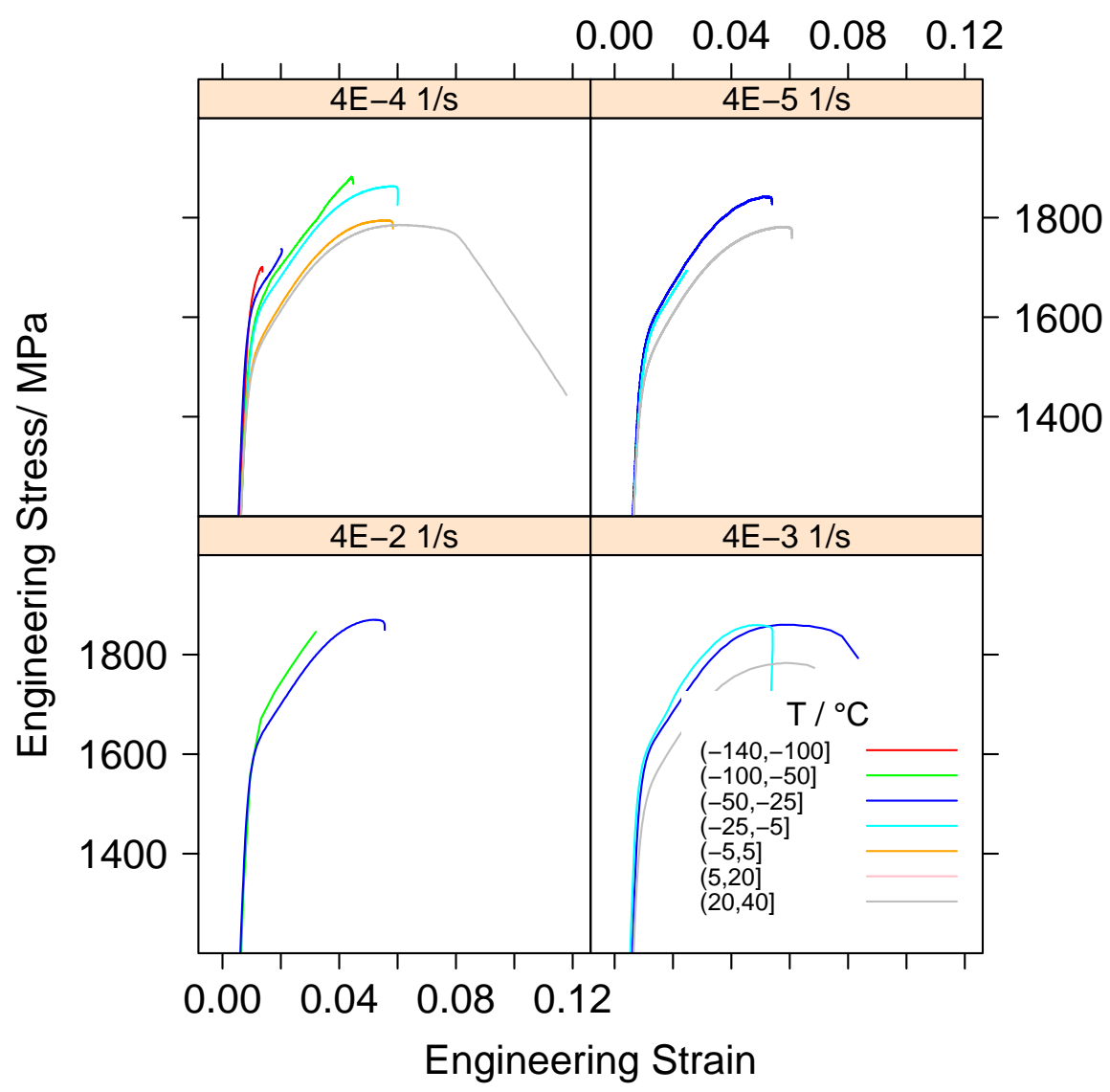

Figure 51: Engineering stress-strain test data by nominal strain rate.

from the actuator position and extensometer were acquired. The differences in the relationship between the extensometer position and the actuator position in the four calibration checks were not statistically significantly different.

\subsection{Results}

Figures 51 and 52 show the engineering-stress-strain behavior of the successful tests organized by nominal strain rate and by temperature range. The shape of the curve indicates the success of the test. In tests in which the specimen failed in the gage, between the extensometer arms, the engineering strain continues well past the tensile strength. In tests in which the specimen failed outside the gage length, the stress bends over rapidly with increasing strain. Tests in which the specimen failed in the grips generally terminate with no stress drop. Figures 53 and 54 plot the data as true stress-strain, with all data after necking truncated.

Table 6 summarizes the mechanical properties from the tensile tests. Because of the difficulty in achieving the nominal temperature of the test, and the slight non-uniformity of the temperature along the gage length, Table 6 also reports the uncertainty in the measured temperature, $u(T)$. This term is one-half the range of temperature measured by the three thermocouples at the start of the 


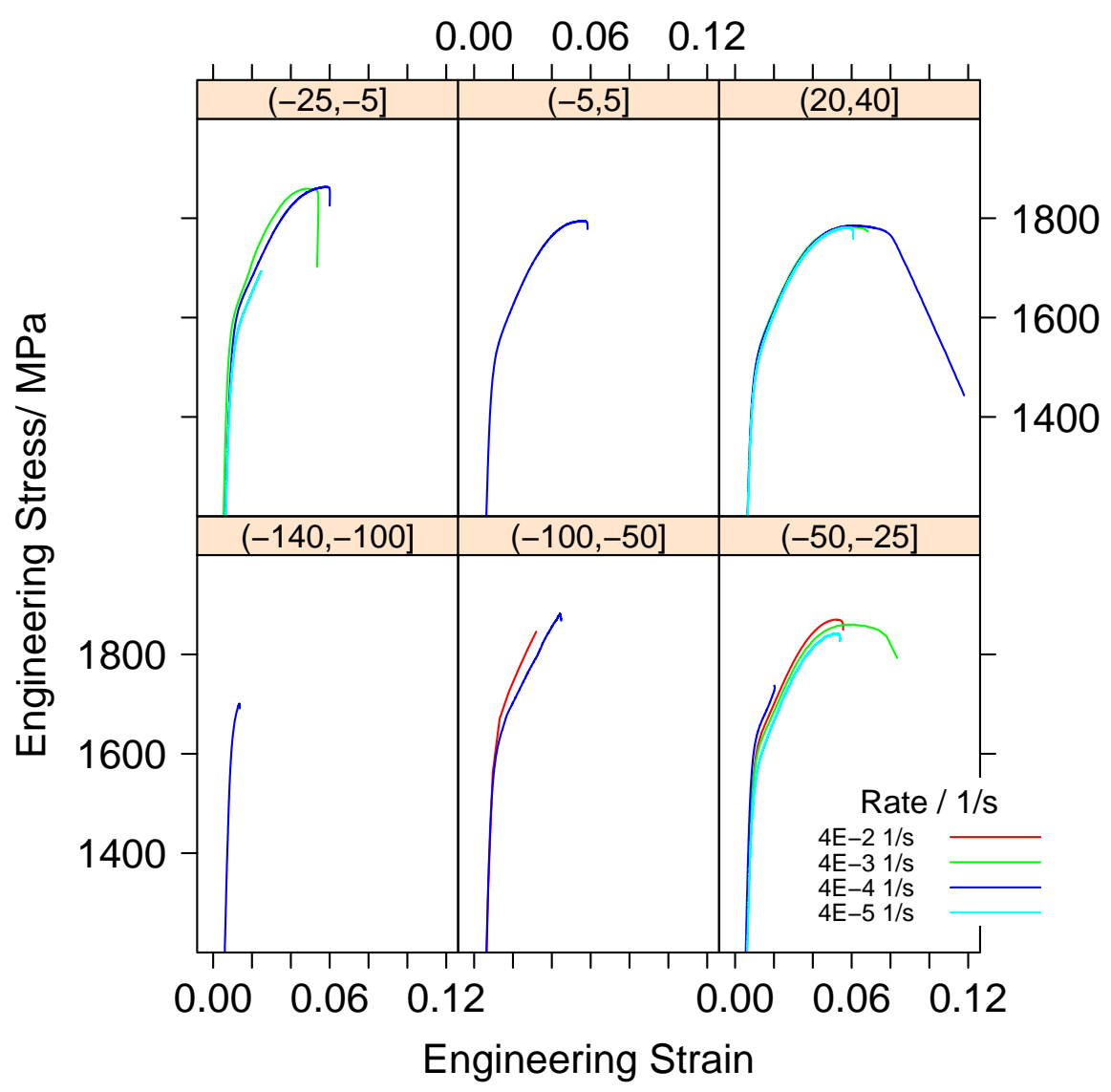

Figure 52: Engineering stress-strain test data by temperature range. Strips above the curves show the temperature range in Celsius.

test.

Figures $55 \mathrm{a}$-c plot three measures of the yield strength of the wire, summarized in Table 6. The term YSOO2 is the $0.2 \%$ offset yield strength defined in ASTM E08[13]. The other two measures, YSO1 and YSO2 are the the engineering stress measured at $e=0.01$ and $e=0.02$ total elongation, including the elastic strain. All three yield strength measures are determined from the engineering stress-strain curves.

Figure 55d shows the elastic modulus, $E$, measured in the engineering stress-strain curves, and used to calculate the $0.2 \%$ offset yield strength, YSOO2. These data should not be used for design.

Figure 56 shows the engineering strain, $e_{\max }$, evaluated at the tensile, or maximum, engineering stress, $T S$, for different failure locations in the specimen. Table 7 summarizes the failure data. The plot highlights the difficulty in obtaining stress-strain curves out to failure. It separates the data into five different failure locations. "Gage" failures occurred between the extensometer arms, and correspond to a traditional, successful test. "Grip" failures occurred in the wedge-gripped region of the specimen, possibly from damage caused by the sample slipping in the grips. "End" failures occurred outside the extensometer-defined gage length but outside the scarred area of the grips. Two specimens, identified as "unknown," were destroyed before the failure position was recorded. 


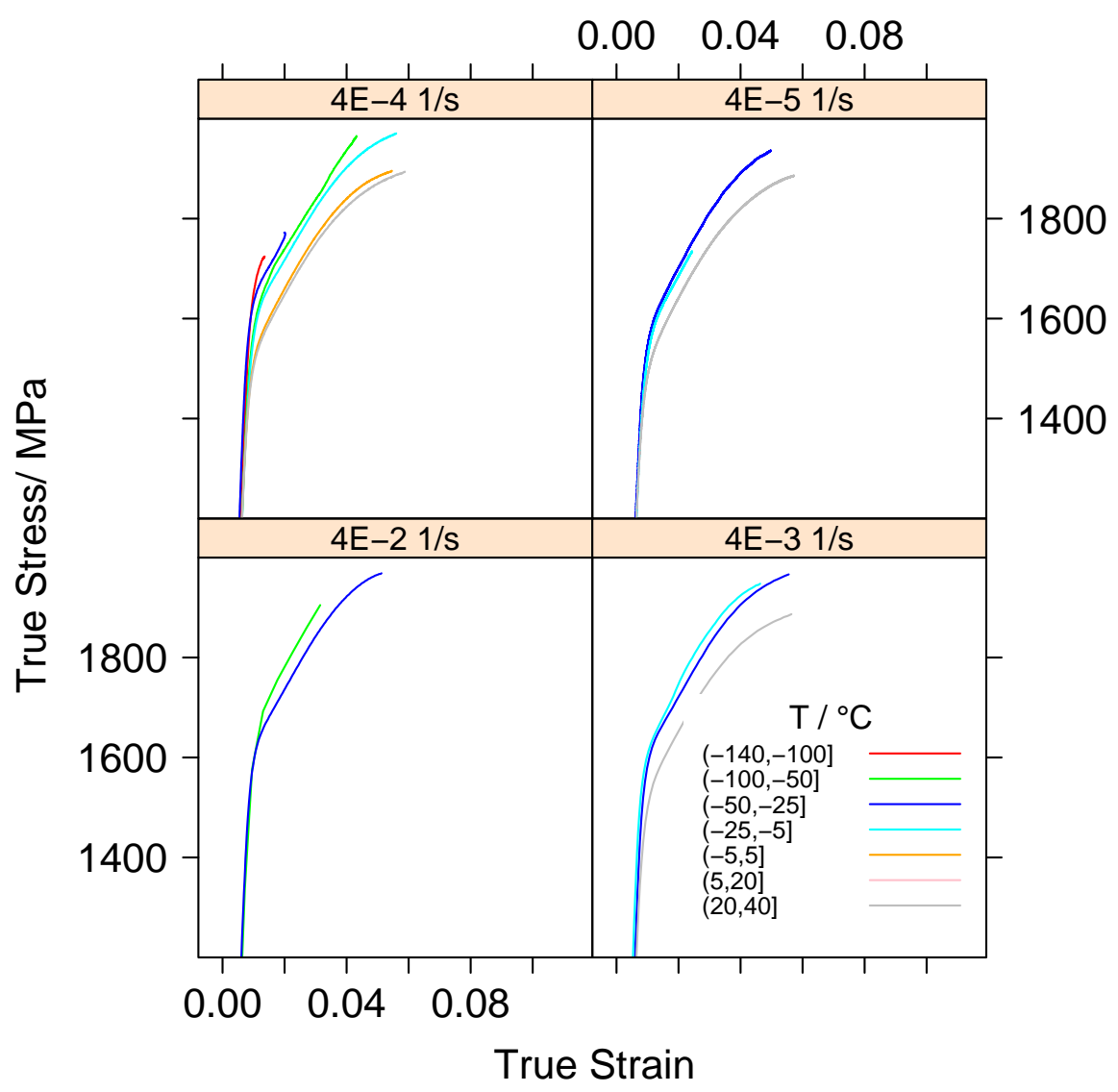

Figure 53: True stress-strain test data by nominal strain rate.

Finally, unlike all the other tests, the specimen in the lowest-temperature test, $T=-117.9{ }^{\circ} \mathrm{C}$, , identified as "nut," failed in the threads at the very end of the specimen, which held the nut used to secure the wedges. Two other tests at a similar temperature, not reported here, also failed at the nut, but in the elastic regime, before any plastic deformation, and so did not yield any information.

\subsection{Analysis and Discussion}

\subsubsection{Representing stress-strain behavior at all temperatures}

A simple method for representing the stress-strain behavior of the wire both above and below room-temperature is via power-law work-hardening. For true stress-strain $(\sigma-\epsilon)$ :

$$
\sigma=K \epsilon^{n}
$$

For engineering stress-strain $(S-e)$ :

$$
S=K_{e} e^{n_{e}}
$$

where the two parameters use subscript " $e$ " to denote engineering units. Figure 57 shows the results of the analysis of each true stress-strain curve to determine $K$ and $n$ in Eq. 35. Fits used the 


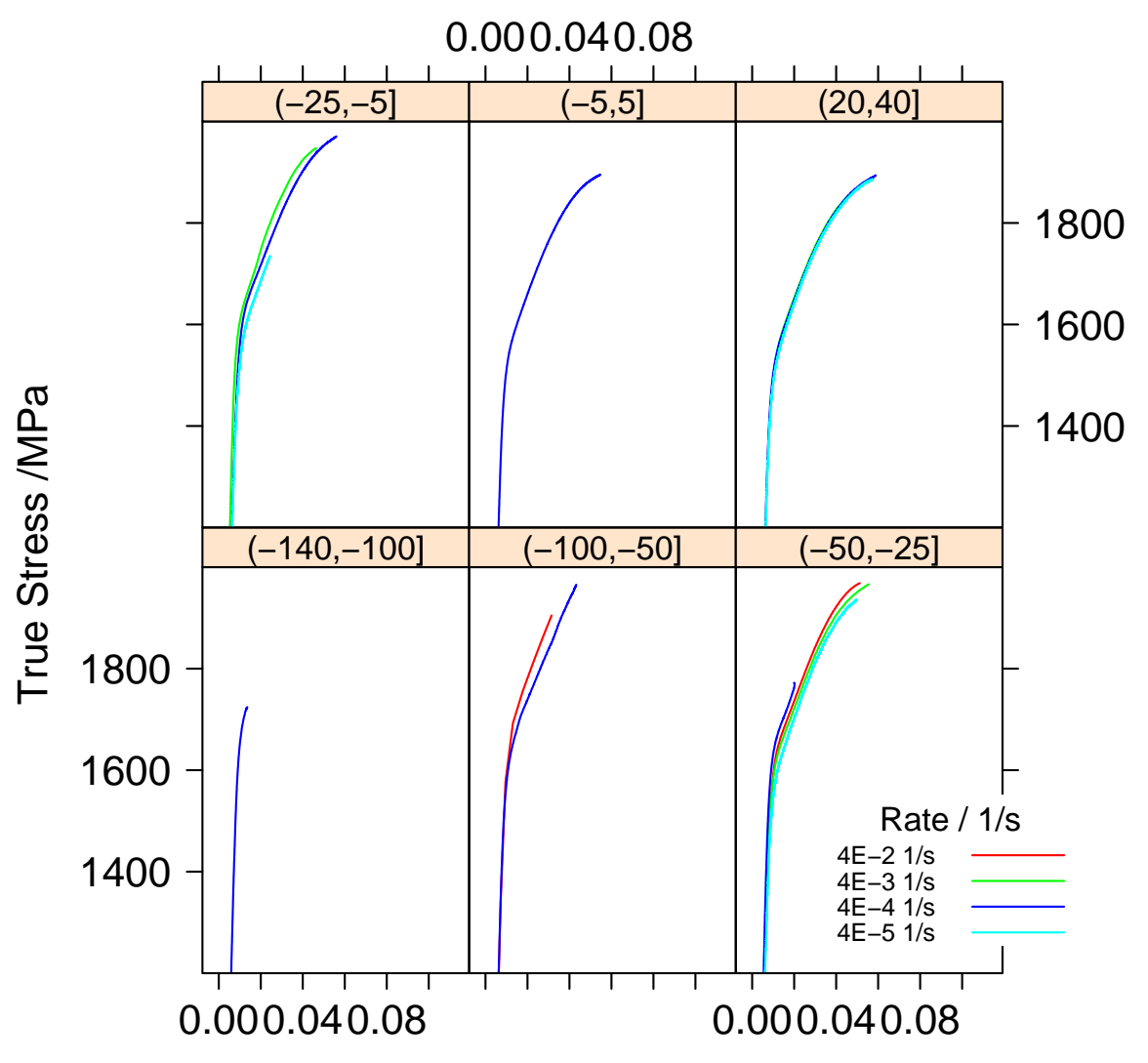

True Strain

Figure 54: True stress-strain test data by temperature range. Strips above the curves show the temperature range in Celsius.

$\mathrm{R}$ statistical language[14] function $\mathrm{nls}$ in the range $0.01<e<e_{\max }$, where the maximum strain, $e_{\max }$, Table 7, is evaluated at the tensile strength in the engineering stress-strain curve. Figure 58 is the corresponding plot for engineering units. In both figures, the test temperature decreases from the top of the page to the bottom of the page, and the strain rate increases from left to right. Note that the fit was not done on the log-transformed data. Table 6 summarizes the fitted values of $K, n$, $K_{e}$, and $n_{e}$. Figure 59 plots the data of Table 6 as a function of strain rate, grouped by temperature range.

The prefactors, $K$ and $K_{e}$ increase with decreasing temperature, as expected, and are independent of strain rate, which is unexpected. Their expected dependence on strain rate may be masked by the repeatability of the individual tests, however. The work-hardening exponents, $n$ and $n_{e}$, are independent of strain rate and temperature. For details of these calculations see Tables 8 and 9 . which show the output of a linear analysis using the R[14] linear model function $1 \mathrm{~m}$. 
Table 6: Tensile test data.

\begin{tabular}{|c|c|c|c|c|c|c|c|c|c|c|}
\hline \multirow[t]{2}{*}{ Test } & \multicolumn{2}{|c|}{$T u(T)$} & \multirow{2}{*}{$\begin{array}{r}d e / d t \\
1 / \mathrm{s}\end{array}$} & $Y S 002$ & \multirow{2}{*}{$\begin{array}{r}Y S 01 \\
\mathrm{MPa}\end{array}$} & \multirow{2}{*}{$\begin{array}{r}Y S 02 \\
\mathrm{MPa}\end{array}$} & \multirow{2}{*}{$\begin{array}{r}K \\
\mathrm{MPa}\end{array}$} & \multirow{2}{*}{\multicolumn{2}{|c|}{$\begin{array}{l}n \quad K_{e} \\
\mathrm{MPa}\end{array}$}} & \multirow[t]{2}{*}{$n_{e}$} \\
\hline & ${ }^{\circ} \mathrm{C}$ & ${ }^{\circ} \mathrm{C}$ & & $\mathrm{MPa}$ & & & & & & \\
\hline 200 & 27 & 0.1 & 110 & 1420 & 44 & 1616 & 7 & 4 & 244 & \\
\hline & & & & & & & & & 2 & \\
\hline & - & 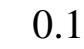 & & & 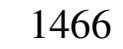 & & 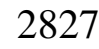 & & 2 & \\
\hline & 0 & 5 & & & & 1625 & T & & 10 & \\
\hline 200 & 0 & 5 & & & 8 & 09 & 2952 & & 260 & 77 \\
\hline 200 & & & & & & & 2925 & & 5 & 05 \\
\hline 200 & & 0.5 & & 1502 & 2 & 1 & 2850 & & 2611 & 17 \\
\hline 200 & 30 & 0.5 & & 1543 & 72 & 1700 & 2943 & . & 2578 & 06 \\
\hline 200 & -38 & $\mathrm{~N}$ & & 1505 & 1 & $\mathrm{~N} /$ & NA & & NA & NA \\
\hline 200 & -40 & 0.5 & 4. & 1 & 1562 & 1685 & 2896 & & 2529 & 0.103 \\
\hline 200 & 1 & .5 & 04 & 35 & 1613 & 1728 & 2671 & 07 & 2432 & 0.088 \\
\hline 200 & .4 & 15 & 4.7 & 1525 & 14 & 1666 & 2981 & 2 & 261 & 15 \\
\hline 200 & & 5 & & 3 & 5 & $1^{\prime}$ & 3076 & & 2716 & 19 \\
\hline 200 & & 2 & & & & 1743 & 3018 & & 2667 & 0.108 \\
\hline 20080 & 17.9 & 7.6 & $3.49 \mathrm{e}-04$ & 1617 & 1631 & $\mathrm{NA}$ & 3154 & 0.14 & 2945 & 0.127 \\
\hline
\end{tabular}

\subsubsection{Temperature dependence for low temperature}

The Johnson-Cook equation[15]

$$
\sigma=\left(A+B \epsilon^{n}\right)\left(1+C \log _{e} \frac{\dot{\epsilon}}{\dot{\epsilon_{0}}}\right)\left(1-\left(\frac{T-T_{R}}{T_{m}-T_{R}}\right)^{m}\right)
$$

is a common method to describe the stress-strain-strain-rate-temperature dependence of a material. In this formalism, the temperature dependence is captured in a single function. The work hardening and strain-rate sensitivity are independent of temperature. Table 10 describes the terms and their definitions. The reference temperature, $T_{R}$, can be set to zero, in which case the the temperature function is just the homologous temperature: the ratio of the absolute test temperature to the melting temperature, $T_{m}$. Note that if a reference temperature is used, it must be less than any expected test temperature, to enable the exponentiation. In this analysis, the term $T_{m}$ is arbitrarily set to the liquidus temperature of pure iron, $T=1534{ }^{\circ} \mathrm{C}$.

The dependence of the prefactors, $K$ and $K_{e}$, in Eqs. (35) and (36) can be analyzed in terms of the temperature dependence of the Johnson-Cook equation: Eq. 37.

$$
\begin{aligned}
K & =K_{0}\left(1-\left(\frac{T-T_{R}}{T_{m}-T_{R}}\right)^{m}\right) \\
K_{e} & =K_{0 e}\left(1-\left(\frac{T-T_{R}}{T_{m}-T_{R}}\right)^{m_{e}}\right)
\end{aligned}
$$

Figure 61 shows the analysis of the temperature dependence of the prefactors $K$ and $K_{e}$. In Figure 61 the fits have been extended past the limits of the data to show that the function is wellbehaved in the entire possible temperature region of use: $(-273<T<100){ }^{\circ} \mathrm{C}$. Table 11 


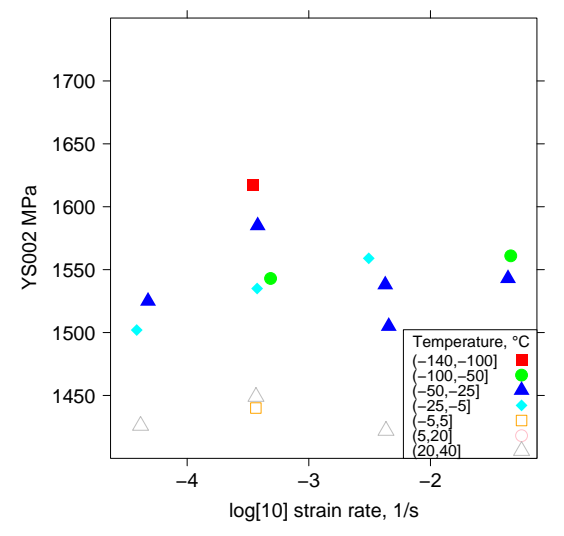

(a) $Y S 002$

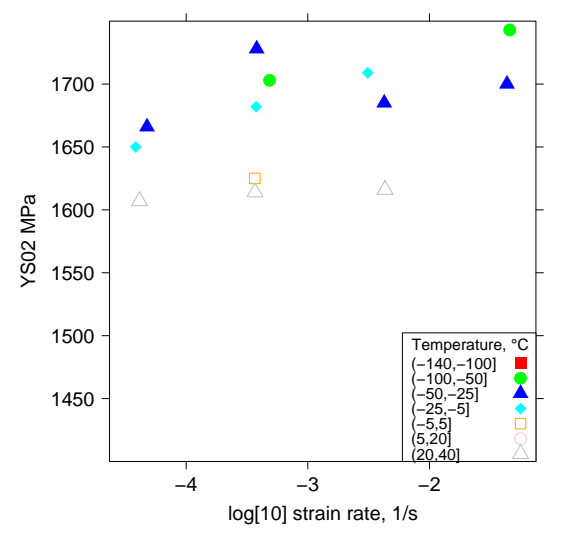

(c) $\mathrm{YSO}_{2}$

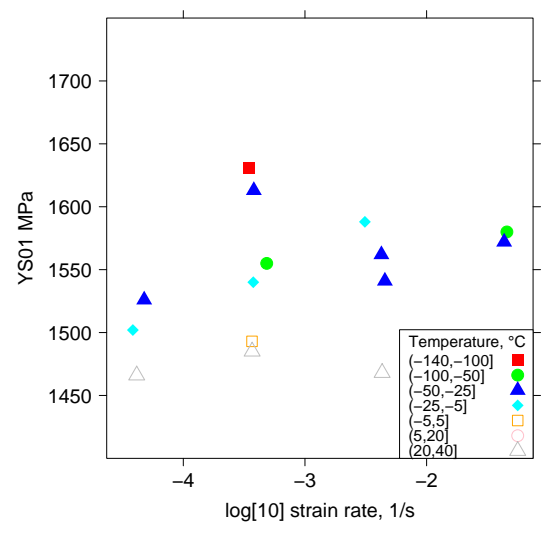

(b) $\mathrm{YSO1}$

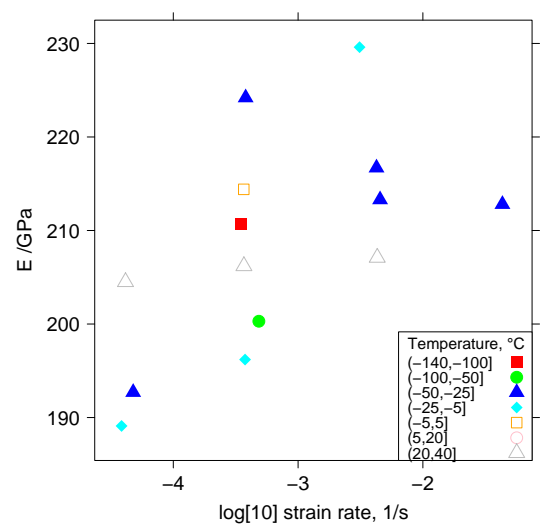

(d) $E$

Figure 55: Yield strength and modulus measures (a) $0.2 \%$ offset yield strength, YSOO2, (b) $2.0 \%$ total elongation yield strength, YSO1, (c) $1.0 \%$ total elongation yield strength, YSO2, (d) elastic modulus, $E$.

summarizes the results of the non-linear least squares fit to evaluate the parameters $K_{0}, m, K_{0 e}$, and $m_{e}$.

\subsubsection{Ductility as a function of temperature}

Because of the experimental difficulties in gripping the specimens, very little data exist to predict the behavior of the ductility as a function of temperature. Figure 56 shows that the strain at the tensile strength (the maximum stress achieved in the engineering stress-strain curve) does not decrease significantly down to $-40{ }^{\circ} \mathrm{C}$. The fact that three consecutive specimens tested at $T \approx-120{ }^{\circ} \mathrm{C}$ failed in the threads that held the wedge-grip nut could be taken as evidence that the toughness has decreased significantly at that temperature. 


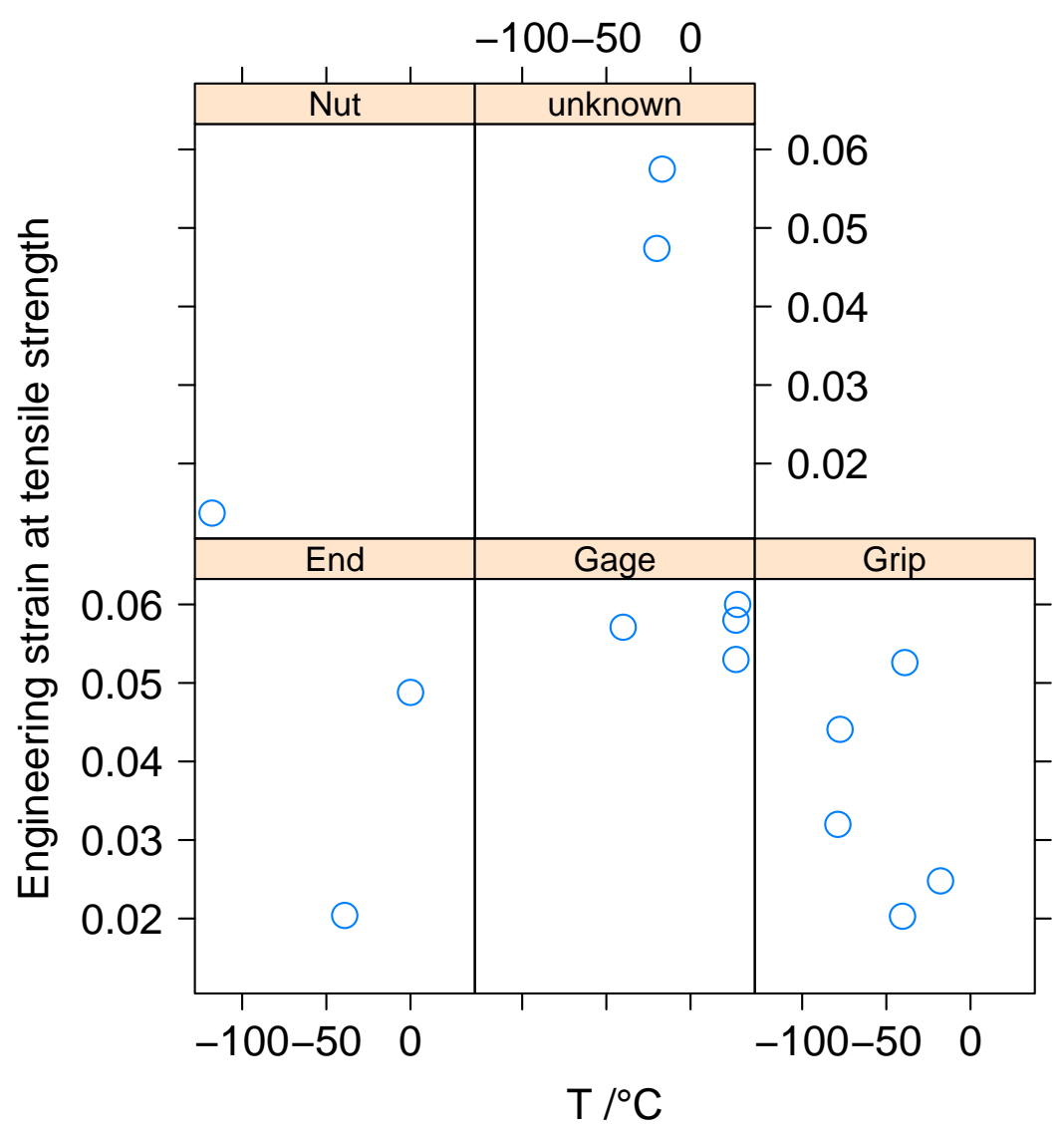

Figure 56: Engineering strain at the tensile strength, $T S$, separated by failure location.

Recommended value for stress-strain behavior below room temperature The low-temperature true stress-strain $(\sigma-\epsilon)$ behavior should be represented by

$$
\sigma=K_{0}\left(1-\left(\frac{T-T_{R}}{T_{m}-T_{R}}\right)^{m}\right) \epsilon^{n}
$$

The low-temperature engineering stress-strain behavior should be represented by

$$
S=K_{0 e}\left(1-\left(\frac{T-T_{R}}{T_{m}-T_{R}}\right)^{m_{e}}\right) e^{n_{e}}
$$

with the values in Table 12 ,

Figure 62 compares the true stress-strain $(\sigma-\epsilon)$ curves calculated from the fit of Table 11 with the measured data. Figure 63 compares the engineering stress-strain $(S-e)$ curves calculated with the measured data.

If the analysis is conducted by predicting strain as a function of stress, the usual representation 


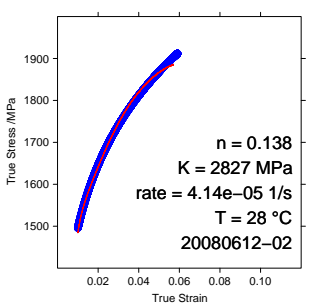

(a) 20080612-02

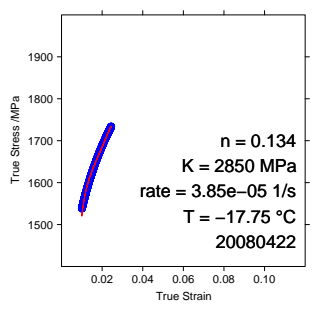

(d) 20080422

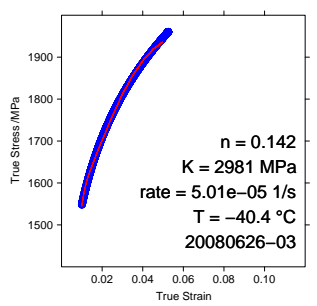

(g) 20080626-03

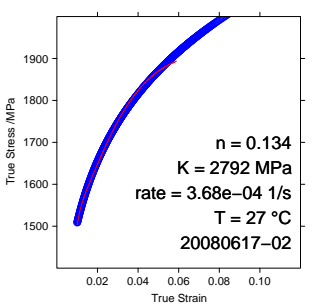

(b) $20080617-02$

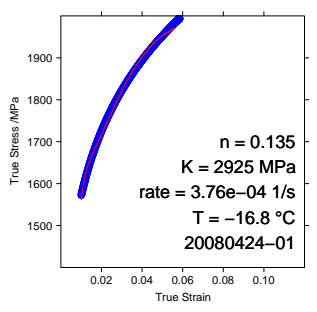

(e) 20080424-01

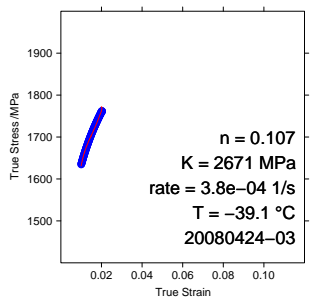

(h) 20080424-03

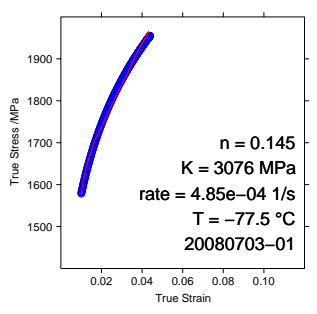

(k) 20080703-01

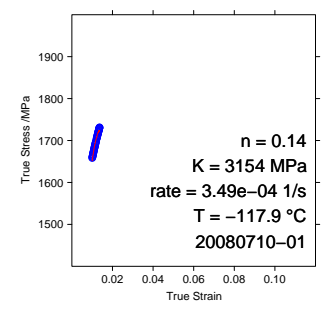

(m) 20080710-01

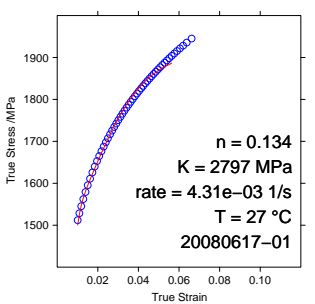

(c) 20080617-01

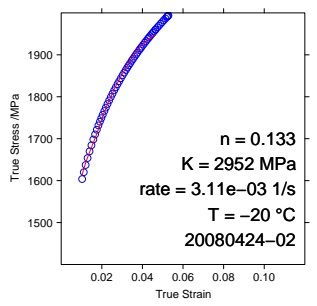

(f) 20080424-02

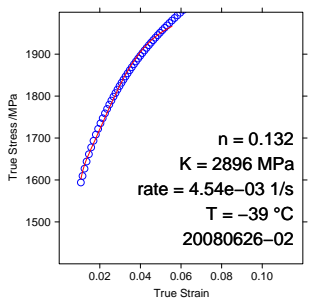

(i) $20080626-02$

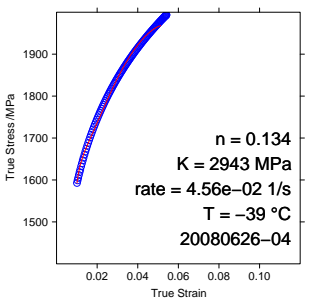

(j) 20080626-04

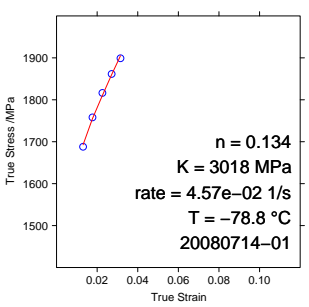

(1) 20080714-01

Figure 57: Analysis of $K$ and $n$ from the true stress-strain curves. 


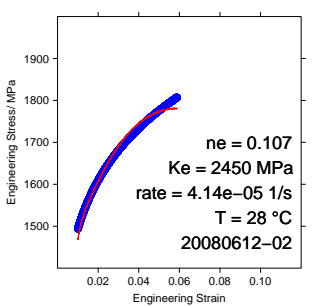

(a) 20080612-02

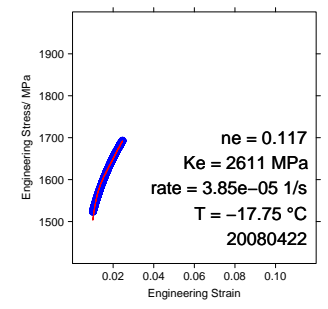

(d) 20080422

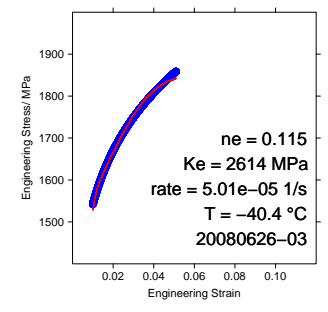

(g) 20080626-03

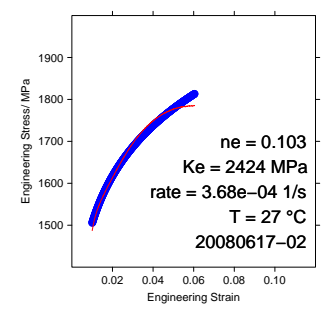

(b) $20080617-02$

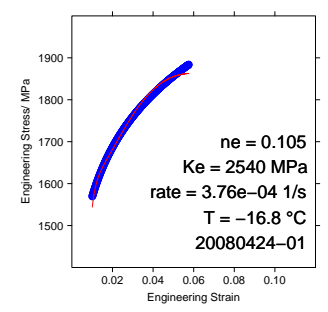

(e) 20080424-01

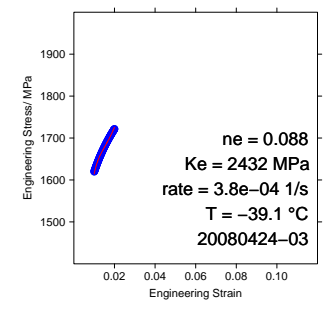

(h) 20080424-03

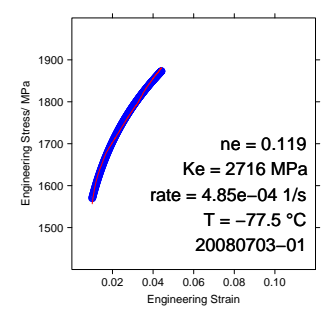

(k) 20080703-01

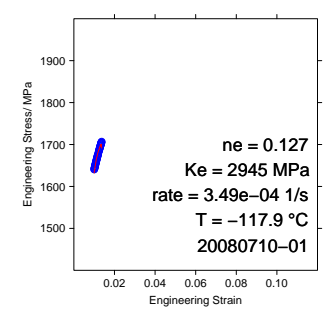

(m) 20080710-01

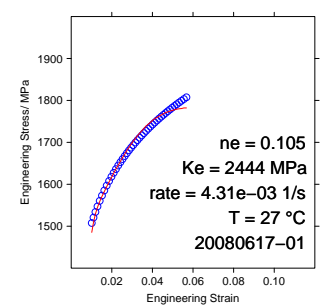

(c) 20080617-01

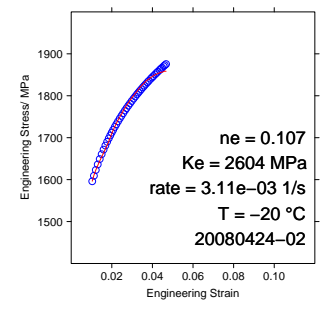

(f) 20080424-02

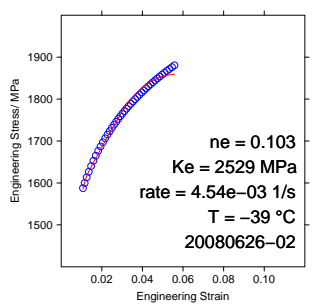

(i) $20080626-02$

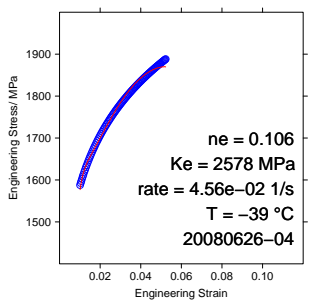

(j) 20080626-04

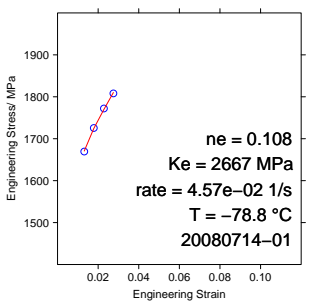

(1) 20080714-01

Figure 58: Analysis of $K_{e}$ and $n_{e}$ from the engineering stress-strain curves. 
Table 7: Failure data from the tensile tests.

\begin{tabular}{lrrl}
\hline Test & $\begin{array}{r}T \\
{ }^{\circ} \mathrm{C}\end{array}$ & $e_{\max }$ & Failure type \\
\hline $20080617-01$ & 27 & 0.058 & Gage \\
$20080617-02$ & 27 & 0.053 & Gage \\
$20080612-02$ & 28 & 0.06 & Gage \\
$20080617-03$ & 0 & 0.0488 & End \\
$20080424-02$ & -20 & 0.0474 & unknown \\
$20080424-01$ & -16.8 & 0.0575 & unknown \\
20080422 & -17.8 & 0.0248 & Grip \\
$20080626-04$ & -39 & 0.0526 & Grip \\
$20080626-01$ & -38 & NA End \\
$20080626-02$ & -40 & 0.0571 & Gage \\
$20080424-03$ & -39.1 & 0.0204 & End \\
$20080626-03$ & -40.4 & 0.0203 & Grip \\
$20080703-01$ & -77.5 & 0.0441 & Grip \\
$20080714-01$ & -78.8 & 0.032 & Grip \\
$20080710-01$ & -117.9 & 0.0137 & Nut \\
\hline
\end{tabular}

Table 8: Linear analysis of the dependence of $K$ on temperature and strain rate.

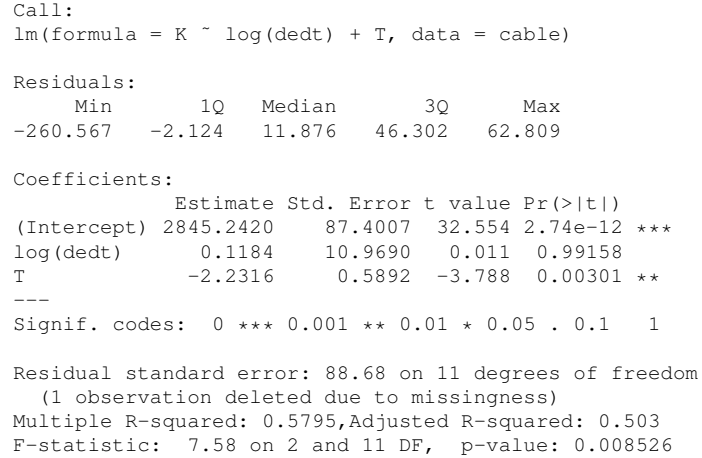

can be inverted to solve for the engineering strain:

$$
e= \begin{cases}\frac{S}{E(T)} & \text { if } S<S_{i} \\ \left(\frac{S}{K_{0 e}\left(1-\left(\frac{T-T_{R}}{T_{m}-T_{R}}\right)^{m_{e}}\right)}\right)^{1 / n_{e}} & \text { if } S \geq S_{i}\end{cases}
$$

where $S_{i}$ is a "yield strength," computed from the intersection of the temperature-dependent elastic 


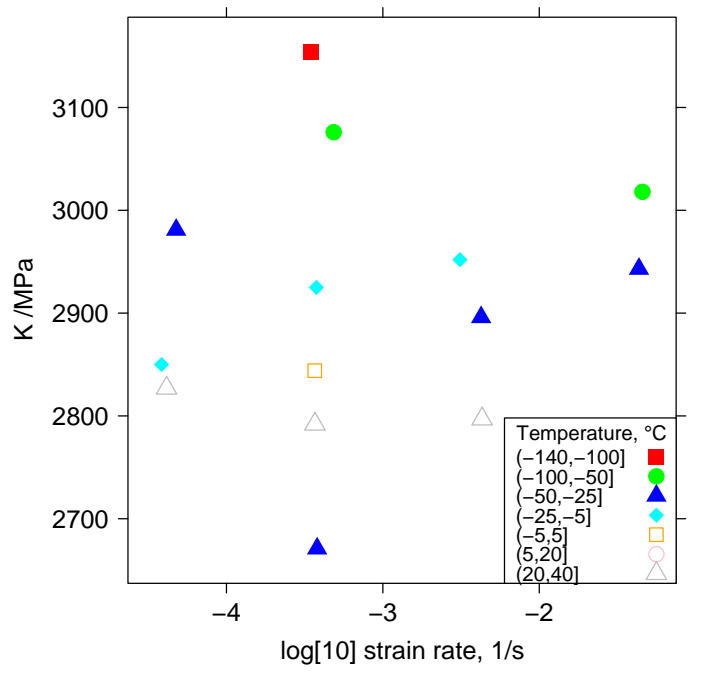

(a) $K$

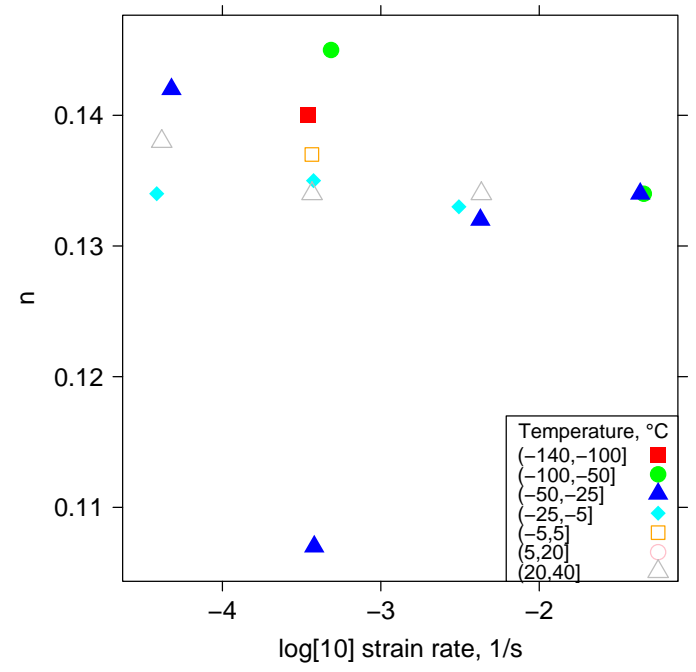

(b) $n$

Figure 59: $K$ and $n$.

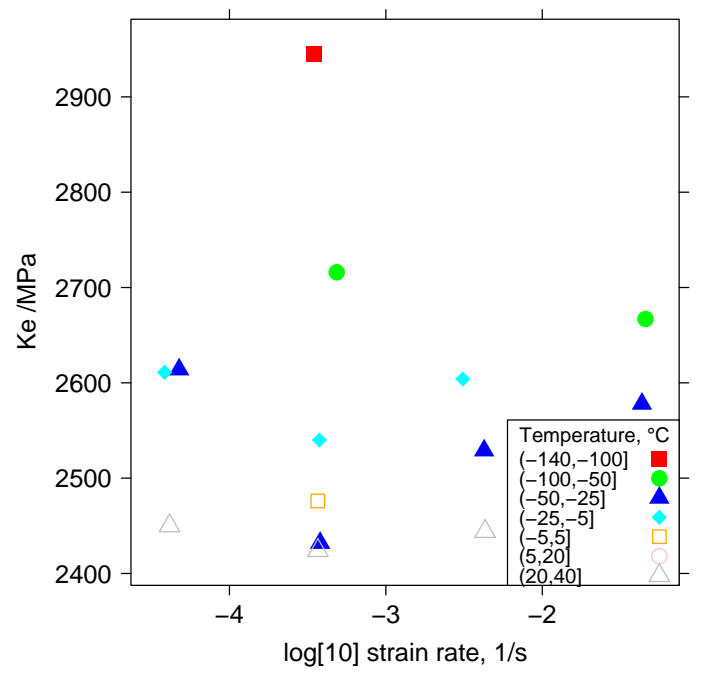

(a) $K_{e}$

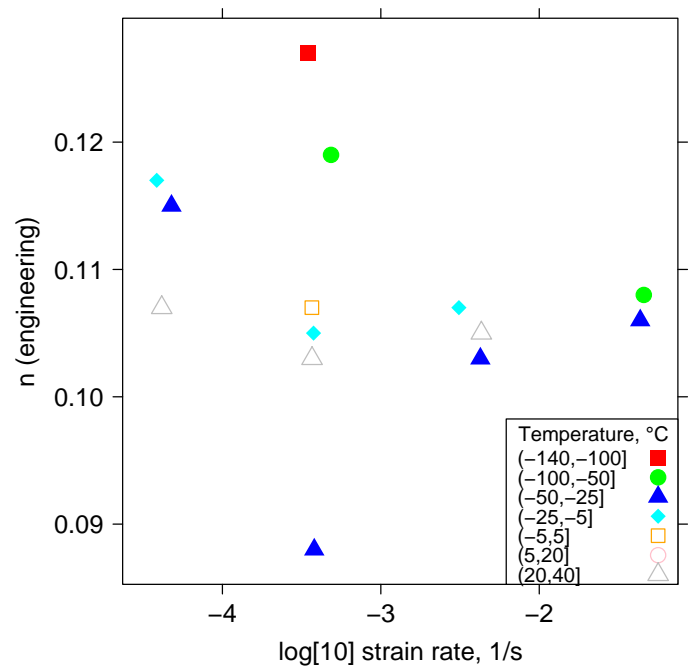

(b) $n_{e}$

Figure 60: $K_{e}$ and $n_{e}$.

loading strain using the modulus from Eq. 54 and the temperature-dependent plastic strain obtained from Eq. (41):

$$
E(T) e=K_{0 e}(T) e^{n_{e}}
$$


Table 9: Linear analysis of the dependence of $n$ on temperature and strain rate.

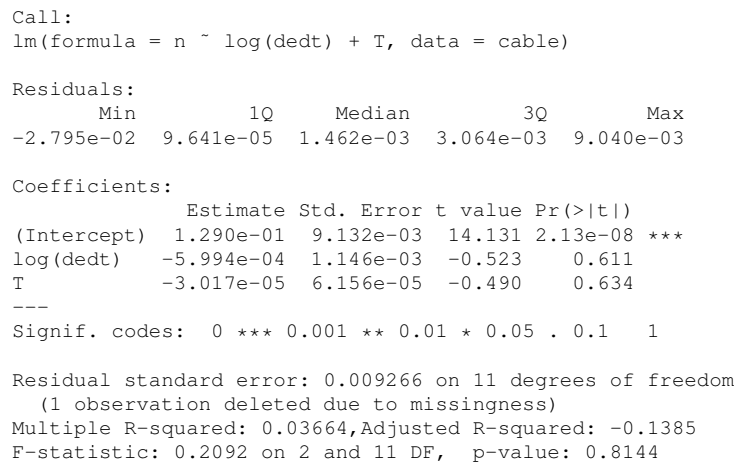

Table 10: Terms in the Johnson-Cook equation (Eq. 37).

\begin{tabular}{cc}
\hline Parameter & Definition \\
\hline$A$ & Yield strength \\
$B$ & equivalent plastic strain \\
$\epsilon$ & equivalent plastic strain rate \\
$\dot{\epsilon}$ & strain rate sensitivity \\
$\dot{\epsilon}_{0}$ & evaluation temperature \\
$C$ & melting point, $T=1534{ }^{\circ} \mathrm{C}$ \\
$T$ & reference temperature, $T=0 \mathrm{~K}$ \\
$T_{m}$ & temperature function exponent \\
$T_{R}$ &
\end{tabular}

and solving for the intersection point as a function of temperature.

$$
S_{i}=\left(\frac{E(T)^{n_{e}}}{K_{0 e}\left(1-\left(\frac{T-T_{R}}{T_{m}-T_{R}}\right)^{m_{e}}\right)}\right)^{\frac{1}{n_{e}-1}}
$$

Figure 64 shows the value of this "yield strength," $S_{i}$, as a function of temperature.

The engineering strain at the tensile strength, $e_{T S}$, below room temperature should assumed to be constant: $\bar{e}_{T S}=0.057$.

The behavior of the tensile strength, $T S$, below room temperature can be estimated from Eq. (41) using $e=e_{T S}$. Figure 65 shows the tensile strength, $T S$, calculated from Eq. 41. For comparison, the mean value of the measured room-temperature tensile strength is $\overline{T S} S_{20}=1784 \mathrm{MPa}$. 


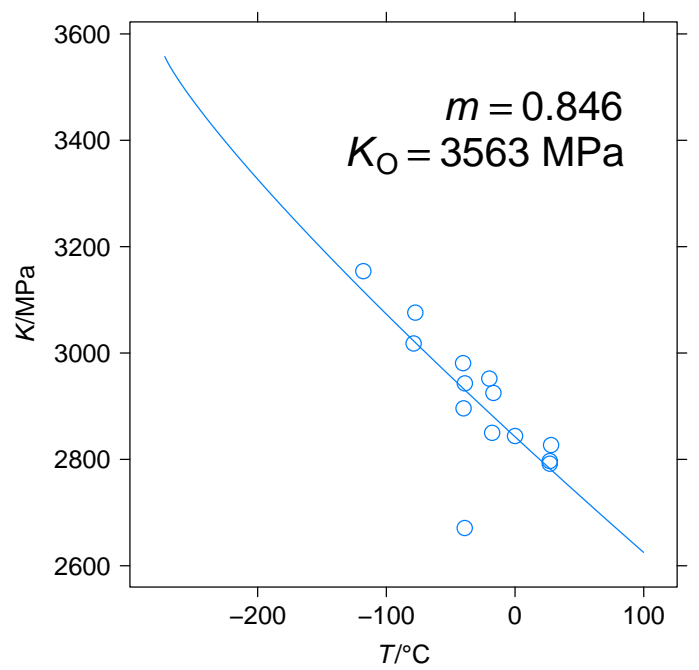

(a) True stress

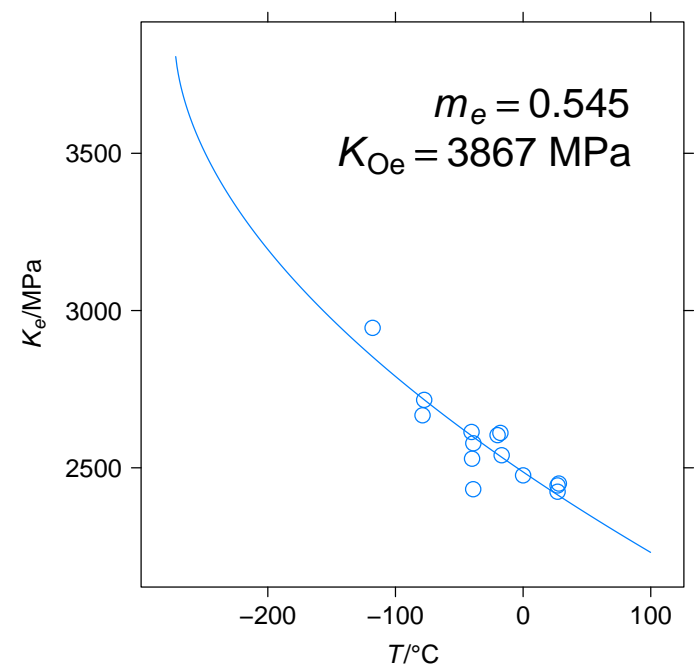

(b) Engineering stress

Figure 61: Analysis of the $m$ and $m_{e}$ exponents for the Johnson-Cook equation for $K$ and $K_{e}$ for (a) true and (b) engineering stress-strain behavior.

Table 11: Linear analysis of the dependence of $K$ on temperature using Eq. (38).

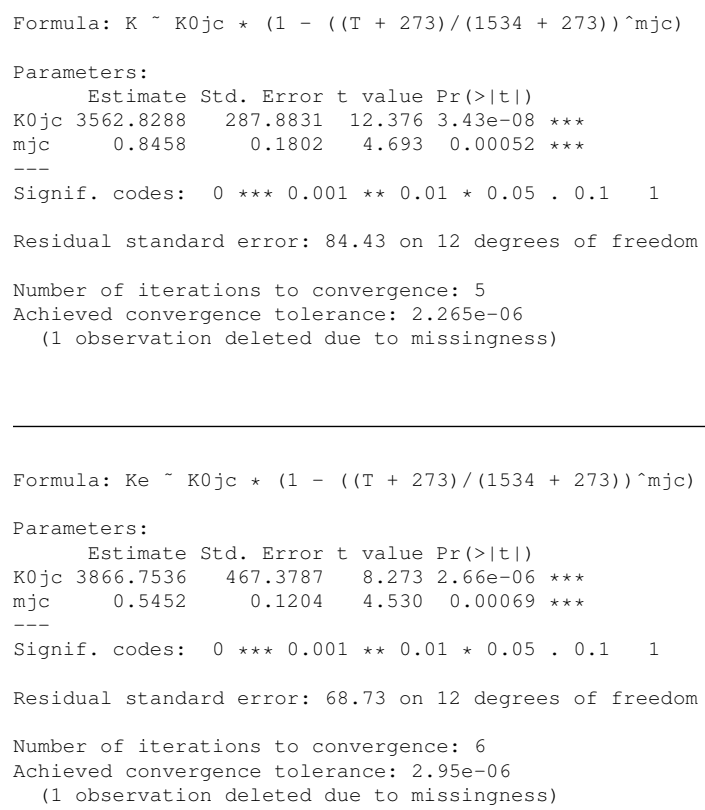

In the table the terms in Eq. 38 are $K_{0}=\mathrm{K} 0 \mathrm{jc} m=\mathrm{mjc}, K_{0 e}=\mathrm{K} 0$ ejc, $m_{e}=\mathrm{mejc}, T_{R}=0 \mathrm{~K}$, and $T_{m}=1534^{\circ} \mathrm{C}$. 
Table 12: Values of the Johnson-Cook parameters for predicting true and engineering stress-strain below room temperature using Eqs. (38) and (39).

\begin{tabular}{lr}
$K_{0}$ & $3563 \mathrm{MPa}$ \\
$m$ & 0.846 \\
$n$ & 0.134 \\
$K_{0 e}$ & $3867 \mathrm{MPa}$ \\
$m_{e}$ & 0.545 \\
$n_{e}$ & 0.108 \\
$T_{m}$ & $1534^{\circ} \mathrm{C}$ \\
$T_{R}$ & $-273.15^{\circ} \mathrm{C}$ \\
\hline
\end{tabular}

\subsubsection{Temperature dependence for high temperature}

Background and assumptions The stress-strain behavior above room temperature can also be described with a power-law work-hardening model, Eq.(35), where the two terms $K$ and $n$ can depend on temperature. No experimental data exist, so the curves must be estimated using literature information. Creating stress-strain curves for high-temperature deformation requires a number of assumptions. The following paragraphs describe the limitations of those assumptions.

Stress-true strain behavior can be estimated by a power law. Previous unpublished work modeled the stress-strain behavior as a function of temperature by making $K$ and $n$ in Eq. (35) and $K_{e}$ and $n_{e}$ in Eq. (36) depend on temperature:

$$
\begin{aligned}
& \sigma=K(T) \epsilon^{n(T)} \\
& S=K_{e}(T) e^{n_{e}(T)}
\end{aligned}
$$

where the prefactor and stress exponents take the form

$$
\begin{gathered}
K(T)=k_{0} \exp \left(-\left(\frac{T}{k_{2}}\right)^{k_{1}}\right) \\
K_{e}(T)=k_{e 0} \exp \left(-\left(\frac{T}{k_{2}}\right)^{k_{1}}\right)
\end{gathered}
$$

and

$$
\begin{aligned}
n(T) & =n_{0} \exp \left(-\left(\frac{T}{n_{2}}\right)^{n_{1}}\right) \\
n_{e}(T) & =n_{e 0} \exp \left(-\left(\frac{T}{n_{2}}\right)^{n_{1}}\right)
\end{aligned}
$$

Note that temperature dependence of the strength degradation will be the same for both true and engineering units. Insufficient data exist to estimate the behavior of $n(T)$ or $n_{e}(T)$, so in this the work hardening exponent can be assumed to be independent of temperature with a value equal to the average value measured in all the low-temperature tests: $n(T)=\bar{n}$ and $n_{e}(T)=\bar{n}_{e}$. 


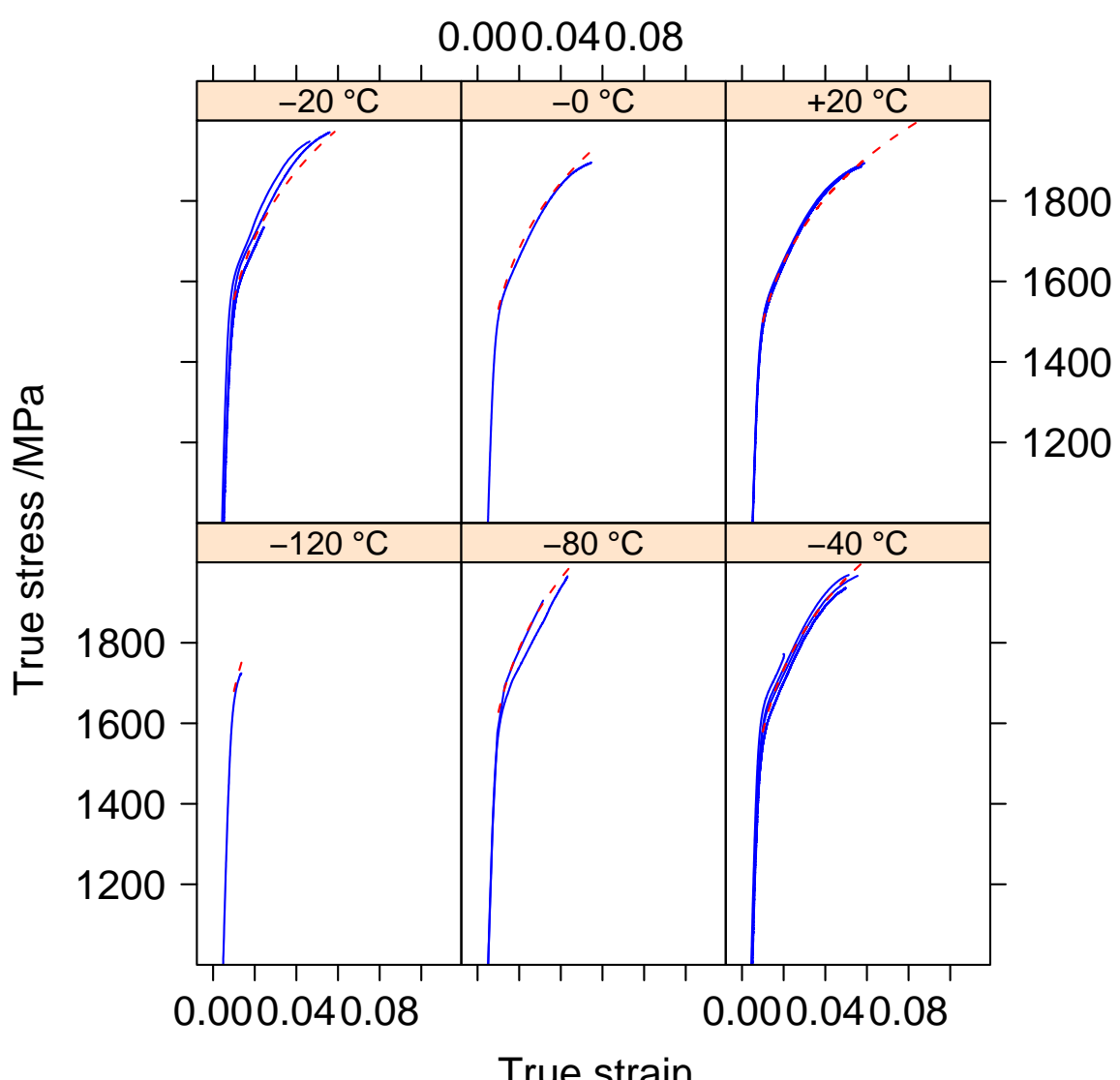

Figure 62: Comparison of the fits (dashed red line) to the true stress-strain data evaluated using Eq. 40).

Literature bolt tensile strength can be used to estimate the stress-strain behavior. No data exist on the high-temperature properties of suspension bridge cable, so it is necessary to model the strength degradation. The wire is made from a eutectoid steel that has been work hardened.[7] One possible model for estimating the strength degradation with temperature is the behavior of bolt steel, for which literature data exist.[16], [17], [18] The NIST World Trade Center collapse report [19] indicated that the strength of bolt steel degrades with temperature faster than ordinary construction steel. Figure 66a shows the degradation of the tensile strength of bolt steel from two sources [17][20], and Figure 66p shows the corresponding change for the yield strength. In both plots the values are normalized to the room-temperature value. Analysis used in the World Trade Center collapse investigation[19] indicate that de-rating by the change in of the tensile strength rather than the yield strength provides better fidelity for steels with unmeasured properties.

Figure 66a also plots the non-linear fit to the data of the form

$$
T S=k_{0} \exp \left(-\left(\frac{T}{k_{2}}\right)^{k_{1}}\right)
$$




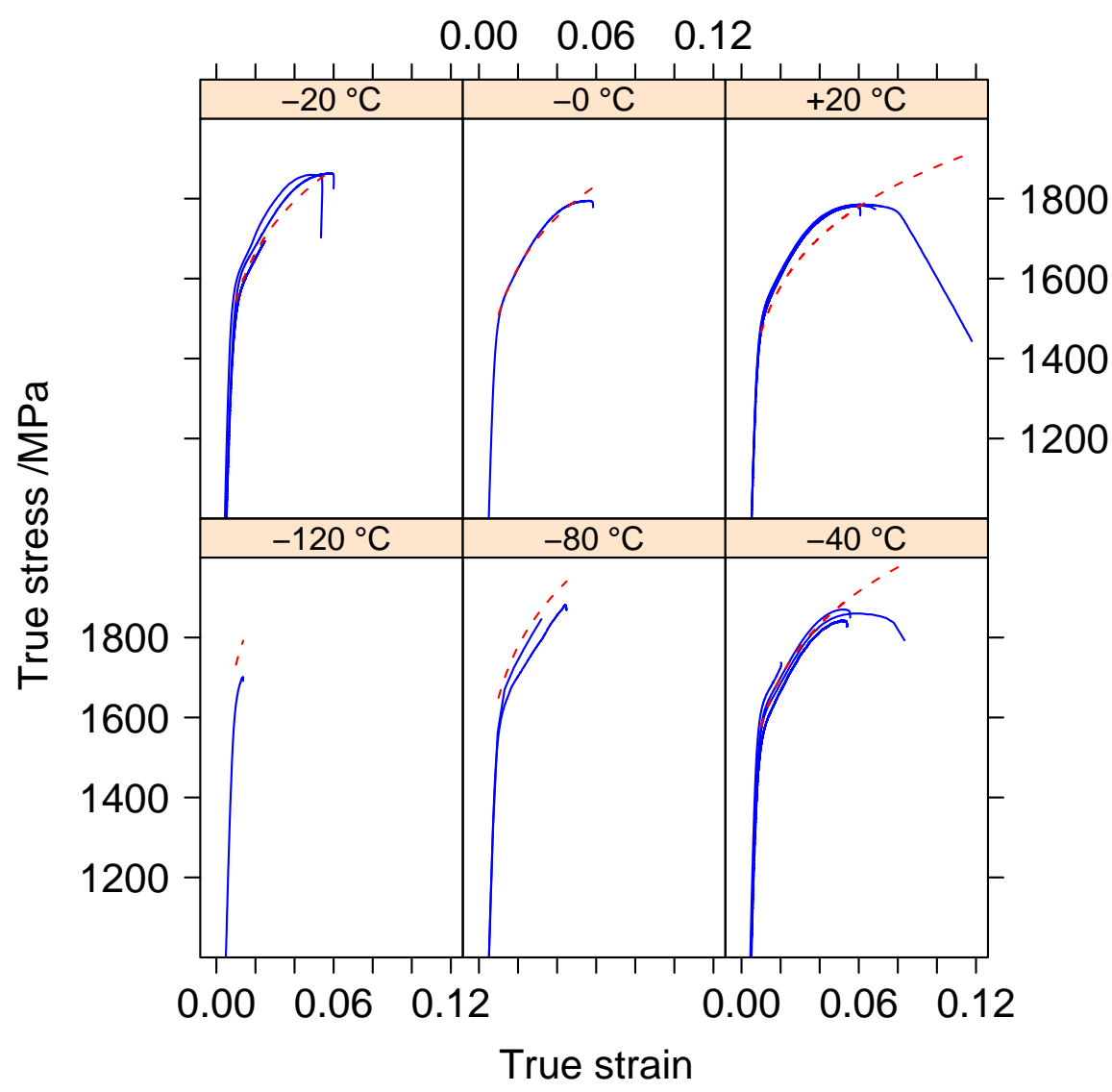

Figure 63: Comparison of the fits (dashed red line) to the engineering stress-strain data evaluated using Eq. 41 .

with $k_{0}=1$. The fit was computed using the $\mathrm{n} l \mathrm{~s}$ non-linear fitting routine of the $\mathrm{R}$ statistical language.[14]. The values computed are $k_{1}=3.711 \pm 0.4881$ and $k_{2}=(587.3 \pm 14.09){ }^{\circ} \mathrm{C}$. Table 13 summarizes the fit statistics of the linear model used to calculate $k_{1}$ and $k_{2}$.

The predictions of stress-strain behavior for low and high temperature should agree at room temperature. The low- and high-temperature strength models use different formalisms, but their room temperature predictions should agree. The values are

- $K\left(T=20^{\circ} \mathrm{C}\right)=2798 \mathrm{MPa}$

- $\bar{n}=0.134$

- $K_{e}\left(T=20^{\circ} \mathrm{C}\right)=2433 \mathrm{MPa}$

- $\bar{n}_{e}=0.108$ 


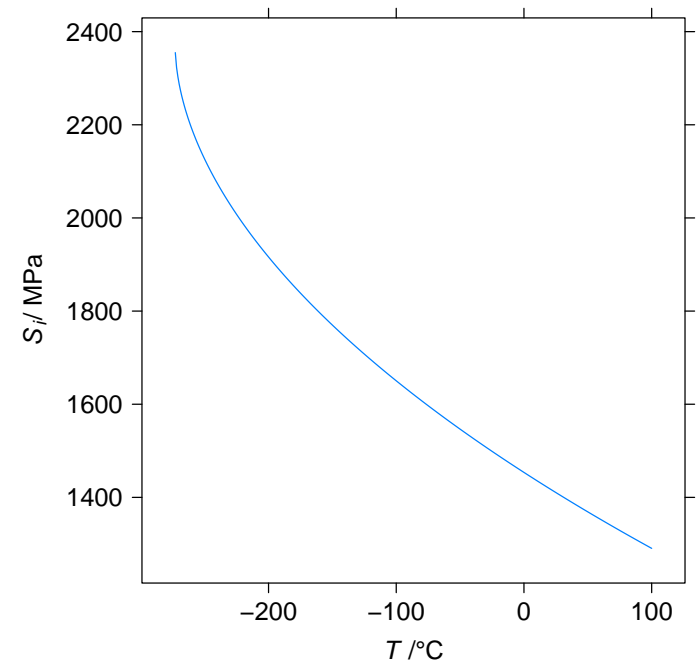

Figure 64: Yield stress, $S_{i}$, of the intersection of the elastic loading with the plastic deformation.

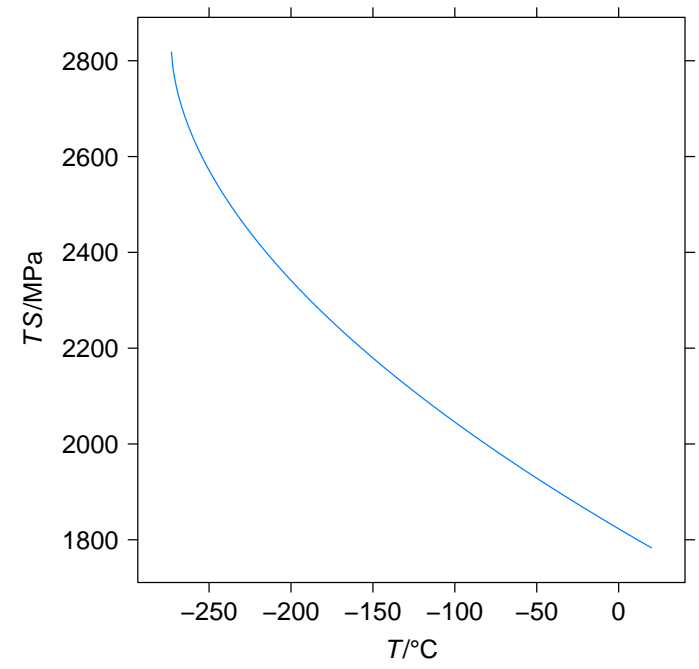

Figure 65: Tensile strength, TS, below room temperature calculated from Eq. 41) with $e=\bar{e}_{T S}=$ 0.057 .

where $K$ is predicted from Eq.(38), $K_{e}$ is predicted from Eq. (39), and $\bar{n}$ and $\bar{n}_{e}$ are calculated as the average of all the work hardening exponents in the low-temperature tests, Table 6. These can be equated to the prefactors in Eq.(47) and (49):

$$
\begin{gathered}
k_{0}=K\left(T=20{ }^{\circ} \mathrm{C}\right) \\
n_{0}=\bar{n}
\end{gathered}
$$

The mean values from the three room-temperature tests are $\bar{K}_{20}=2805 \mathrm{MPa}$ and $\bar{n}_{20}=0.135$, which are quite similar to the predicted values. 


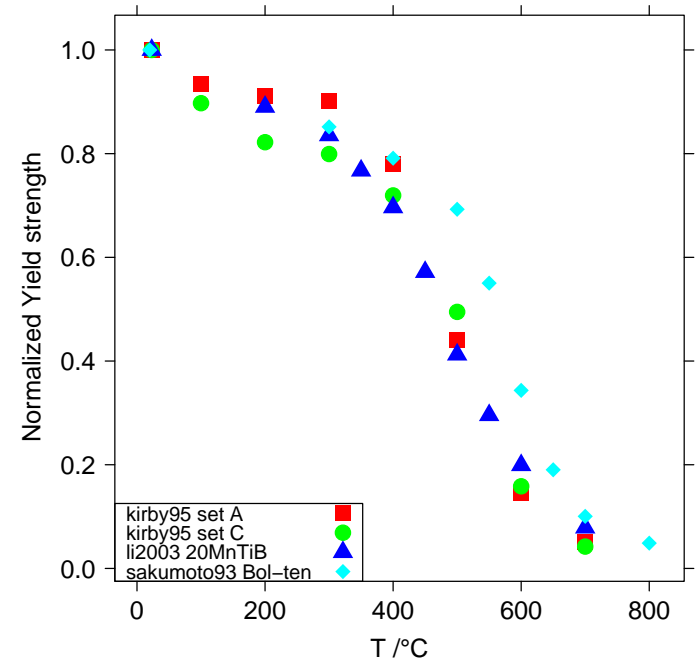

(a) Yield strength

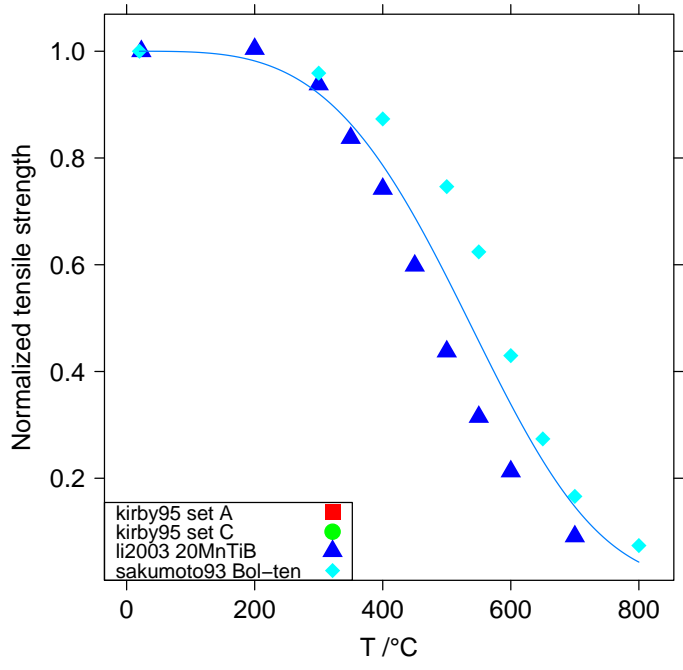

(b) Tensile strength

Figure 66: Degradation of (a) yield and (b) tensile strength of bolt steel with temperature. Data from three sources: kirby95[16], li2003[17], sakumoto93[18]

Table 13: Fit statistics calculated using nls for the degradation of tensile strength with temperature

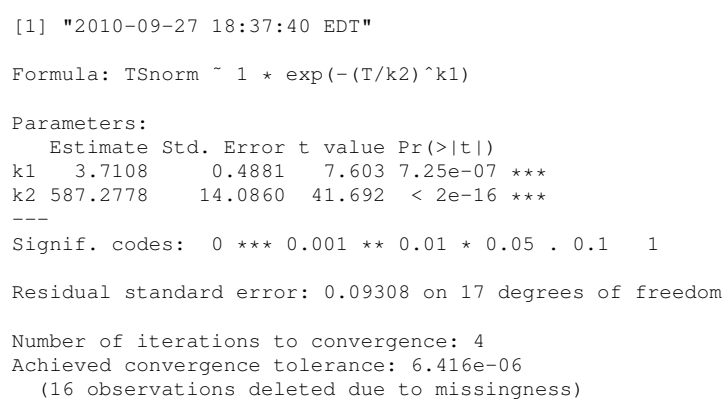

In this table TSnorm is the normalized tensile strength, $\mathrm{k} 1=k_{1}$ and $\mathrm{k} 2=k_{2}$.

The dependence of work hardening on temperature can be neglected. Insufficient data exist to model the work hardening as a function of temperature.

The behavior of the elastic modulus with temperature can be taken from the NIST World Trade Center Report. Assume that the elastic modulus of the wire, E, can be represented using the data from the NIST World Trade Center collapse report[19] equation 2-2.

$$
E=e_{0}+e_{1} T+e_{2} T^{2}+e_{3} T^{3}
$$

where

$$
\text { - } e_{0}=206.0 \mathrm{GPa} \text {, }
$$


- $e_{1}=-0.04326 \mathrm{GPa} /{ }^{\circ} \mathrm{C}$,

- $e_{2}=-3.502 \times 10^{-5} \mathrm{GPa} /{ }^{\circ} \mathrm{C}^{2}$

- $e_{3}=-6.592 \times 10^{-8} \mathrm{GPa} /{ }^{\circ} \mathrm{C}^{3}$.

Recommended value for stress-strain behavior above room temperature The recommended method for computing stress-strain curves for temperatures above room temperature is

$$
\begin{array}{r}
\sigma=k_{0} \exp \left(-\left(\frac{T}{k_{2}}\right)^{k_{1}}\right) \epsilon^{\bar{n}} \\
S=k_{0 e} \exp \left(-\left(\frac{T}{k_{2}}\right)^{k_{1}}\right) e^{\bar{n}_{e}}
\end{array}
$$

where

- $k_{0}=2798 \mathrm{MPa}$

- $k_{0 e}=2433 \mathrm{MPa}$

- $k_{1}=3.722$

- $k_{2}=586.8{ }^{\circ} \mathrm{C}$

- $\bar{n}=0.134$

- $\bar{n}_{e}=0.108$

and temperatures are measured in ${ }^{\circ} \mathrm{C}$.

If the strain is solved in terms of the stress, the recommended values become

$$
\begin{aligned}
& e= \begin{cases}\frac{S}{E(T)} & \text { if } S<S_{h t} \\
\left(\frac{S}{K_{0 e} \exp \left(-\left(\frac{T}{k_{2}}\right)^{k_{1}}\right)}\right)^{1 / n_{e}} & \text { if } S \geq S_{h t}\end{cases} \\
& \epsilon= \begin{cases}\frac{\sigma}{E(T)} & \text { if } \sigma<\sigma_{h t} \\
\left(\frac{\sigma}{K_{0} \exp \left(-\left(\frac{T}{k_{2}}\right)^{k_{1}}\right)}\right)^{1 / n} & \text { if } \sigma \geq \sigma_{h t}\end{cases}
\end{aligned}
$$




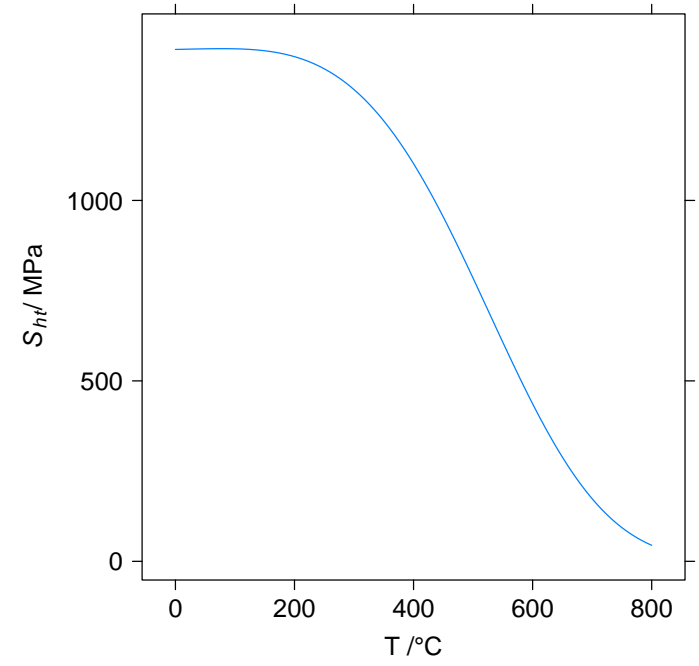

Figure 67: Yield stress, $S_{h t}$ of the intersection of the elastic loading with the plastic deformation.

where $S_{h t}$ and $\sigma_{h t}$ are "yield strengths" calculated from the intersection of the temperature-dependent elastic loading strain using the modulus from Eq. 54 and the plastic strain from Eq. 55 or Eq.:

$$
S_{h t}=\left(\frac{E(T)^{n_{e}}}{K_{0 e} \exp \left(-\left(\frac{T}{k_{2}}\right)^{k_{1}}\right)}\right)^{\frac{1}{n_{e}-1}}
$$

and the values in Table 12. Figure 67 shows the value of this "yield strength" as a function of temperature.

Figure 68 plots the stress-strain curves from Eq. [56]. For stresses below the yield strength, $S_{h t}$ the stress is the predicted from the elastic behavior using Eq.(54). The behavior of the tensile strength, should it be needed, can be modeled using the Eq.(51):

$$
T S=\bar{T} S_{20} \exp \left(-\left(\frac{T}{k_{2}}\right)^{k_{1}}\right)
$$

where $\bar{T} S_{20}=1784 \mathrm{MPa} k_{1}=3.711 \pm 0.4881$ and $k_{2}=(587.3 \pm 14.09)^{\circ} \mathrm{C}$.

High-temperature ductility The ductility of steel increases with increasing temperature, see for example the NIST World Trade Center collapse report.[19] But the engineering strain, $e_{T S}$, at the strain location of the tensile strength generally decreases with increasing temperature, see Figs 69 and 70, which plot data on structural steels tested as part of the NIST World Trade Center collapse investigation[19]. The strain at the tensile strength can be normalized to its roomtemperature value to try to create a universal curve to predict its behavior, Fig 71. The behavior 


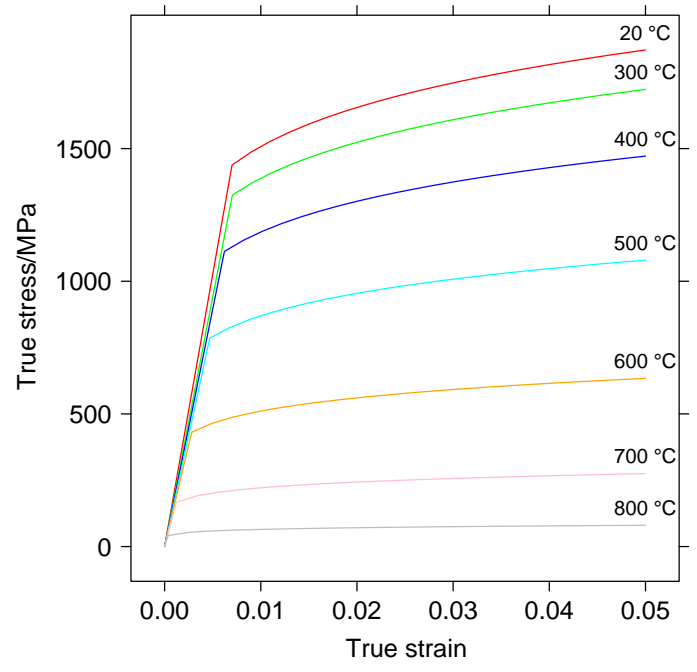

(a) True stress

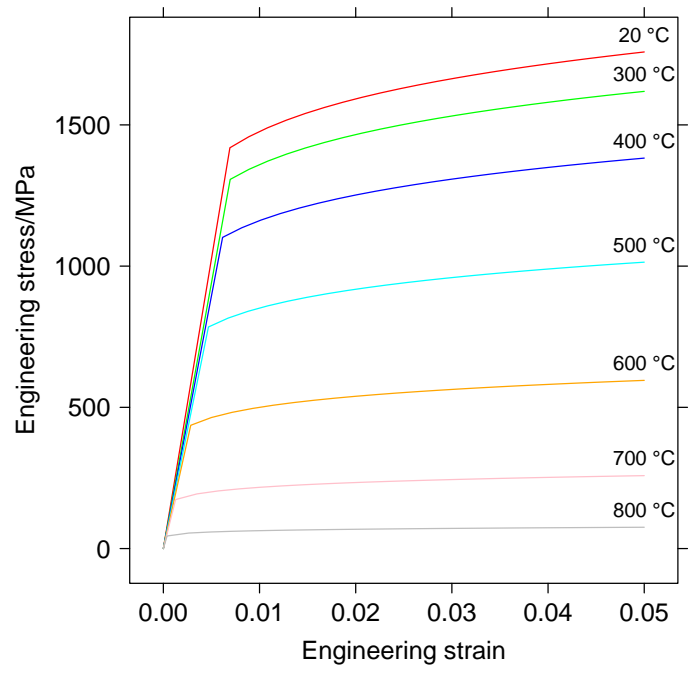

(b) Engineering stress

Figure 68: High-temperature stress-strain behavior for (a) true and (b) engineering stress

Table 14: Fit statistics calculated using n 1 s for the degradation of normalized strain at the tensile strength, $e_{T S}$, with temperature

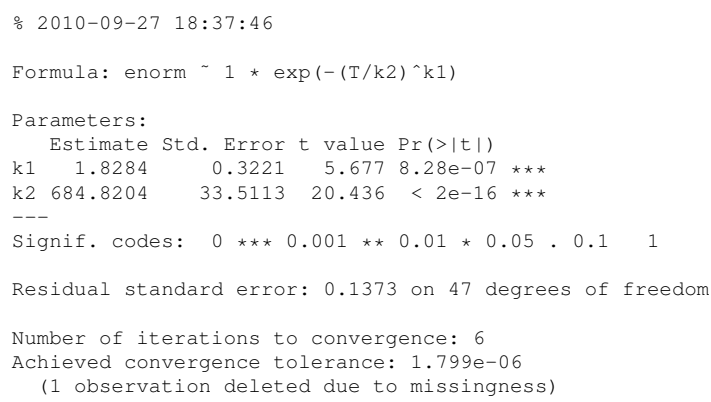

In this table enorm is the normalized engineering strain at the tensile strength, $\mathrm{k} 1=k_{1}$ and $\mathrm{k} 2=k_{2}$.

can be represented in the same manner as the tensile strength, Eq. 51).

$$
e_{T S}=\bar{e}_{T S} \exp \left(-\left(\frac{T}{k_{2}}\right)^{k_{1}}\right)
$$

where $\bar{e}_{T S}=0.057 k_{1}=1.828 \pm 0.3221$ and $k_{2}=(684.8 \pm 33.51){ }^{\circ} \mathrm{C}$. The solid line in Fig. 71 is the non-linear regression of the normalized data for the engineering strain at the tensile strength. Table 14 summarizes the results of the fit. The values computed are $k_{1}=1.828 \pm 0.3221$ and $k_{2}=(684.8 \pm 33.51){ }^{\circ} \mathrm{C}$ 


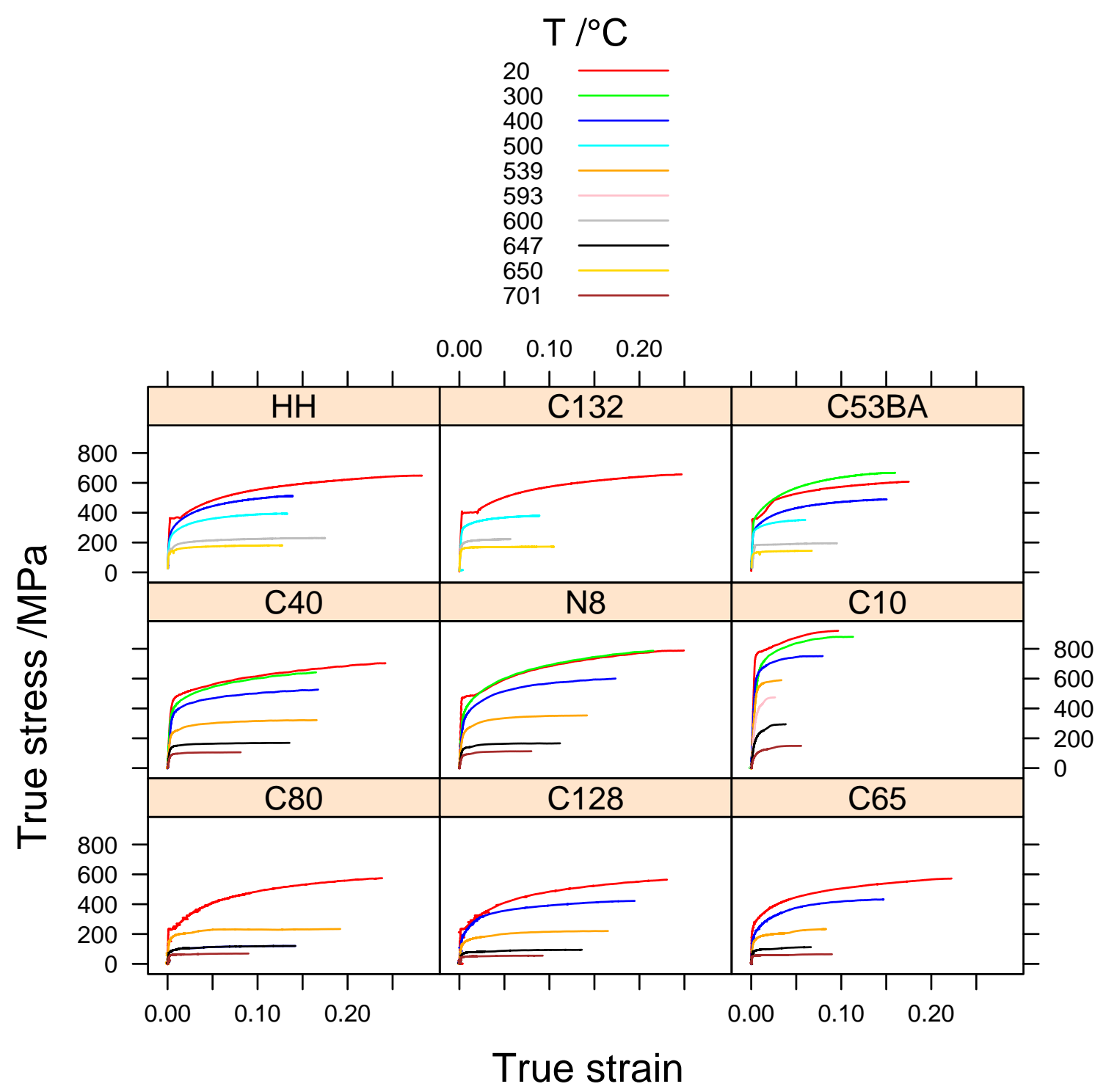

Figure 69: True stress-strain behavior as a function of temperature for nine steels analyzed in the NIST WTC investigation. Curves terminate at the tensile strength. Strips at the top of each subfigure identify the specimen code of the steel. Data source: [19]

\subsubsection{Intersection of high- and low-temperature predictions}

The temperature dependence of the stress-strain behavior above and below room temperature differ. Below room-temperature, the temperature dependence uses the Johnson-Cook[15] equation, Eq. (38) and the stress-strain behavior is predicted by Eq.40) or (41). Above room temperature, the temperature dependence is similar to that used to describe steels in the NIST WTC report[19] and the stress-strain behavior is predicted by Eq. (55) or (56). Figure 72 shows that the stress-strain behavior above and below room temperature is consistent. 


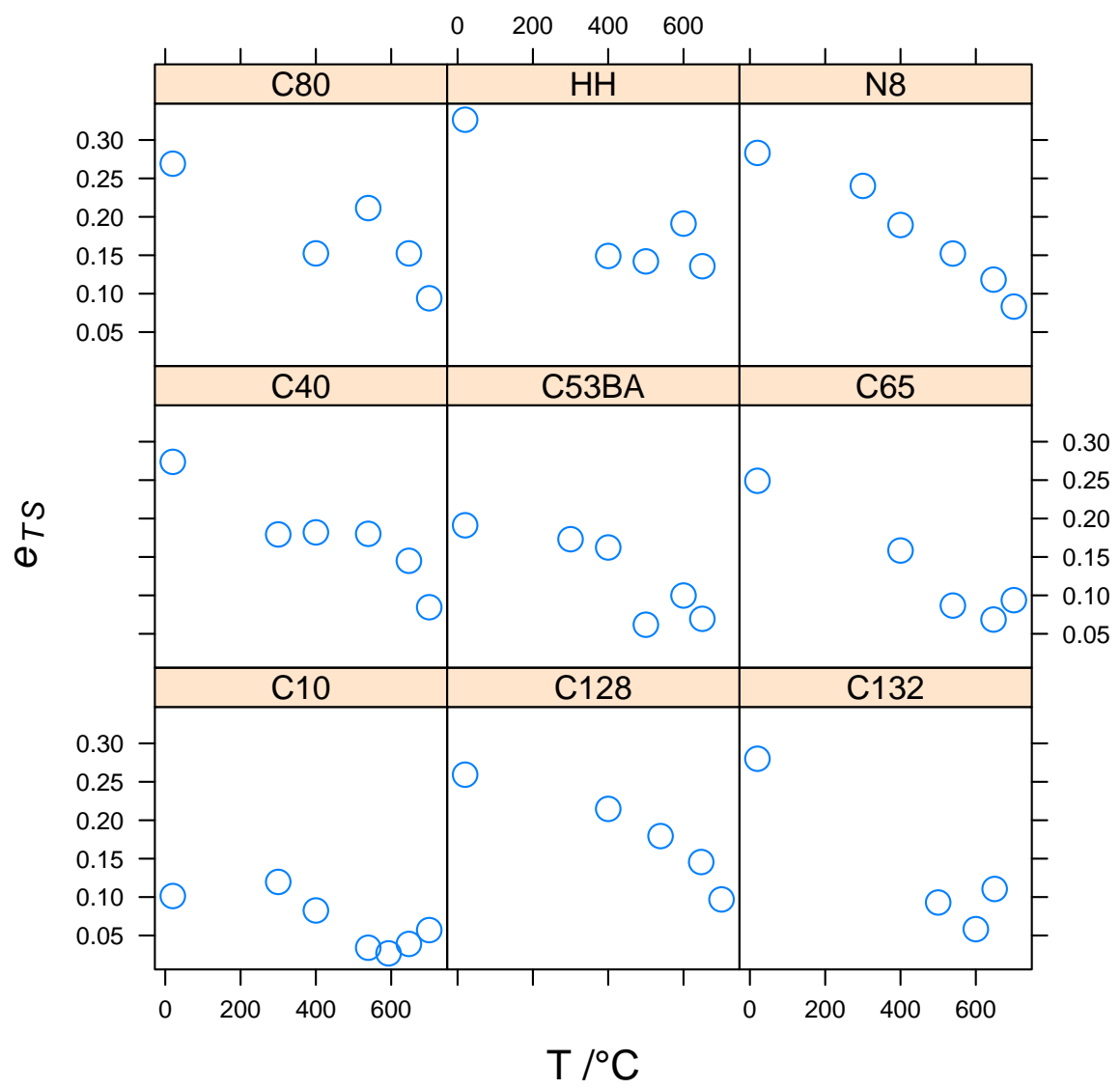

Figure 70: Engineering strain at the tensile strength for nine steels analyzed in the NIST WTC investigation. Strips at the top of each subfigure identify the specimen code of the steel. Data source: [19]

\subsubsection{Toughness as a function of temperature}

Mahmoud[10] evaluated the room-temperature fracture toughness of actual bridge wire from precracked specimens and reported a value $K_{I c}=65.7 \mathrm{MPa} \cdot \mathrm{m}^{1 / 2}$. Data on toughness as a function of temperature, even including Charpy data, for wire steels, however are unavailable. Searches for data used the Web of Science[21] using search terms (Charpy and wire), (toughness and wire), (toughness and pearlite). Another source of mechanical property data, Matweb[22], an on-line metal property database, has no low-temperature Charpy data on AISI 1070 or 1080 steel, which are chemically close to the composition of the bridge wire. Shoemaker and Rolfe[23] reported the low-temperature toughness of low-carbon structural steels for temperatures below their nilductility transition (NDT) temperatures. Figure 73 plots the fracture toughness, $K_{I c}$, as a function of temperature, for temperatures below the nil-ductility-transition temperature, NDT, of three lowcarbon construction steels. Figure 74 replots that data, but normalizes the fracture toughness of each steel to its maximum value, $K_{I c}^{\max }$, and expresses the temperature as the temperature below the NDT. The solid line is a linear regression of the normalized toughness $k=K_{I c} / K_{I c}^{\max }$ to 


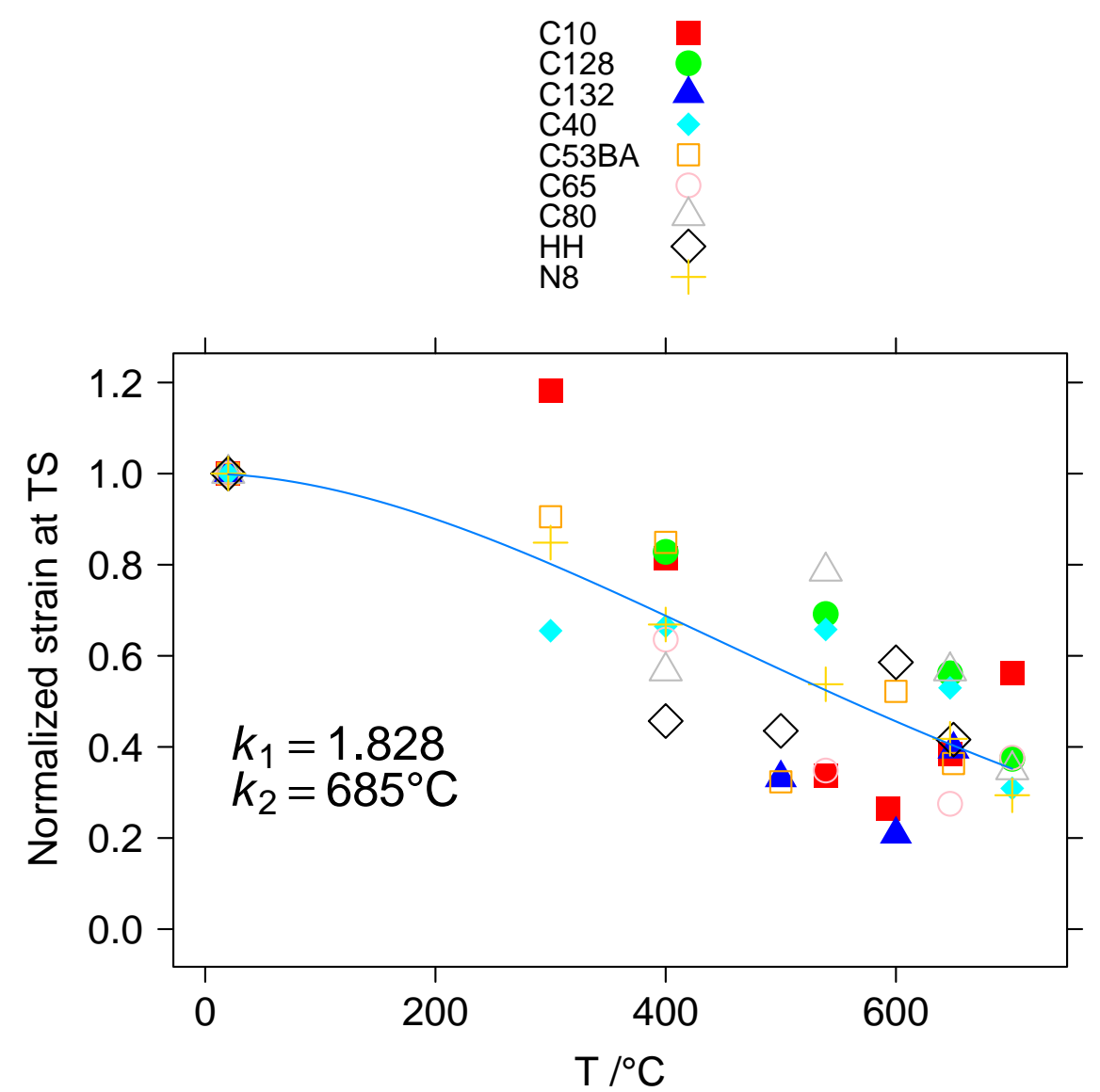

Figure 71: Engineering strain at the tensile strength, normalized to the room-temperature value for nine steels analyzed in the NIST WTC investigation. Data source: [19]

temperature below the nil-ductility transition temperature, $T$-NDT. The slope of the regression is $d k / d(T-\mathrm{NDT})=2.7557 \times 10^{-3} 1 / \mathrm{K}$. Since the data from Shoemaker[23] extend to liquid nitrogen temperature, this regression might be useful in estimating the decrease in toughness with temperature. Unfortunately, the NDT of the bridge wire is unknown. It might be reasonable to assume that the NDT is room temperature, however. Using that assumption (NDT=293 K), the toughness as a function of temperature would be

$$
K_{I c}(T)=K_{I c}(T=293 \mathrm{~K})+K_{I c}(T=293 \mathrm{~K}) \frac{d k}{d T}(T-293 \mathrm{~K})
$$

where $K_{I c}(T=293 \mathrm{~K})=65.7 \mathrm{MPa} \cdot \mathrm{m}^{1 / 2}$.

\section{Acknowledgements}

WEL thanks Dr. Raimondo Betti of Columbia University and Dyab Khazem of Parsons Inc. for supplying the $30 \mathrm{~m}$ spool of wire used in this study. 


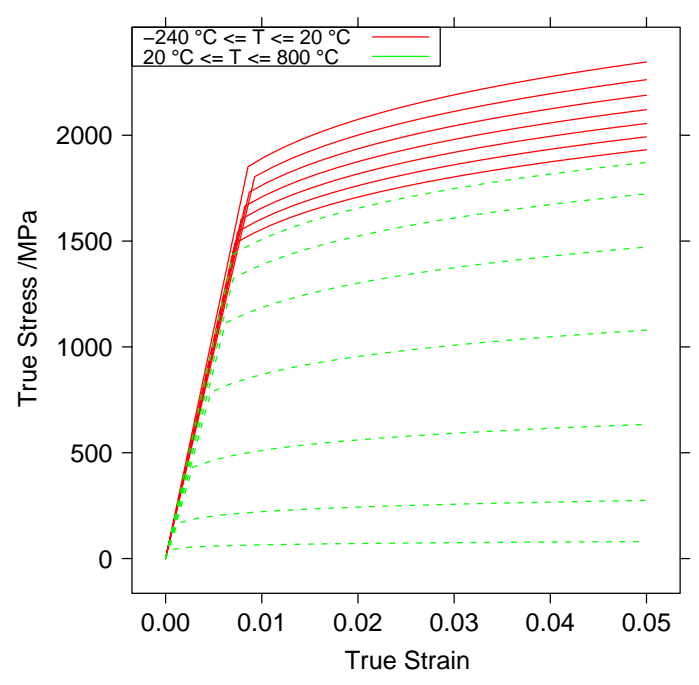

(a) True stress

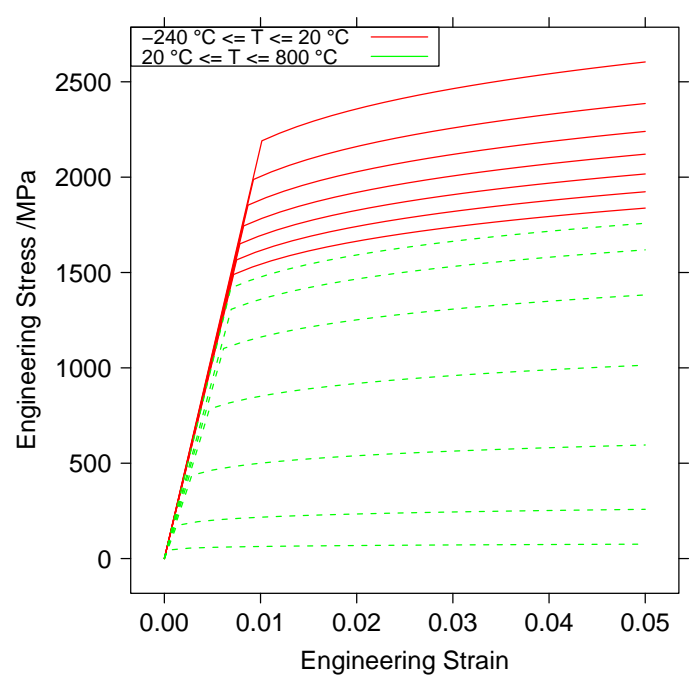

(b) Engineering stress

Figure 72: Comparison of predicted (a) true and (b) engineering stress-strain behavior above and below room temperature.

\section{References}

[1] Y. S. Touloukian and E. H. Buyco. Specific heat: metallic elements and alloys. Thermophysical properties of matter, v. 4. IFI/Plenum, New York, 1970.

[2] Minoru Umemoto and Koichi Tsuchiya). Fundamental properties of cementite and their present understanding. Tetsu-to-Hagane, 88(3):117-128, 2002. Available from: http: //www.journalarchive.jst.go.jp/english/jnlabstract_en.php? cdjournal=tet sutohagane $1955 \& \mathrm{cdvol}=88 \&$ noissue=3\&startpage=117.

[3] M. Umemoto, Z. G. Liu, K. Masuyama, and K. Tsuchiya. Influence of alloy additions on production and properties of bulk cementite. Scripta Materialia, 45(4):391 - 397, 2001. doi:10.1016/S1359-6462(01)01016-8.

[4] Y. S. Touloukian. Thermal Conductivity: Metallic Elements and Alloys. Thermophysical properties of matter, v. 1. IFI/Plenum, New York, 1970.

[5] Y. S. Touloukian. Specific expansion: metallic elements and alloys. Thermophysical properties of matter, v. 12. IFI/Plenum, New York, 1975.

[6] R. M. Mayrbaurl and S. Camo. Cracking and fracture of suspension bridge wire. Journal of Bridge Engineering, 6(6):645-650, 2001. doi:10.1061/(ASCE) 1084-0702 (2001) $6: 6(645)$.

[7] National Cooperative Highway Research Program. Guidelines for inspection and strength evaluation of suspension bridge parallel wire cables. Report 534, Transportation Re- 


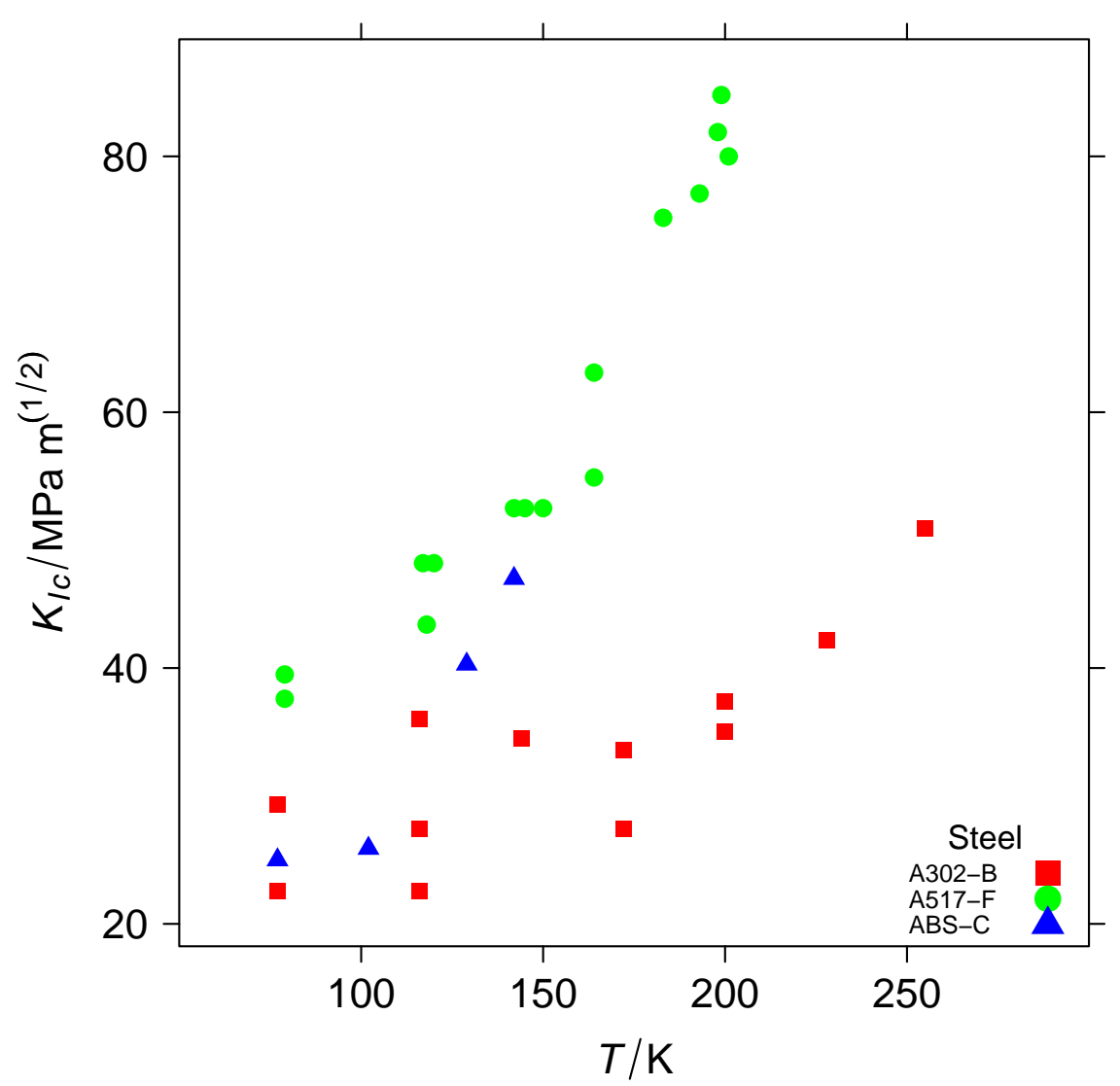

Figure 73: Fracture toughness, $K_{I c}$, of three structural steels below their nil-ductility transition temperature, NDT, evaluated at low rate, using fracture mechanics specimens. Data source: [23]

search Board of the National Academies, Washington, DC, 2005. Available from: http: //onlinepubs.trb.org/onlinepubs/nchrp/nchrp_rpt_534.pdf

[8] Gongkan Fu, Fred Moses, and Dyab A. Khazem. Strength of parallel wire cables for suspension bridges. In A. Kareem, A. Haldar, B.F. Spencer, and E. A. Johnson, editors, Proceedings of the 8th ASCE Specialty Conference on Probabalistic Mechanics and Structural Reliability, number PMC2000-222, 2000. University of Notre Dame, Notre Dame, Indiana, July 24-26, 2000 .

[9] Bamdad Pourladian. Fracture Toughness Evaluation of High-strength Cold-drawn Eutectoid Steel Wires used in Wire Ropes. PhD thesis, University of Kansas, Mechanical Engineering, 1999. OCLC 42257060.

[10] K. M. Mahmoud. Fracture strength for a high strength steel bridge cable wire with a surface crack. Theoretical and Applied Fracture Mechanics, 48:152-160, 2007. doi:10.1016/ j.tafmec.2007.05.006. 


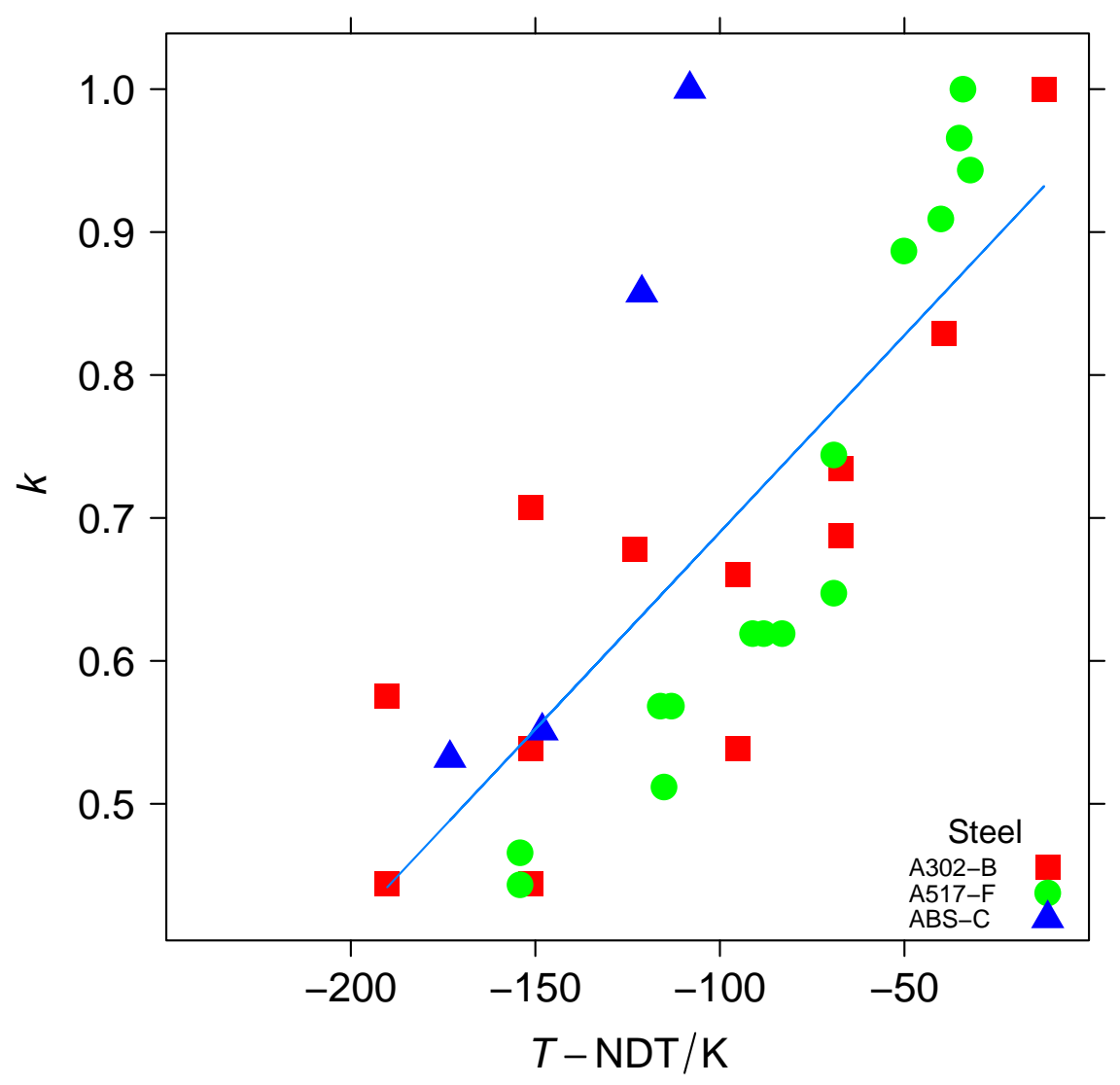

Figure 74: Normalized fracture toughness, $k=K_{I c} / K_{I c}^{\max }$, normalized to maximum value near NDT, of structural steels below their nil-ductility transtion temperature, NDT, evaluated at low rate, using fracture mechanics specimens. Data source: [23].

[11] Eric M. Taleff, John J. Lewandowski, and Bamdad Pourladian. Microstructure-property relationships in pearlitic eutectoid and hypereutectoid carbon steels. JOM-Journal of the Minerals Metals \& Materials Society, 54(7):25-30, JUL 2002. doi:10.1007/BF02700982.

[12] R. Gostautas, M. Carlos, R. Finlayson, R. Betti, and D. Khazem. Structural health monitoring of suspension bridge cables. In Chang, FK, editor, Structural Health Monitoring 2007: Quantification, Validation, And Implementation, Vols 1 AND 2, pages 315-321, 439 Duke Street, Lancaster, PA 17602-4967 USA, 2007. Destech Publications, Inc. 6th International Workshop on Structural Health Monitoring, Stanford, CA, Sep 11-13, 2007.

[13] ASTM International. Standard test methods for tension testing of metallic materials [metric]. Standard E8/E8M-09, ASTM International, W. Conshohocken, Pa, 2002. doi:10.1520/ E0008_E0008M-09.

[14] R Development Core Team. R: A Language and Environment for Statistical Computing. R Foundation for Statistical Computing, Vienna, Austria, 2008. ISBN 3-900051-07-0. Avail- 
able from: http://www.R-project.org.

[15] G. R. Johnson and W. H. Cook. A constitutive model and data for metals subjected to large strains, high strain rates and high temperatures. In Proceedings, Seventh International Symposium on Ballistics, the Hague, the Netherlands, 19-21 April, 1983, pages 541-547. American Defense Preparedness Association and Koninklijk Instituut van Ingenieurs, 1983.

[16] B. R. Kirby. The behaviour of high-strength grade 8.8 bolts in fire. J. Construct. Steel. Research, 33(1-2):3-38, 1995. doi:10.1016/0143-974X(94)00013-8.

[17] G. Q. Li, S. C. Jiang, Y. Z. Yin, K. Chen, and M. F. Li. Experimental studies on the properties of constructional steel at elevated temperatures. J. Struct. Engineering-ASCE, 129:17171721, 2003. doi:10.1061/(ASCE) 0733-9445(2003) 129:12(1717).

[18] Y. Sakumoto, K. Keira, F. Furumura, and T. Ave. Tests of fire-resistant bolts and joints. Journal of Structural Engineering, 119(11):3131-3150, 1993. doi:10.1061/(ASCE) 0733-9445(1993) 119:11(3131).

[19] William E. Luecke, J. David McColskey, Christopher N. McCowan, Stephen W. Banovic, Richard J. Fields, Timothy Foecke, Thomas A. Siewert, and Frank W. Gayle. Federal building and fire safety investigation of the world trade center disaster: Mechanical properties of structural steel. Technical Report NCSTAR 1-3D, National Institute of Standards and Technology, 2005. Available on-line at http://wtc.nist.gov. Available from: http://wtc.nist.gov/ NCSTAR1/PDF/NCSTAR201-3D\%20Mechanical\%20Properties.pdf.

[20] Y. Sakumoto. Research on new fire-protection materials and fire-safe design. J. Struct. Engineering-ASCE, 125(12):1415-1422, 1999. doi:10.1061/(ASCE) 0733-9445(1999) 125:12(1415).

[21] ISI Web of Science, 2008. Available from: http:/apps.isiknowledge.com.

[22] MatWeb Material Property Data, 2008. Available from: http://www. matweb. com.

[23] A.K. Shoemaker and S.T. Rolfe. The static and dynamic low-temperature crack-toughness performance of seven structural steels. Engineering Fracture Mechanics, 2(4):319 - 339, 1971. doi:10.1016/0013-7944(71)90017-8. 